\title{
TRANSFERRED ARC PRODUCTION OF FUMED SILICA: RHEOLOGICAL PROPERTIES
}

\author{
M.Eng. Thesis \\ Department of Chemical Engineering \\ McGill University \\ Under the Supervision of Dr. R.J. Munz
}

Ramona Pristavita

December 2006 


$\begin{array}{ll}\begin{array}{l}\text { Library and } \\ \text { Archives Canada }\end{array} & \begin{array}{l}\text { Bibliothèque et } \\ \text { Archives Canada }\end{array} \\ \begin{array}{l}\text { Published Heritage } \\ \text { Branch }\end{array} & \begin{array}{l}\text { Direction du } \\ \text { Patrimoine de l'édition }\end{array} \\ \begin{array}{l}\text { 395 Wellington Street } \\ \text { Ottawa ON K1A 0N4 } \\ \text { Canada }\end{array} & \begin{array}{l}\text { 395, rue Wellington } \\ \text { Ottawa ON K1A ON4 } \\ \text { Canada }\end{array}\end{array}$

Your file Votre référence ISBN: 978-0-494-32615-2 Our file Notre référence ISBN: 978-0-494-32615-2

NOTICE:

The author has granted a nonexclusive license allowing Library and Archives Canada to reproduce, publish, archive, preserve, conserve, communicate to the public by telecommunication or on the Internet, loan, distribute and sell theses worldwide, for commercial or noncommercial purposes, in microform, paper, electronic and/or any other formats.

The author retains copyright ownership and moral rights in this thesis. Neither the thesis nor substantial extracts from it may be printed or otherwise reproduced without the author's permission.
AVIS:

L'auteur a accordé une licence non exclusive permettant à la Bibliothèque et Archives Canada de reproduire, publier, archiver, sauvegarder, conserver, transmettre au public par télécommunication ou par l'Internet, prêter, distribuer et vendre des thèses partout dans le monde, à des fins commerciales ou autres, sur support microforme, papier, électronique et/ou autres formats.

L'auteur conserve la propriété du droit d'auteur et des droits moraux qui protège cette thèse. $\mathrm{Ni}$ la thèse ni des extraits substantiels de celle-ci ne doivent être imprimés ou autrement reproduits sans son autorisation.
In compliance with the Canadian

Privacy Act some supporting forms may have been removed from this thesis.

While these forms may be included in the document page count, their removal does not represent any loss of content from the thesis.
Conformément à la loi canadienne sur la protection de la vie privée, quelques formulaires secondaires ont été enlevés de cette thèse.

Bien que ces formulaires aient inclus dans la pagination, il n'y aura aucun contenu manquant. 


\begin{abstract}
The thermal plasma production of fumed silica in a transferred arc consists of the decomposition of quartz to $\mathrm{SiO}(\mathrm{g})$ and oxygen followed by an oxidizing quench back to $\mathrm{SiO}_{2}$. The particles formed have diameters of the order of 10 to $20 \mathrm{~nm}$ and are linked in a three dimensional branched chain aggregate. Previous work by Addona and Munz (1999) demonstrated the technical feasibility of producing fumed silica using this method, but was unable to demonstrate the special rheological properties of the powder. The most important characteristic of fumed silica is the presence of hydroxyls on the surface of the particles, in the form of isolated hydroxyl groups, hydrogen-bonded hydroxyl groups and siloxane groups.
\end{abstract}

In the present work, we studied the changes in the powder quality by varying the quench conditions used for the production of the powder and by agglomerating the obtained particles. The fumed silica was agglomerated by conveying in a length of tubing with sharp bends. The powder was characterized using BET, Viscosity tests, FTIR, TEM, SEM and XRD. The product was compared to both a commercial product (Aerosil 200) and the material previously produced by Addona. Tests were done before and after the agglomeration experiments.

The experimental results showed that the agglomeration had no effect on the powder's rheological properties. We concluded that the smaller viscosity values obtained for the plasma produced fumed silica were due to the lack of the free hydroxyl groups from the surface of the particles. 


\section{Résumé}

La production par plasma thermique de la silice fumée dans un arc transféré comprend la décomposition du quartz à $\mathrm{SiO}(\mathrm{g})$ et oxygène, suivi d'une trempe oxydante de nouveau à $\mathrm{SiO}_{2}$. Les particules formées ont des diamètres de l'ordre de 10 à $20 \mathrm{~nm}$ et sont liées dans un agrégat à chaînes embranchées tridimensionnel. Les travaux précédents d'Addona et de Munz (1999) ont démontré la praticabilité technique de produire la silice fumée en utilisant cette méthode, mais ne pouvaient pas démontrer les propriétés rhéologiques spéciales de la poudre. La caractéristique la plus importante de la silice fumee est la présence des hydroxyles sur la surface des particules, sous forme de groupes d'hydroxyle isolés, des groupes d'hydroxyle hydrogène-collés et des groupes de siloxane.

Dans ce travail, nous avons étudié les changements de la qualité de poudre en changeant les conditions de trempe utilisées pour la production de la poudre et en agglomérant les particules obtenues. Afin d'agglomérer les particules de silice fumée, nous les avons fait passées dans un tube possédant plusieurs courbes prononcées. Plusieurs techniques analytiques ont été employées pour caractériser le produit: BET, des essais de viscosité, FT-IR, MET, MEB et des XRD. Le produit a été comparé à un produit commercial (Aerosil 200) et au matériel précédemment produit par Addona. Des essais ont été faits avant et après les expériences d'agglomération.

Les résultats expérimentaux ont prouvé que l'agglomération n'a eu aucun effet sur les propriétés rhéologiques des poudres. Nous avons conclu que les valeurs plus petites de viscosité obtenues pour la silice fumée produit par le procesus de plasma sont dues au manque de groupes libres d'hydroxyle de la surface des particules. 


\section{ACKNOWLEDGMENTS}

To Professor Richard J. Munz for his moral support, patience and guidance.

To Dr. Tony Addona for the many very helpful discussions we had and for his help.

To Mr Ian Turner and Sitec for the financial support.

To NSERC for the financial support.

To the summer students: Emanuel Resch and Dominic Borde for their help with the DAQ system, the calibration of water lines, the drawings and the testing of the agglomerator.

To all my colleagues from the Chemical Engineering Department, including Ian Castillo and Rao Lakshminarayana, for their help.

To the members of the Chemical Engineering non-academic staff: Emily Musgrave, Alain Gagnon, Ed Siliauskaus, Lou Cusmich, Melanie Gorman, specially to Ranjan Roy for his help with the analysis of samples and for the DRIFT accessory.

To my family and my husband Ciprian for the moral support. 


\title{
TABLE OF CONTENTS
}

\section{ACKNOWLEDGMENTS}

\author{
NOMENCLATURE
}

Chapter 1. INTRODUCTION 1

Chapter 2. BACKGROUND AND LITERATURE REVIEW



2.1.1 Properties and Uses ......................................... 4

2.1.2 Production Processes .......................................

2.1.3 Thermal Plasma Production of Fumed Silica .................... 10

2.2 Rheological Properties .............................................. 13



Chapter 4. EXPERIMENTAL EQUIPMENT

4.1 Experimental Equipment for Plasma Experiments............................17



\section{Chapter 5. EXPERIMENTAL PROCEDURES}

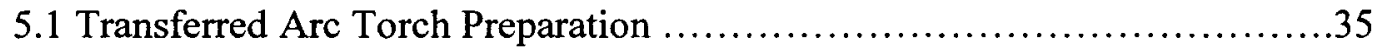

5.2 Experimental Procedure for Operating of the Transferred Arc Reactor .......35



5.4 Experimental Procedure for Operating of the Agglomerator .................39 


\section{Chapter 6. EXPERIMENTAL RESULTS}

6.1 Summary of Plasma Experiments Performed ...............................41

6.2 Product Analysis of Plasma Experiments ..................................47

6.2.1 X-Ray Diffraction (XRD) ......................................4

6.2.2 Scanning Electron Microscopy (SEM) …..........................49

6.2.3 Transmission Electron Microscopy (TEM) …......................52

6.2.4 Rheological Tests ...........................................................................54

6.2.5 Specific Surface Area Measurements (BET) ………..........................60

6.2.6 Diffuse Reflectance InfraRed Fourier Transform (DRIFT)



6.2.7 Thermogravimetric Analysis (TGA) …..........................67

6.3 Experimental Results for Agglomeration Tests ...........................70

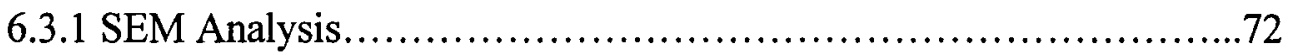

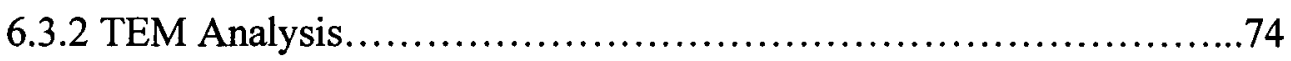

6.3.3 DRIFT Spectroscopy Analysis ....................................... 75








\section{APPENDICES}
A. LabView Interface of DAQ
.84
B. Voltage and Current Profiles FOR Experiments 10 to $16 \ldots \ldots \ldots \ldots \ldots \ldots \ldots \ldots . . .85$
C. Temperatures Profiles of Exit Tube, Quench Zone, Steam Line and Filter for Experiments 10 to 16 ...............................................
D. Drawings of Graphite Parts ....................................... 105
E. Apparent Viscosity Data Analysis .......................................111 
slpm Standard litter per minute $\left(20^{\circ} \mathrm{C}, 1 \mathrm{~atm}\right)$

gpm Grams per minute

I.D. Internal diameter

O.D. Outer diameter

W.D. Working distance

DC Direct current

HF High frequency

RPM Rotations per minute

NM Not measured

RH Relative humidity

Ar Argon

$\mathrm{t}$

Total experimental time ( $\mathrm{min})$

I Current (A)

V Voltage (V)

$P_{\mathbf{r}} \quad$ Pressure in the reactor (psig)

$P_{f} \quad$ Pressure at the filter entrance (psig)

Q $\quad$ Ar flow rate (Nlpm)

$\mathrm{Q}_{\mathrm{q}} \quad$ Quench flow rate (gpm)

$\mathrm{Q}_{\mathrm{v}} \quad$ Air flow rate entering the venture system (Nlpm)

$\mathrm{Q}_{\mathrm{f}} \quad$ Air flow rate entering the feeder (Nlpm)

$\mathrm{r}_{\mathrm{D}} \quad$ Quartz decomposition rate (gpm)

$r_{f} \quad$ Quartz feeding rate (gpm)

$T_{r} \quad$ Temperature of gases leaving the reactor $\left({ }^{0} \mathrm{C}\right)$

$\mathrm{m}_{\mathrm{qi}} \quad$ Mass of quartz in the crucible, at the beginning of the experiment $(\mathrm{g})$

$\mathrm{m}_{\mathrm{qf}} \quad$ Mass of quartz fed during the experiment $(\mathrm{g})$

$\mathrm{m}_{\mathrm{qt}} \quad$ Mass of quartz in the reactor (crucible and chamber), at the end of the experiment $(\mathrm{g})$

$\mathrm{m}_{\mathrm{p}} \quad$ Mass of product collected at the end of each experiment $(\mathrm{g})$ 


$\begin{array}{ll}\mathrm{M}_{\mathrm{f}} & \text { Mass of powder fed into the agglomerator }(\mathrm{g}) \\ \mathrm{M}_{\mathrm{c}} & \text { Mass of powder collected after the agglomeration }(\mathrm{g}) \\ \mathrm{t}_{\mathrm{f}} & \text { Feeding time }(\mathrm{min}) \\ \mathrm{S}_{\text {total }} & \text { Total surface area }\left(\mathrm{m}^{2}\right) \\ \mathrm{S} & \text { Specific surface area }\left(\mathrm{m}^{2} / \mathrm{g}\right) \\ \mathrm{N} & \text { Avogadro's number }\left(\mathrm{N}=6,02217 \times 10^{23} \mathrm{~mol}^{-1}\right) \\ \mathrm{V}_{\mathrm{m}} & \text { Volume of gas absorbed }(\mathrm{l}) \\ \mathrm{S} & \text { Adsorption cross section }\left(\mathrm{m}^{2}\right) \\ \mathrm{M} & \text { Molecular weight of adsorbate }(\mathrm{u}) \\ \mathrm{a} & \text { Weight of solid sample }(\mathrm{g})\end{array}$

\section{LIST OF FIGURES}

Figure 1. Typical groups on the surface of fumed silica particles

Figure 2. Schematic diagram of the flame process

Figure3. Thermal plasma synthesis of ultrafine particles

Figure 4. Block diagram of the thermal plasma production of fumed silica

Figure 5. Schematic representation of the interactions between fumed silica particles in liquids

Figure 6. Thickening of various liquids with Aerosil ® 200

Figure 7. Dependence of the viscosity on the BET surface 
Figure 8. Experimental apparatus

Figure 9. Transferred arc reactor

Figure 10. Photograph of transferred arc reactor

Figure 11. Torch assembly

Figure 12. Photograph of torch assembly

Figure 13. Steam manifold

Figure 14. Steam measurement and control system

Figure 15. Steam calibration curve

Figure 16. Baghouse filter used for powder collection

Figure 17. Electrical circuit diagram of the DC power transferred arc reactor

Figure 18. Analog input module for DAQ

Figure 19. Flame hydrolysis process for fumed silica production

Figure 20. Schematic diagram of the agglomerator used in this work

Figure 21. XRD spectrum of Aerosil 200

Figure 22. XRD spectrums of experimental powders

Figure 23. SEM pictures of: a) Aerosil 200 and b) Experimental powders 
Figure 24. TEM pictures of Aerosil 200 and experimental powders

Figure 25. Apparent viscosity values of Aerosil 200 and different experimental powders (different quench steam flows)

Figure 26. Viscosity profiles of Aerosil 200 and experimental powder with different mixing times (@5 RPM)

Figure 27. Variation of apparent viscosity values (@ 5RPM) of plasma produced powders with the specific surface area

Figure 28. Variation of specific surface area of plasma produced powders with the quench flow rate

Figure 29. IR spectrum of Aerosil 200

Figure 30. IR spectrum of powder exp. 12

Figure 31. IR spectrum of powder exp.13

Figure 32. IR spectrum of powder exp. 10 (steam quench), 13 (air + steam quench) and 14 (air quench)

Figure 33. TGA curves for Aerosil 200 and experimetal powders 8 (steam quench), 13 (air + steam quench) and 16 (air quench)

Figure 34. TGA derivative curves for Aerosil 200 and experimetal powders 8 (steam quench) and 13 (steam + air quench)

Figure 35. SEM pictures of experimental powder 16 (steam quench) 
Figure 36. Agglomerated particles (experiment 16, air quench)

Figure 37. TEM pictures of experimental powder 11 (steam quench)

Figure 38. DRIFT spectra of experimental powder 11 (steam quench)

Figure 38. DRIFT spectra of experimental powder 16 (steam quench)

\section{LIST OF TABLES}

Table 1. Properties of fumed silica

Table 2. Summary of experiments

Table 3. Decomposition and feeding rates values

Table 4. Viscosity test for Aerosil 200

Table 5. Specific surface area of experimental powders

Table 6. Important peaks in the silica spectrum

Table 7. Summary of conditions for the agglomeration tests

Table 8. Apparent viscosity values before and after agglomeration tests 


\section{Chapter 1 - INTRODUCTION}

Fumed silicon dioxide is referred to as fumed silica because of its smoke-like appearance as it forms in the flame. The term "pyrogenic" silica, formerly used, has been discontinued because of other common definitions of the word, like "flammable" or "fever-producing". The substance has neither of these properties.

Fumed silica is considered to be unique in industry because of its unusual particle characteristics. Its extremely fine-particle size, its large surface area, its high purity and its chain-forming tendencies set it apart in a class of its own. Fumed silica is a "light, fluffy and pure white" (Cabot Corp., 1983), amorphous powder.

Common applications of the powder include its use as a thickening and thixotropic agent in paints, thermosetting resins and printing inks, a reinforcing filler in rubbers, a free-flow, an anti-caking agent in the processing of dry materials, and a thermal insulator (especially in the high temperature range up to $1000^{\circ} \mathrm{C}$ ).

At the present, fumed silica is produced industrially by the vapor phase hydrolysis of silicon tetrachloride in a hydrogen/oxygen flame. The combustion process results in silicon dioxide molecules that condense to form particles. The particles collide, attach and sinter together forming a three dimensional branched chain aggregate. Once the aggregates cool below the fusion point of silica $\left(1710^{\circ} \mathrm{C}\right)$, further collisions result in mechanical entanglement of the chains, termed agglomeration. Along with the main product, this process also generates a large quantity of $\mathrm{HCl}_{(\mathrm{g})}$ as by-product.

Currently, there is interest in the use of thermal plasma technology for the production of fumed silica. The plasma process does not involve chlorine, it uses cheap raw material (quartz instead of $\mathrm{SiCl}_{4}$ ) and it has no negative impact on the environment, because no by-products such as $\mathrm{HCl}$, are generated. This process consists of the reduction of quartz to $\mathrm{SiO}_{(\mathrm{g})}$ followed by oxidation back to $\mathrm{SiO}_{2}$. Usually, a reducing agent $\left(\mathrm{C}, \mathrm{Si}, \mathrm{H}_{2}, \mathrm{CH}_{4}\right.$ or $\mathrm{NH}_{3}$ ) is used to increase the rate of quartz decomposition. The oxidation is done with steam. This process has enjoyed little commercial success because it has two main problems which have yet to be overcome: process economics and product quality. 
Thermal plasma processes for the production of fumed silica can be classified, according to their method of plasma generation, in:

- processes based on high intensity dc arcs;

- processes based on radio frequency $(\mathrm{RF})$ discharges.

In the terms of industrial applications, the dc transferred arc processes are seen as having the greatest potential, because of their high thermal efficiency. To date, most of the arc processes investigated have been of the non-transferred type with quartz reduction occurring in the tail of a plasma flame. Important transferred arc processes have involved the mixing of quartz particles with electrically conducting reducing agents such as $\mathrm{C}$ and Si (Biegler et al., 1963, Illigen and Neugebauer, 1969, and Bakken, 1993) or with a conductive, volatile impurity such as $\mathrm{NaOH}$ (Addona, 1998).

Previous research (Addona, 1998) demonstrated the technical feasibility of making fumed silica using this method, but was unable to demonstrate the special rheological properties of the powder. It was hypothesized that an agglomerator, which was present in the commercial process but absent in the laboratory scale plasma process might be able to provide the required rheological properties. In the present work, we used different quench conditions to produce the powders and we correlated the effect of these conditions with powder properties. We also built and tested an agglomerator and examined the effect of agglomeration on the rheological properties of the product. 


\section{Chapter 2 - BACKGROUND AND LITERATURE REVIEW}

\subsection{Fumed Silica}

Many people assume that fumed silica is a recent product of modern technology. In reality, this powder was mentioned in literature as far back as 1887 (Ferch, 1981). The inventor of the product was Dr. Harry Klopfer, chemist of Degussa AG. He obtained, in

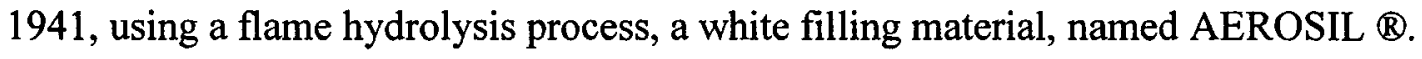

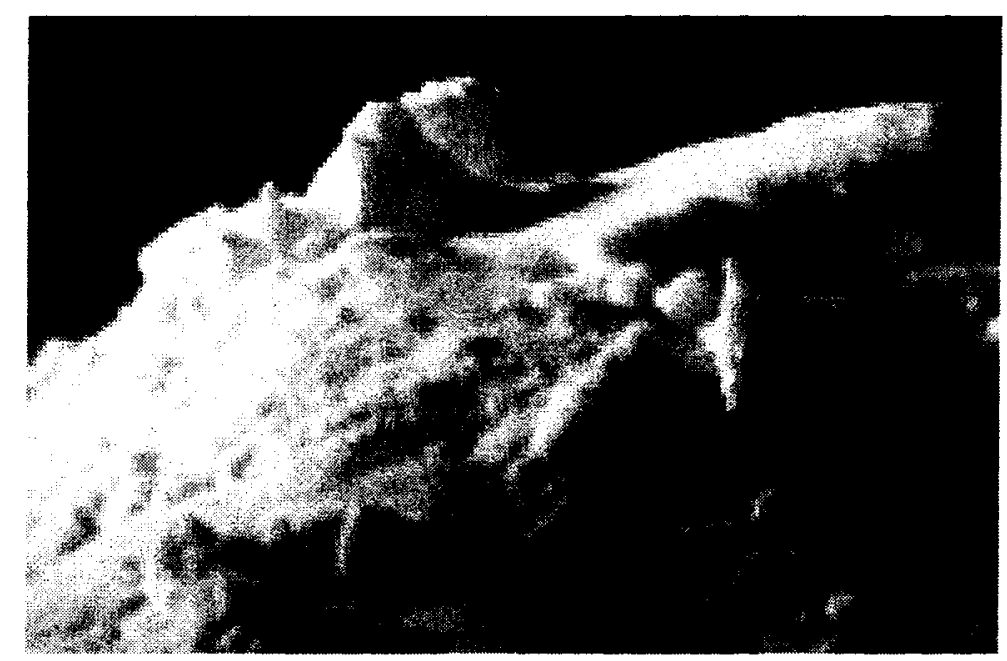

According to Ullmann's Encyclopedia of Industrial Chemistry, the present producers are Degussa (AEROSIL®), Cabot (CAB-O-SIL(B), Wacker (HDK®) and Tokuyama (REOSILß).

A market study of Specialty Silicas by Freedonia Group (04/2004) noted that US demand for specialty silicas is forecast to grow 5.1 percent per annum to over one billion pounds in 2008. Market value will advance to $\$ 1.5$ billion due, in part, to rebounding nondurable goods production as well as across-the board price increases, reflecting higher costs of production. 


\subsubsection{Properties and Uses}

The chemical formula of fumed silica is $\mathrm{SiO}_{2}$, but it must be taken into consideration that in reality no isolated $\mathrm{SiO}_{2}$ molecules are present.

The most important characteristic of fumed silica is the presence of hydroxyls on the surface of the particles, in the form of isolated hydroxyl groups, hydrogen-bonded hydroxyl groups, geminal hydroxyl groups and siloxane groups (Figure 1). Other unique characteristics include a large surface area, the chain-like aggregate structure and an amorphous morphology.

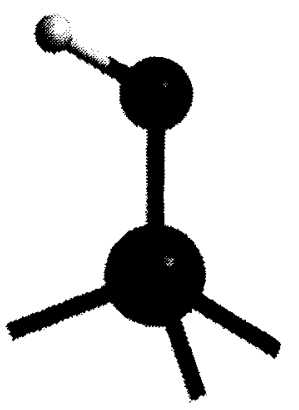

ISOLATED HYDROXYL GROUP

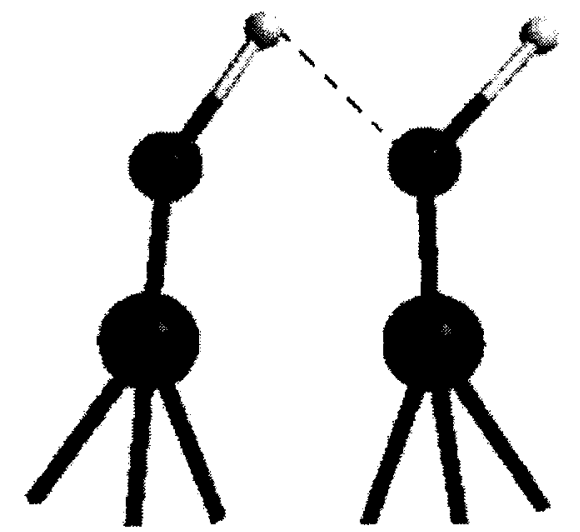

HYDROGEN-BONDED HYDROXYL GROUPS

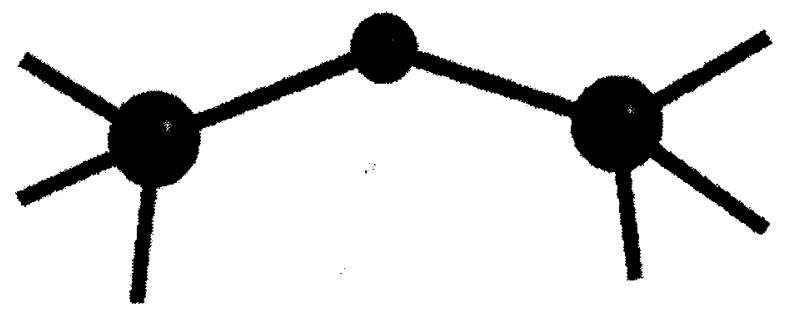

SILOXANE GROUP

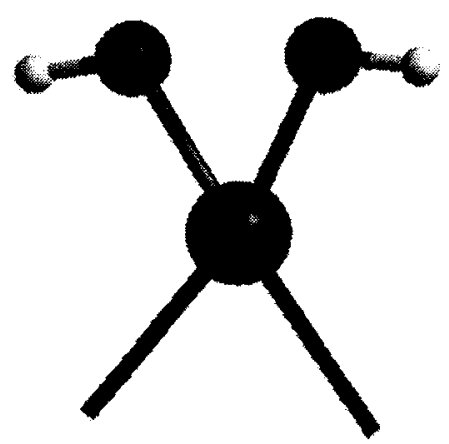

GEMINAL HYDROXYL GROUPS

Figure 1. Typical groups on the surface of fumed silica particles

$\mathrm{Si}$



$\mathrm{H}$ 
Typical properties of fumed silica are given in the table below:

Table 1. Properties of fumed silica (Ferch, 1981)

\begin{tabular}{|l|c|}
\hline \multicolumn{1}{|c|}{ PROPERTY } & VALUE \\
\hline Specific surface area $(\mathbf{B E T}),\left(\mathbf{m}^{2} / \mathbf{g}\right)$ & $50-600$ \\
\hline Primary particle size, $(\mathbf{n m})$ & $5-50$ \\
\hline True density, $\left(\mathbf{k g} / \mathbf{m}^{3}\right)$ & 2200 \\
\hline Bulk density, $\left(\mathbf{k g} / \mathbf{m}^{3}\right)$ & 38 \\
\hline Structure of aggregates & Chain-like \\
\hline Thickening and thixotropic effect & Very pronounced \\
\hline Surface chemistry & Hydroxylated surface \\
\hline X-ray form & amorphous \\
\hline
\end{tabular}

Presently, fumed silica finds many applications in industry. It is also safe for human consumption because of its size and amorphous form. The list of applications of fumed silica in industry includes (Degussa, www1.sivento.com):

$>$ paints and coatings

$>$ catalysts

$>$ airbags

$>$ silicone sealants in the car, -sanitary and electronics sectors

$>$ sealing inserts

$>$ printing inks

$>$ creams, lotion, gels, deodorants

paper properties

$>$ chemical dowels

$>$ unsaturated polyester resins 
light bulbs and fluorescent tubes

toners for photocopying machines

$>$ silicone profiles

$>$ shoe soles

putty

dental composites

2-component mortar

$>$ marine paints

structure adhesives for the production of rotor blades in wind power plants

the dosability of active substances in tablets

high-tension cables

$>$ adhesives, e.g. instant glue and hot-melt adhesives

and more. 


\subsubsection{Production Processes}

The most important process in terms of industrial production is the hydrolysis of silicon tetrachloride vapor in a flame of hydrogen and oxygen, as shown in the reactions below:

$$
\begin{aligned}
& 2 \mathrm{H}_{2}+\mathrm{O}_{2} \rightarrow 2 \mathrm{H}_{2} \mathrm{O}(\mathrm{g}) \\
& \mathrm{SiCl}_{4}(\mathrm{~g})+2 \mathrm{H}_{2} \mathrm{O}(\mathrm{g}) \rightarrow \mathrm{SiO}_{2}(\mathrm{~g})+4 \mathrm{HCl}(\mathrm{g})
\end{aligned}
$$

Overall reaction: $\mathrm{SiCl}_{4}(\mathrm{~g})+2 \mathrm{H}_{2}+\mathrm{O}_{2} \rightarrow \mathrm{SiO}_{2}(\mathrm{~g})+4 \mathrm{HCl}(\mathrm{g})$

During the combustion process (as shown in Figure 2), silicon tetrachloride burns in a flame of hydrogen and oxygen to produce primary molten spherical particles. While still semi-molten, these particles fuse irreversibly into secondary groupings called aggregates*. The next steps are cooling, collecting and bagging. During these processes, the aggregates become physically entangled forming agglomerates. This process can be reversible if the powder is dispersed in a suitable medium.

The reactions take place in a furnace, maintained at the desired operating temperature (1300-2000K) by burning appropriate amounts of hydrogen, using a large excess of air (White and Duffy, 1959 and Cabot, 1983). By varying the flame temperature, concentration of reactants and the dwell time of silica in the combustion chamber, it is possible to vary the particle size and the size distribution, the specific surface area, and the surface properties of the fumed silicas.

\footnotetext{
* A collection of units or particles (e.g., cells) forming a body or mass. (www.biochem.northwestern.edu)
} 

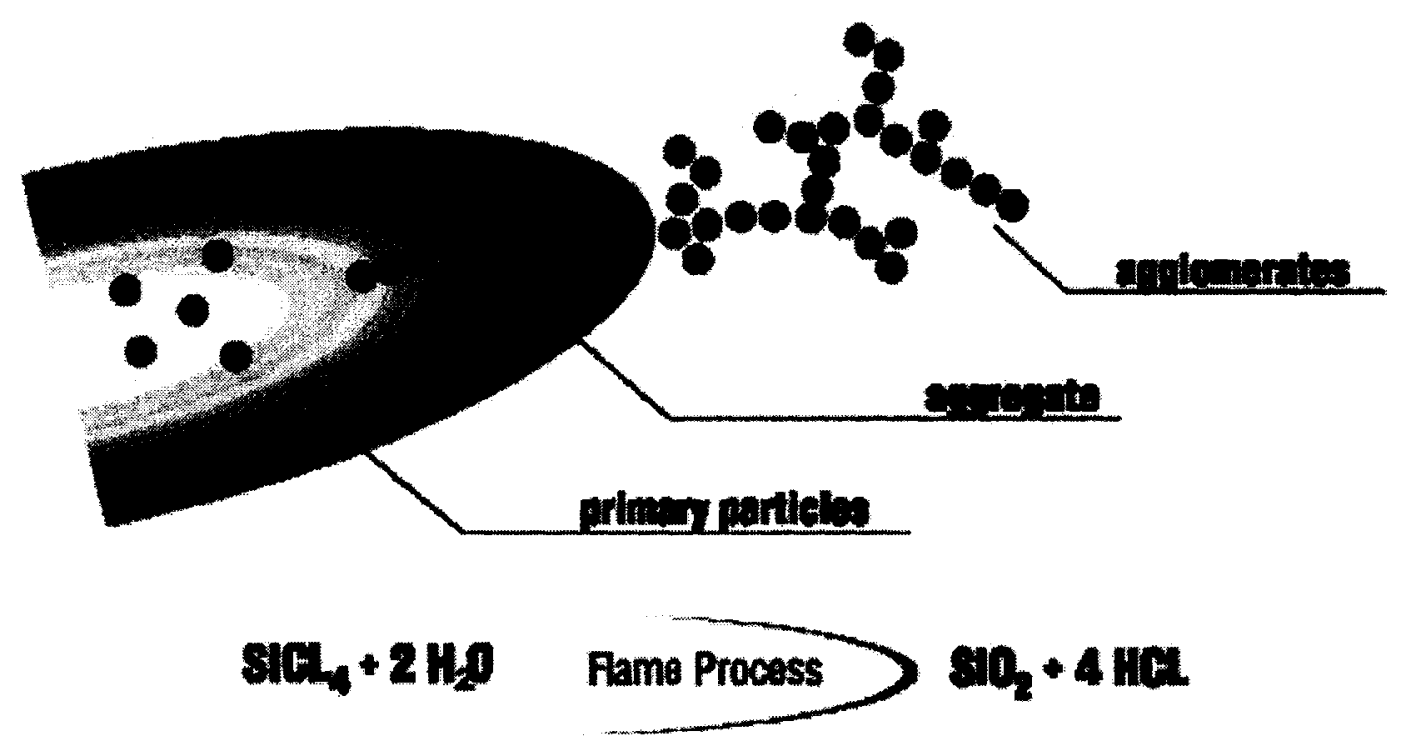

Figure 2. Schematic diagram of the flame process (CAB-O-Sil Untreated Fumed Silica: General Application Guide)

Of much less commercial significance is the electric-arc process, which consists of the reduction of quartz sand (or other silica containing material) in an electric-arc furnace using C or Si (Biegler et al., 1963 and Illigen and Neugebauer, 1969). The reactions are:

$$
\begin{aligned}
& \mathrm{SiO}_{2}(\mathrm{l})+\mathrm{C} \rightarrow \mathrm{SiO}(\mathrm{g})+\mathrm{CO} \\
& \mathrm{SiO}_{2}(\mathrm{l})+\mathrm{Si}(\mathrm{l}) \rightarrow 2 \mathrm{SiO}(\mathrm{g})
\end{aligned}
$$

The heat is supplied to the furnace by an arc struck between graphite electrodes. A reducing gas mixture is added into the chamber to dilute the $\mathrm{SiO}(\mathrm{g})$ exiting the furnace. Oxidation of $\mathrm{SiO}(\mathrm{g})$ to $\mathrm{SiO}_{2}(\mathrm{~g})$ is done using a mixture of air and steam. To increase thickening and thixotropic effectiveness, the powder is treated in a fluidized bed with air and steam. 
The process that has attracted increasing attention during the last decade is the thermal plasma process. This process has a great potential to eliminate many of the problems (product contamination, wide size distribution and particle agglomeration) associated with ultrafine powder production (Joshi et al., 1990). The first step of the process is the thermal plasma generation, followed by the vapor phase reaction and aerosol formation (as shown in Figure 3). In most of the cases, all three operations occur in the plasma chamber. A recent desire to improve the powder quality has resulted in a more complete separation of these three operations. This has caused the last two operations to be conducted outside the plasma chamber, where temperature, species concentrations and cooling rate can be better controlled.

This method also can be used to produce powders like ceramics (carbides, oxides, nitrides, borides) and metallic powders ( $\mathrm{Si}, \mathrm{Ag}, \mathrm{Ta}, \mathrm{Mo}, \mathrm{W}$ ).



Figure3. Thermal plasma synthesis of ultrafine particles (Addona, 1998) 


\subsubsection{Thermal Plasma Production of Fumed Silica}

Over the years, the possibility of producing fumed silica more economically and with no negative ecological impact was the subject of many studies. The thermal plasma process offers many advantages, including the use of cheaper raw materials and the elimination of corrosive components $\left(\mathrm{SiCl}_{4}\right.$ and $\left.\mathrm{HCl}\right)$. The steps involved in the thermal plasma production of fumed silica are presented in Figure 4.

One of the first studies demonstrating the feasibility of this process was done by Everest et al. in 1973. Other studies have been conducted by Schnell et al. (1978), Gans and Gauvin (1988), Bakken et al. (1989) and Chang (1994).

In a more recent study, Addona (1998) also examined fumed silica production using a transferred arc process. In this process, quartz decomposition was done by striking a thermal $\mathrm{Ar} / \mathrm{H}_{2}$ arc to a molten bath of silica. The main objectives of the work were to investigate the effects of plasma parameters on $\mathrm{SiO}(\mathrm{g})$ generation and to study the effects of conditions in the mixing zone on powder properties.

The system components used by Addona are: the transferred arc reactor, the data acquisition system, the power supplies, the control console, the water line, the feeder, the steam flow measurement and control system, the reactor exit gas analysis system, the sampling line, the baghouse filter, the condenser and the vacuum pump. 


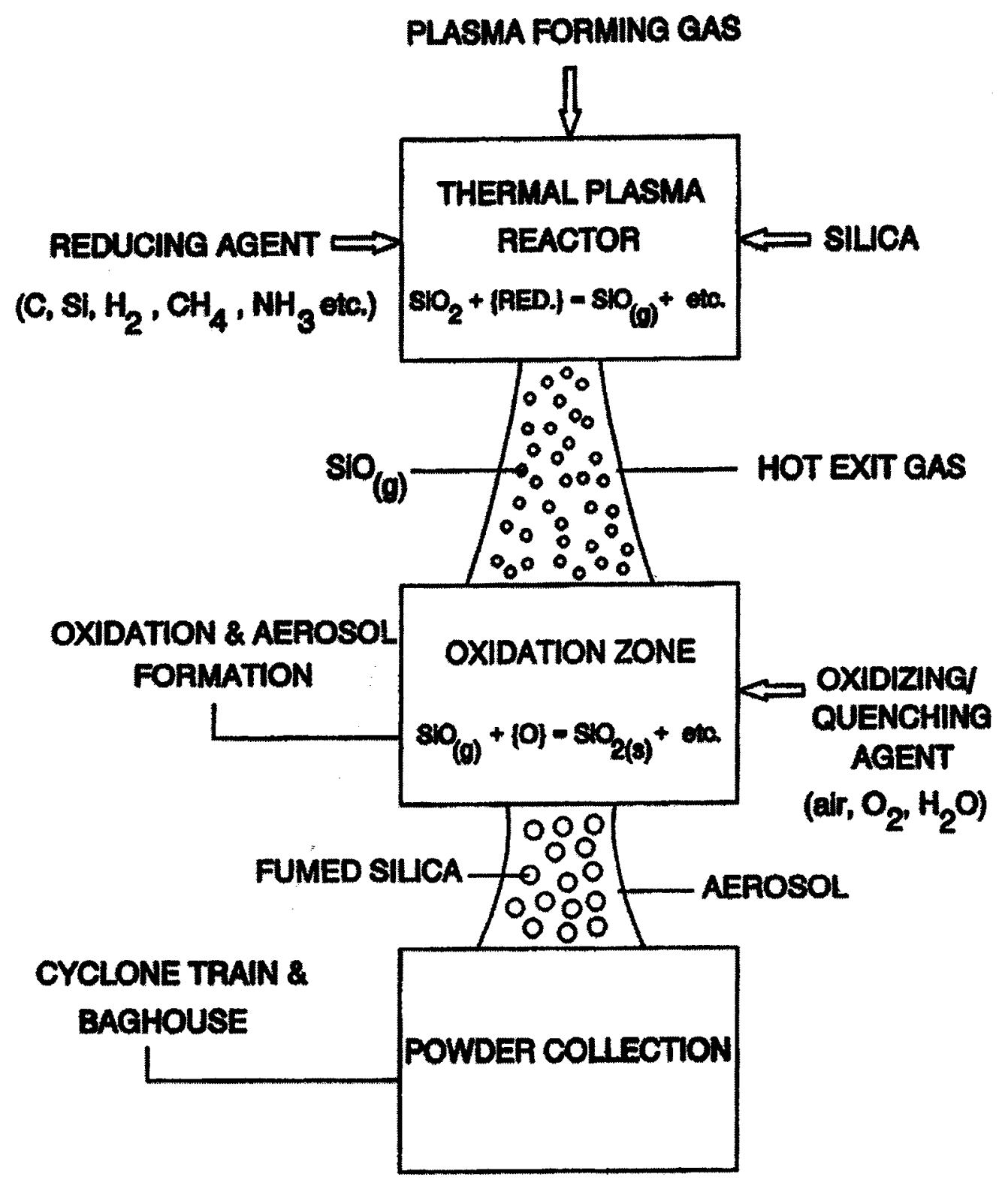

Figure 4. Block diagram of the thermal plasma production of fumed silica (Addona, 1998) 
The process consists of silica decomposition in a thermal plasma reactor with the aid of a reducing agent (such as $\mathrm{H}_{2}$ ) and the rapid quench of $\mathrm{SiO}(\mathrm{g})$ with an oxidizing agent (such as air or steam). The process can be described by the following reactions:

$$
\begin{aligned}
& \mathrm{SiO}_{2}+\text { reducing agent } \rightarrow \mathrm{SiO}(\mathrm{g}) \\
& \mathrm{SiO}(\mathrm{g})+\text { oxidizing agent } \rightarrow \mathrm{SiO}_{2}
\end{aligned}
$$

Because the molten silica anode is contained in a graphite crucible, silica might be reduced by C:

$$
\mathrm{SiO}_{2}+\mathrm{C} \rightarrow \mathrm{SiO}(\mathrm{g})+\mathrm{CO}
$$

In the experiments performed the plasma gas flow rate was $10-20 \mathrm{slpm} \mathrm{Ar}$ and plasma gas was Ar with $0-2.8 \% \mathrm{H}_{2}$. The decomposition rate was determined to be 0.09 $1.8 \mathrm{~g} / \mathrm{min}$. The current was controlled to maintain the $\mathrm{CO}$ concentration in the reactor exit gas constant during the powder collection. The reactor pressure was maintained between 101.3 and $112 \mathrm{kPa}$. The temperature of the reactor exit gas was between $1414 \mathrm{~K}$ and $1801 \mathrm{~K}$ and the steam flow rate was $46-71 \mathrm{~g} / \mathrm{min}$. The duration of experiments varied from 1-3 hours (Addona, 1998).

As a result of this work the following contributions were achieved:

- the silica decomposition using a transferred arc process, in which silica serves as the anode was demonstrated;

- a mathematical model simulating the behavior of the silica anode was developed;

- the effect of plasma gas flow rate and current on the rate of silica anode decomposition was investigated ;

- the effects of temperature and $\mathrm{SiO}(\mathrm{g})$ concentration of the reactor exit gas, and steam flow rate on the properties of fumed silica generated in a given oxidation zone configuration were examinated .

The powder properties: specific surface area, surface hydroxyl density and morphology were also examinated. The specific surface area of the powder (104-257 
$\mathrm{m}^{2} / \mathrm{g}$ ) increased with increasing steam flow rate due to the higher quench rates. The powder had the typical characteristics associated with commercial fumed silica (Aerosil $B 200$ ), except that the thickening and thixotropic properties were lower.

\subsection{Rheological Properties}

The most important factor that affects the rheological properties is the presence and the number of silanol groups ( $\mathrm{SiOH})$. If fumed silica is dispersed in a liquid system, the surface silanol groups interact with each other either directly or indirectly via the molecules in the liquid. This is possible because of the hydrogen bridge linkages and results in a temporary, three-dimensional lattice structure becoming macroscopically "visible" as thickening. If the system is the subject to a mechanical stress (e.g. intensive stirring or shaking) the structure is broken down. As result, the system becomes more fluid; in other words the viscosity drops. In the static state, fumed silica particles join again, and the viscosity regains its original value. This effect is termed thixotropy (Figure5).

As is evident from Figure 6, the thickening and thixotropic effect of fumed silica depends on the ability of the solvent to form hydrogen bonds. When the system in which fumed silica is dispersed contains mono-functional hydrogen-bonding molecules in appreciable concentrations (e.g. water, acids, alcohols etc), formation of chains of aggregates is not possible. The hydroxyl groups of the solvent are preferentially adsorbed on the silica surface, preventing hydrogen bonding.

In systems of intermediate hydrogen-bond-forming tendency (e.g. esters, ethers, vegetable oils etc), the solvent-to-fumed silica and chain-forming reactions take place competitively. The extent of chain formation depends on the fumed silica concentration and degree of dispersion. 
In non-hydrogen-bonding systems (e.g. $\mathrm{CCl}_{4}$, aromatic hydrocarbons, mineral oils etc), fumed silica displays its greatest efficiency as a thickener and thixotropic agent. In these systems, the concentration of the fumed silica is the most important determinant of the degree of chain formation.

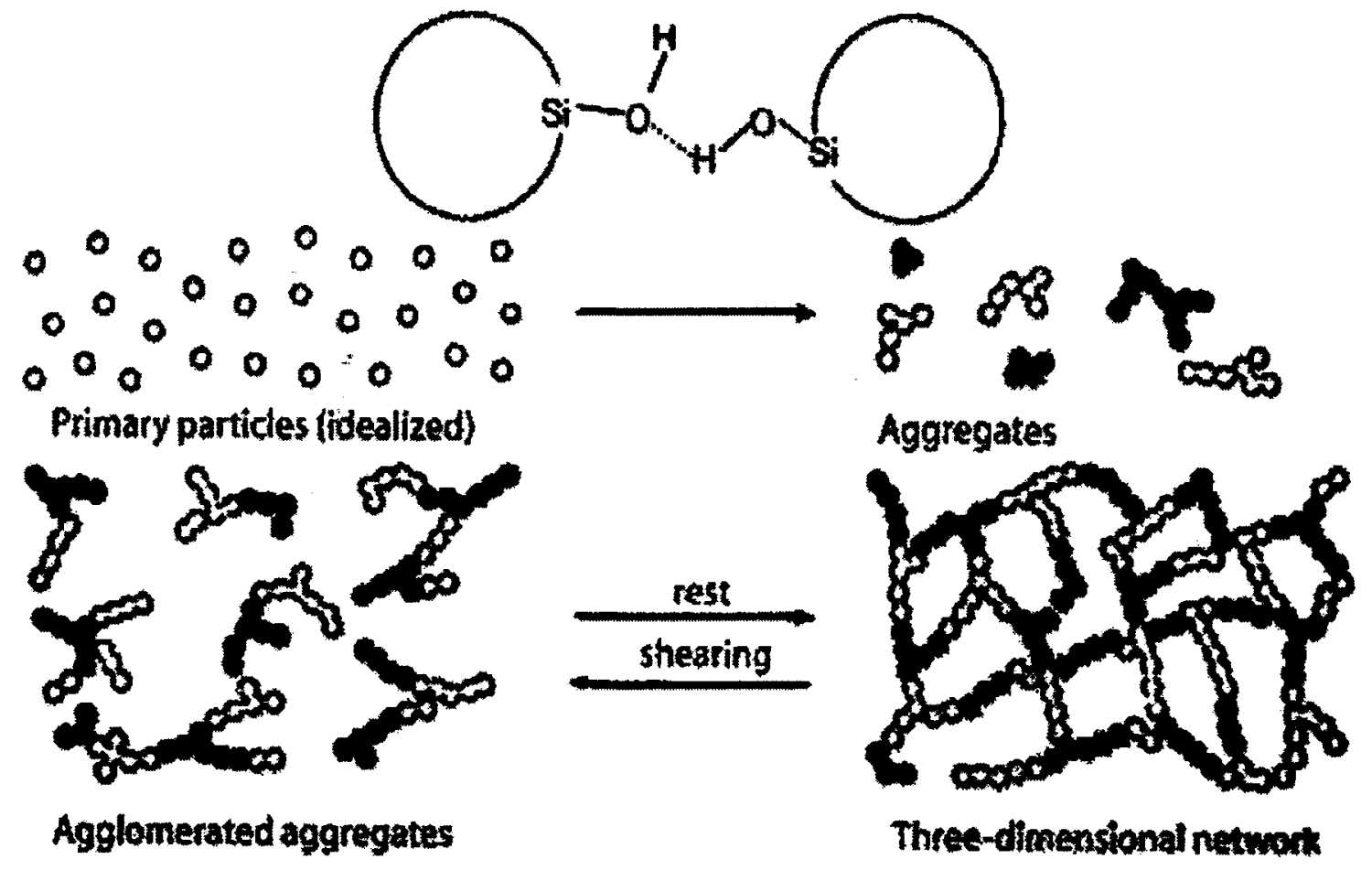

Figure 5. Schematic representation of the interactions between fumed silica particles in liquids ( Degussa, Technical Bulletin Fine Particles) 


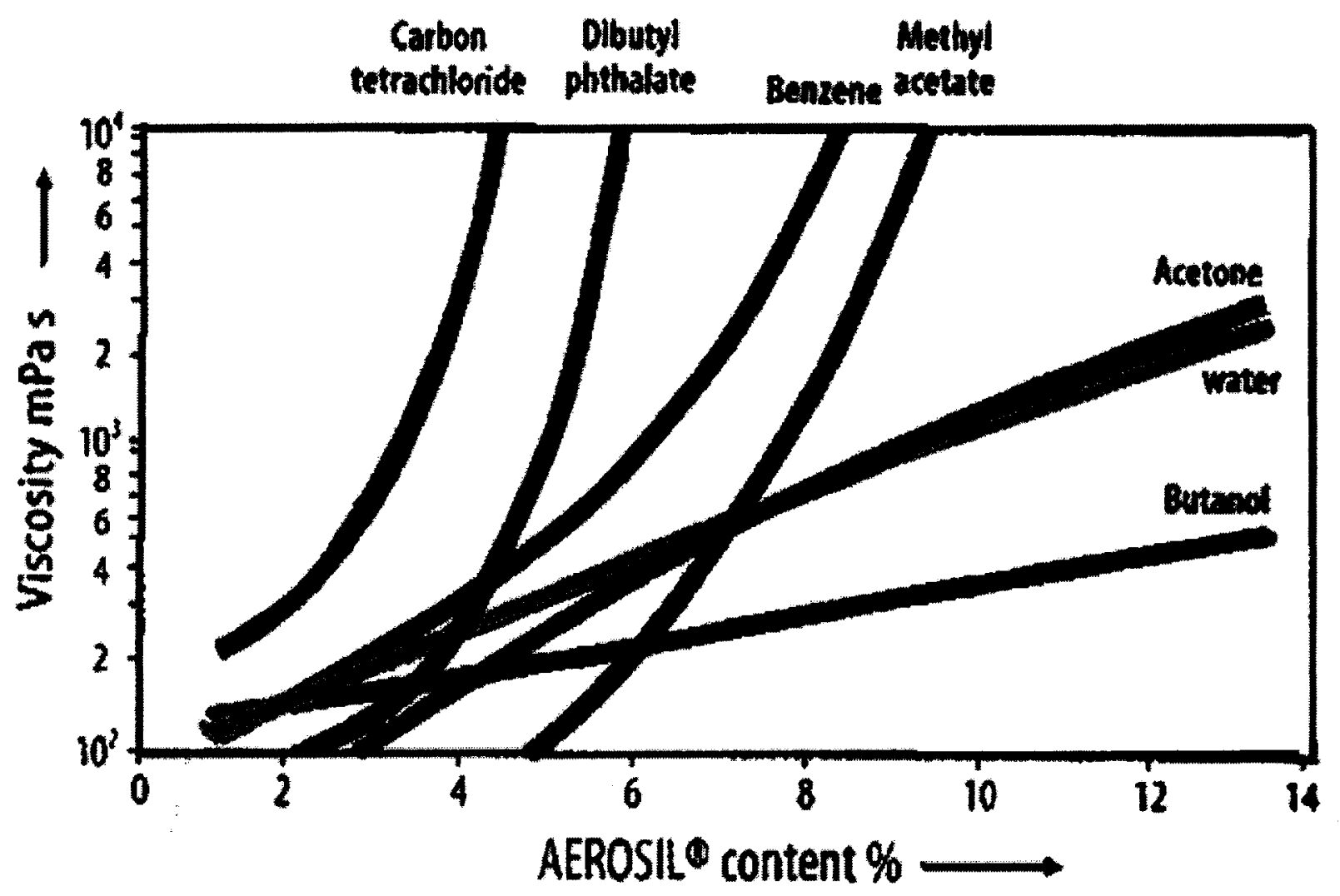

Figure 6. Thickening of various liquids with Aerosil (B) 200

(Degussa, Technical Bulletin Fine Particles)

The thickening effect increases with the BET surface area as can be seen in Figure 7. As the particle size decreases, a higher intensity of dispersion is required to attain the best possible thickening. 


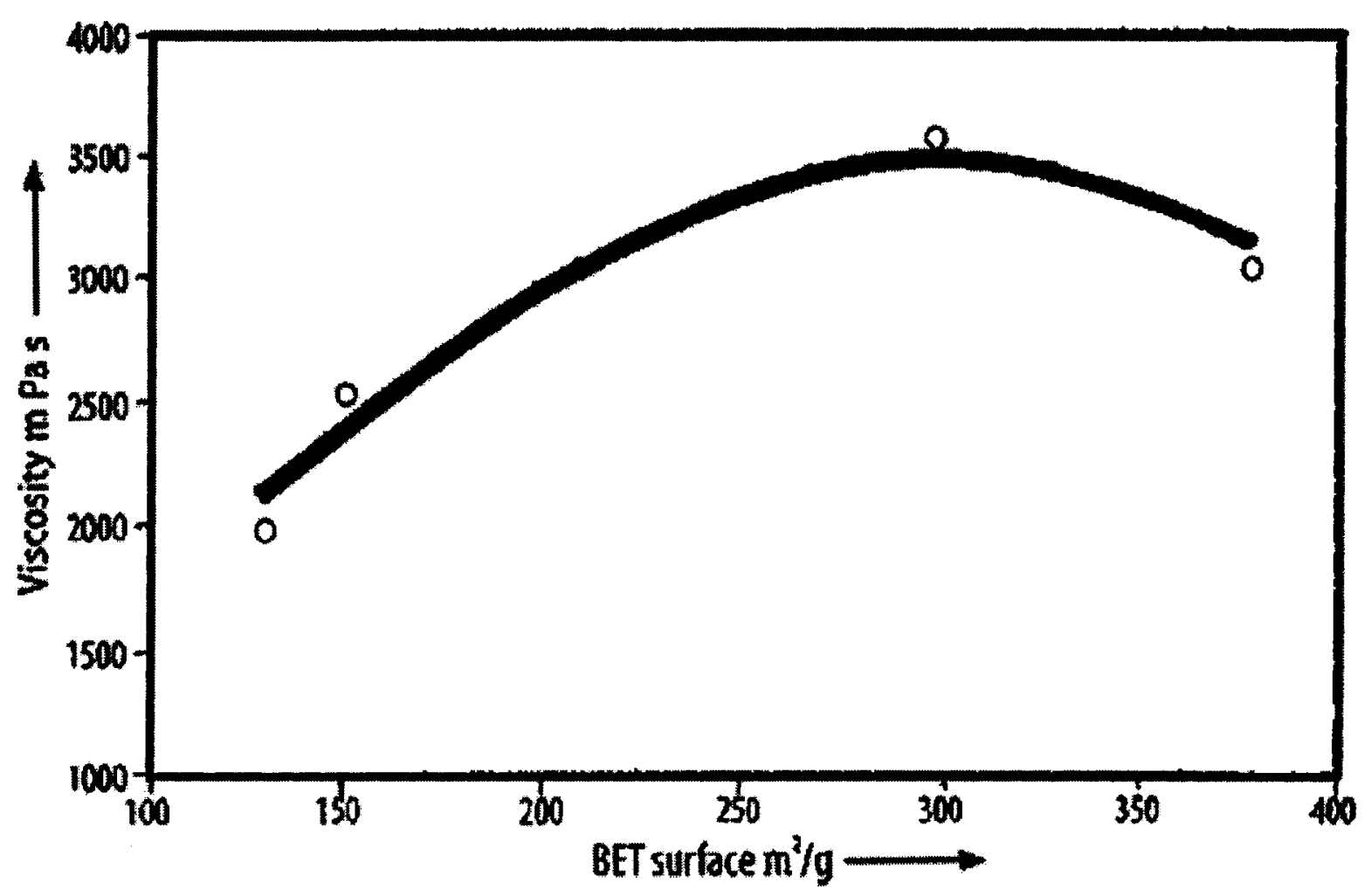

Figure 7. Dependence of the viscosity on the BET surface (Degussa, Technical Bulletin Fine Particles)

An additional property is the greater temperature stability of the liquid system when fumed silica is used to adjust the viscosity. Because the melting point of fumed silica is approximately $1710^{\circ} \mathrm{C}$, the aggregates are unaffected within the range of temperatures normally encountered. In most cases, systems thickened with fumed silica begin to break down only when the other ingredients begin to melt, sublime, boil, decompose, oxidize or otherwise deteriorate. 


\section{Chapter 3 - OBJECTIVES}

This research project is a continuation of Addona's work (Addona, 1998). He demonstrated the feasibility of using transferred arc plasma technology to produce fumed silica from quartz. The novelty in his process was the silica decomposition by striking an $\mathrm{Ar} / \mathrm{H}_{2}$ thermal arc to a high purity ( $(99 \%)$ silica bath. A very important factor which must be added for the successful industrial application of the process is generation of a product with the appropriate rheological properties. Two main problems could cause the differences in the rheological properties between the commercial product and the thermal plasma produced powders: the difference in the surface chemistry or the lack of sufficient agglomeration. The objectives of the present work are given below:

Specific objectives:

i. Production of samples of fumed silica using the transferred arc process.

ii. Use of different quench conditions to produce fumed silica samples.

iii. Correlation of the effect of these conditions with powder properties and comparison of the results with the properties of AEROSIL 200, a commercial product of Degussa.

iv. Agglomeration of plasma produced fumed silica by using different operating conditions. We used dry air for the particles transport inside the agglomerator.

v. Examination of the effect of agglomeration on the rheological properties of the product. The results were also compared with the properties of Aerosil@ 200.

The analyses used were:

- Diffuse Reflectance Infra-Red Fourier Transform (DRIFT) Spectroscopy

- Specific Area Measurements (BET)

- Scanning Electron Microscopy (SEM)

- Transmission Electron Microscopy (TEM)

- X-Ray Diffraction (XRD)

- Thermogravimetric Analysis (TGA)

- Rheological Tests 


\section{Chapter 4 - EXPERIMENTAL EQUIPMENT}

\subsection{Experimental Equipment for Plasma Experiments}

The first step of the project was the refurbishing of the reactor. The apparatus used was the same as that used by Addona (1998). A schematic diagram of the experimental apparatus can be seen in Figure 8. The main components of the system are:

1. Power supply

2. Control console

3. Arc ignition and transfer system

4. Plasma gas and cooling water flow instrumentation

5. Steam flow instrumentation

6. Transferred arc plasma torch

7. Reactor assembly

8. Quench manifold

9. Feeding system

10. Data acquisition system

11. Baghouse filter

12. Condenser

These components are described separately in the following section. 


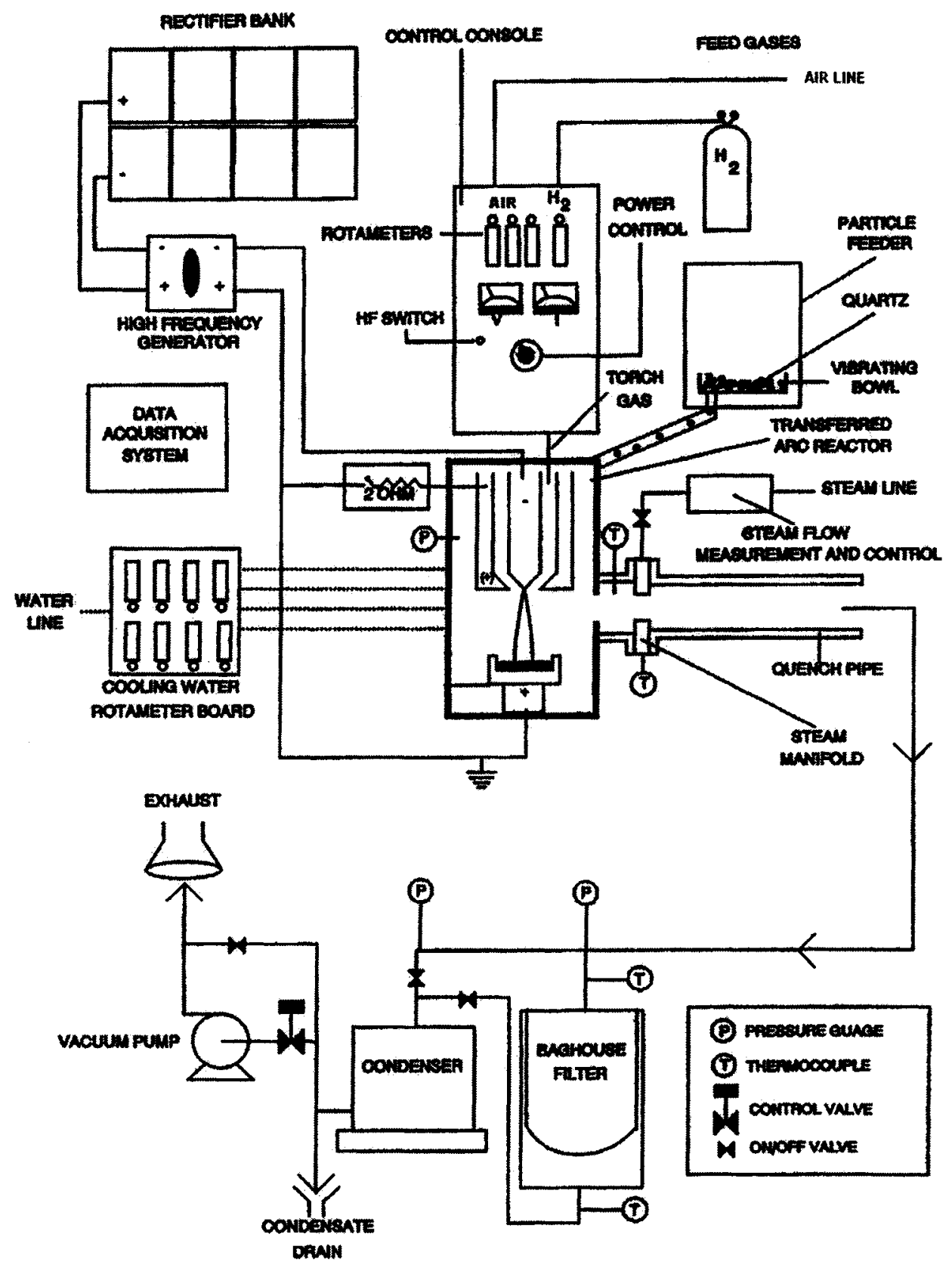

Figure 8. Experimental apparatus (after Addona, 1998) 
The transferred arc reactor, shown in Figures 9 and 10, consists of a water-cooled, cylindrical, stainless steel vessel with a side view port. The stainless steel vessel is internally well insulated with silica cloth (UC100-28, ARMIL C.F.S. INC.) and graphite felt (grade GFA10, SGL Carbon Corporation) surrounded by alumina insulation (blanket type ASB-2600, Zircar Fibrous Ceramics).

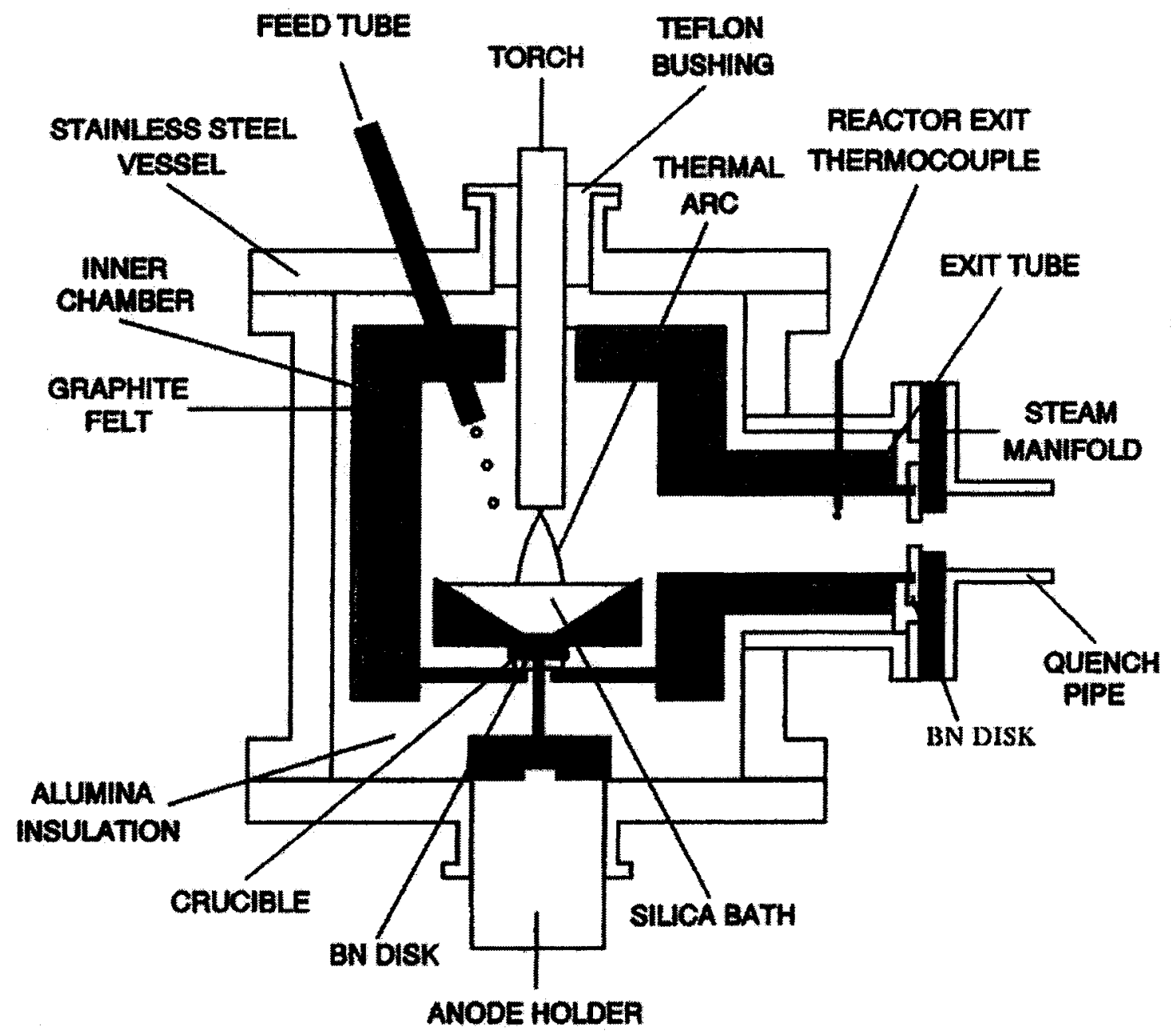

Figure 9. Transferred arc reactor (after Addona, 1998) 


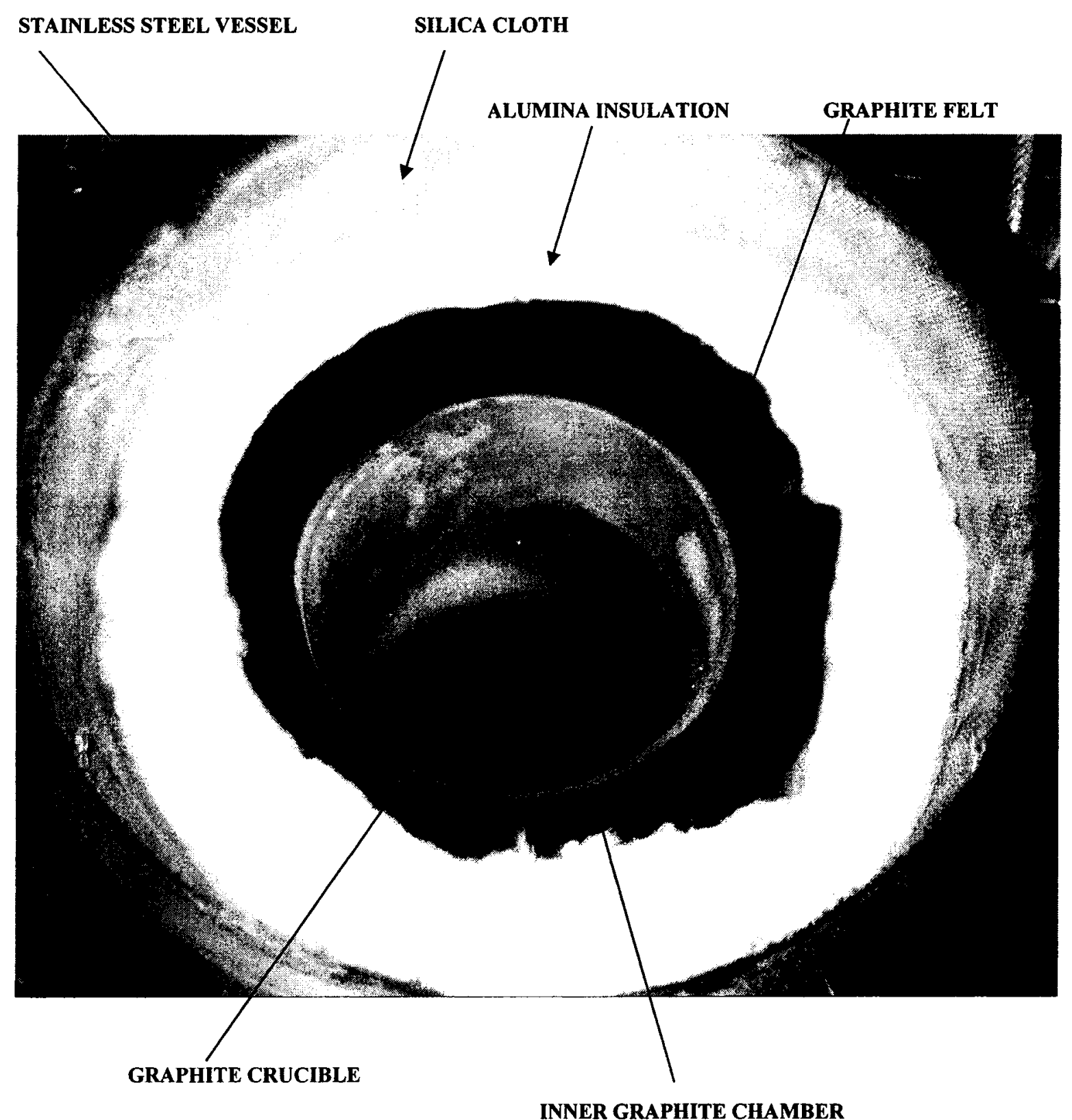

Figure 10. Photograph of transferred arc reactor 
The reactor consists of an inner graphite chamber which has an internal diameter of $12.7 \mathrm{~cm}$ (grade HLM extruded, SGL Carbon Corporation). The chamber bottom is detachable and allows the insertion of the crucible stem. The roof has openings for the torch and feed tube. To prevent arcing to the chamber, it is electrically isolated from the stainless steel vessel by a layer of alumina insulation. Contact of the chamber bottom with the crucible is avoided using a boron nitride disk (grade AX05, The Carborundum Co.). The feed tube is inserted through an opening in the roof, located opposite to the reactor exit. This is an alumina tube (grade Omegatite 450, Omega Canada Inc.) with a diameter of $0.95 \mathrm{~cm}$. It is connected to a particle feeder (vibrating bowl powder feeder, model 104B, TAFA Metallisation Inc.) through silicone tubing.

The water-cooled plasma torch enters the reactor concentrically through a sealed Teflon bushing. The torch (see Figures 11 and 12) consists of a conical $\left(60^{\circ}\right)$, thoriatedtungsten tip cathode inserted in a copper nozzle which serves as an auxiliary anode during arc ignition. The cathode tip is positioned so that is flush with the bottom of the nozzle.

The crucible is located $2 \mathrm{~cm}$ below the torch. The walls are inclined to allow the molten silica to be directed towards the center where arc attachment is most likely. The diameter of the crucible decreased from $10.2 \mathrm{~cm}$ at the top edge to $2.5 \mathrm{~cm}$ at the bottom edge. A small diameter graphite rod $(0.64 \mathrm{~cm})$ is inserted into the center of the crucible to allow initial arc ignition. Connection of the crucible to the anode is done using a stem (a hollow cylinder $16.2 \mathrm{~cm}$ in length, I.D. $=0.95 \mathrm{~cm}$, O.D. $=1.3 \mathrm{~cm}$ ) inserted into a base which sits on a water-cooled holder. The crucible, stem and base are all constructed from graphite (grade HLM extruded, SGL Carbon Corporation).

When placed in the reactor, the top of the crucible is flush with the bottom of the graphite exit tube (grade HLM extruded, SGL Carbon Corporation). The exit tube had a length of $11.4 \mathrm{~cm}$ and a diameter of $3.5 \mathrm{~cm}$. At the entrance of the exit tube is placed a 

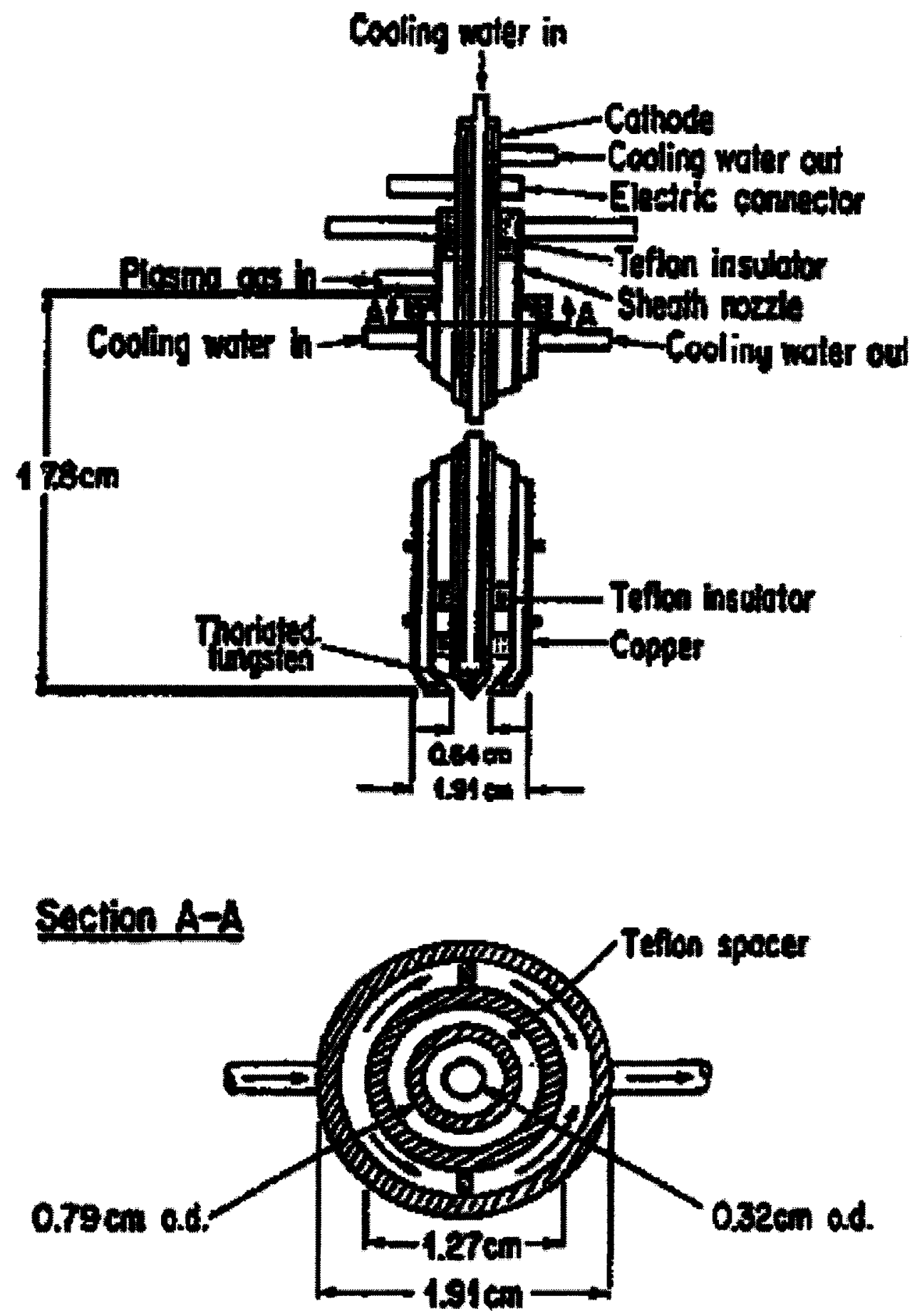

Figure 11. Torch assembly (Parisi, 1984) 


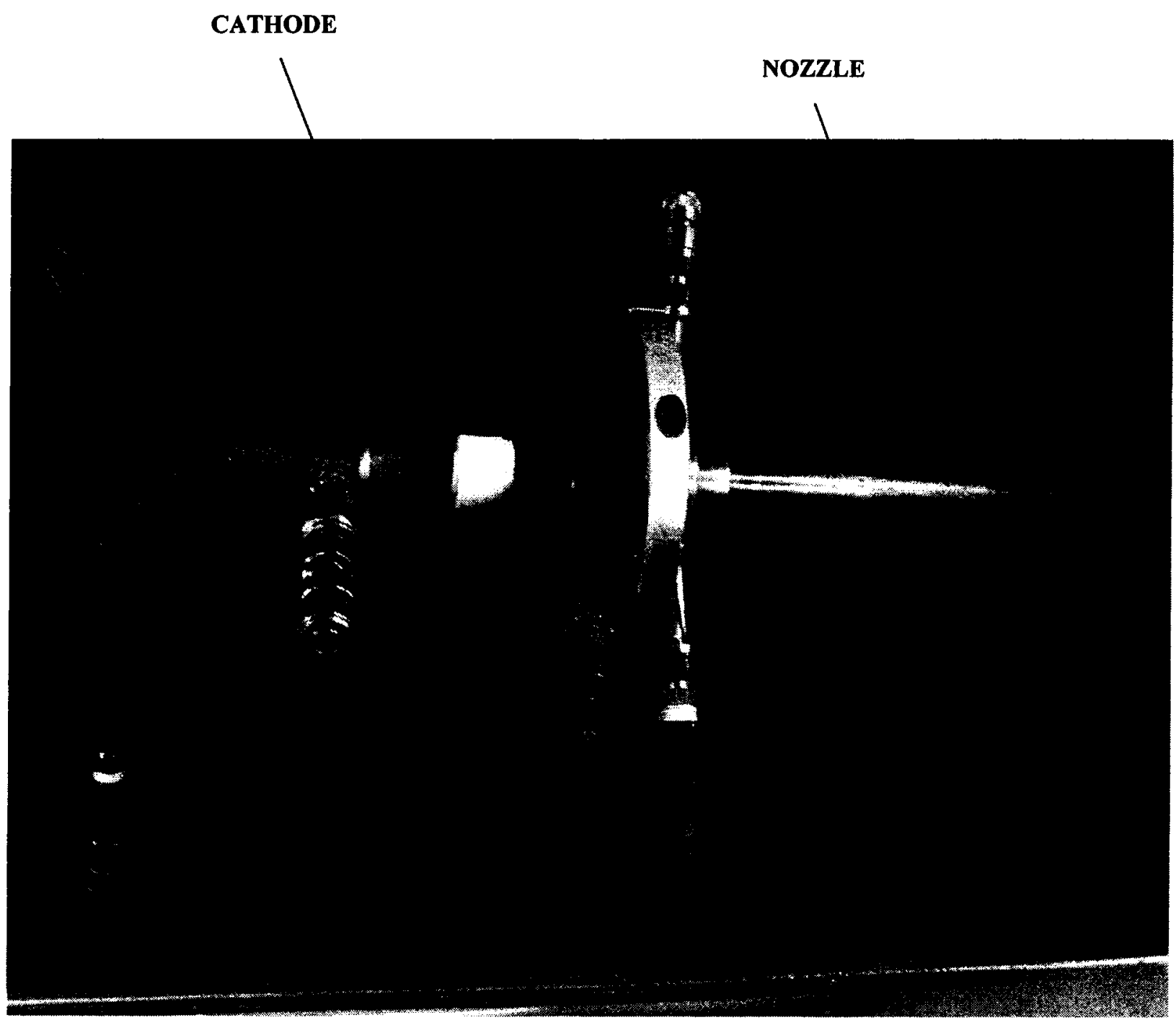

Figure 12. Photograph of torch assembly 
boron nitride disk to prevent backflow. Boron nitride was selected because it is inert, has a high electrical resistivity and good thermal shock resistance.

The steam manifold (see Figure 13) is attached directly to the reactor exit. The steam injection occurred via 18 equally spaced orifices $(0.079 \mathrm{~cm})$, angled downstream to minimize backflow. The steam flow measurement and control system is shown in Figure 14. A steam line was installed in the laboratory and a filter was installed to clean the steam. The steam was available at a pressure of $105 \mathrm{kPa}$. The measurement of the mass flow rate was done by calibrating a gate valve at a constant opening (see Figure 15). The valve was installed before the manifold entrance. The flow rate was varied by varying the inlet valve pressure, using a regulator.

A double-walled, stainless-steel quench pipe with an internal diameter of $3.5 \mathrm{~cm}$ connects the transferred arc reactor to the baghouse filter. The quench pipe was insulated during the experiments in which steam was used as quench gas, and not insulated during the experiments in which air or mixtures of air and steam were used as quench gases. The insulation consisted of alumina insulation, surrounded by alumina foil.

The baghouse filter (see Figure 16) was a cylindrical container $(\mathrm{L}=45.7 \mathrm{~cm}, \mathrm{~W}=$ $30.5 \mathrm{~cm}, \mathrm{H}=48.3 \mathrm{~cm}$ ), made of stainless steel. It was wrapped with heating tapes and heavily insulated (during steam experiments only) to prevent steam condensation during powder collection. The powder was collected in a Nomex B filter bag (Filtration Quebec).

A condenser was installed after the filter to condense the steam and the water was directed to the drain. The exhaust gas was evacuated using two parallel diaphragm vacuum pumps (DAA Shown, GAST) installed at the condenser exit. A control valve was installed at the pump's entrance to regulate the reactor pressure.

The gases used for these experiments were high purity Ar (MEGS), supplied from regulated high pressure cylinders and dry air, supplied from the air line available in the laboratory at a pressure of $700 \mathrm{kPa}$. 


\section{SIDE VIEW - CROSS SECTION}
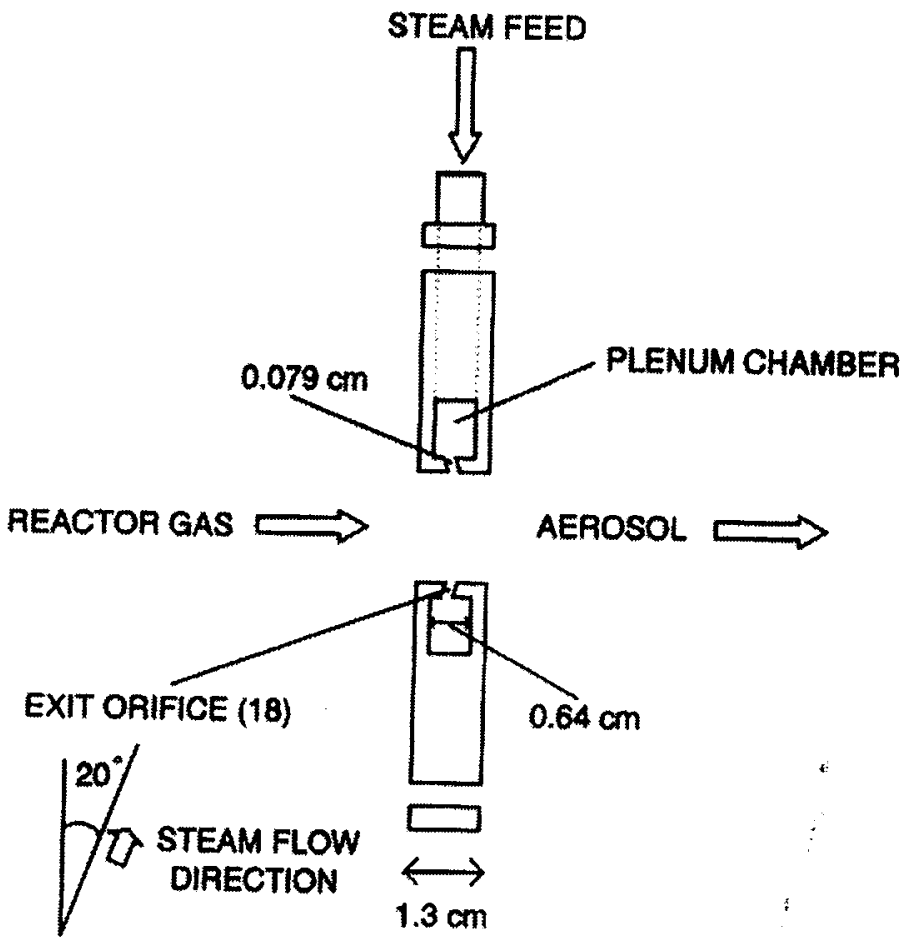

\section{END VIEW}

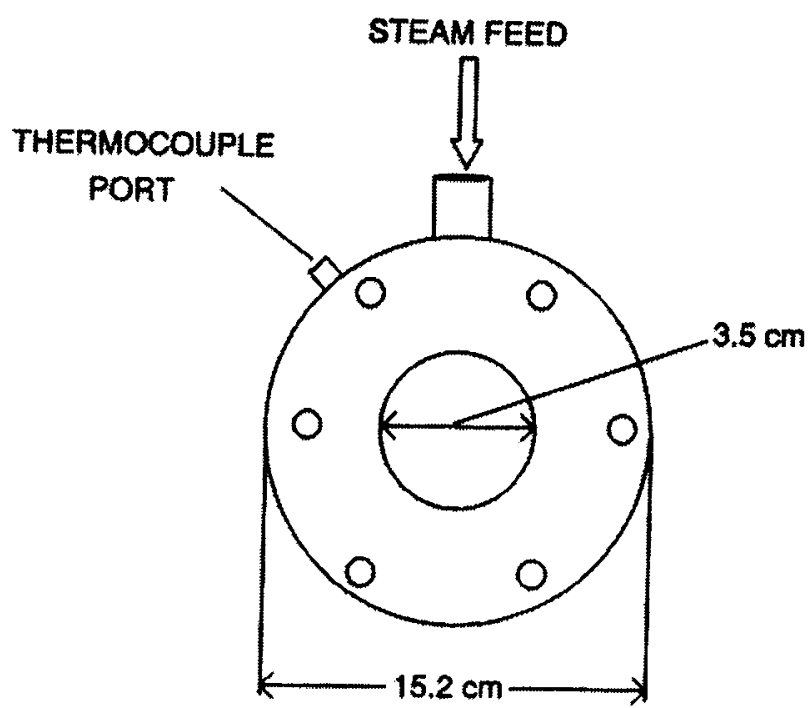

Figure 13. Steam manifold (Addona, 1998) 


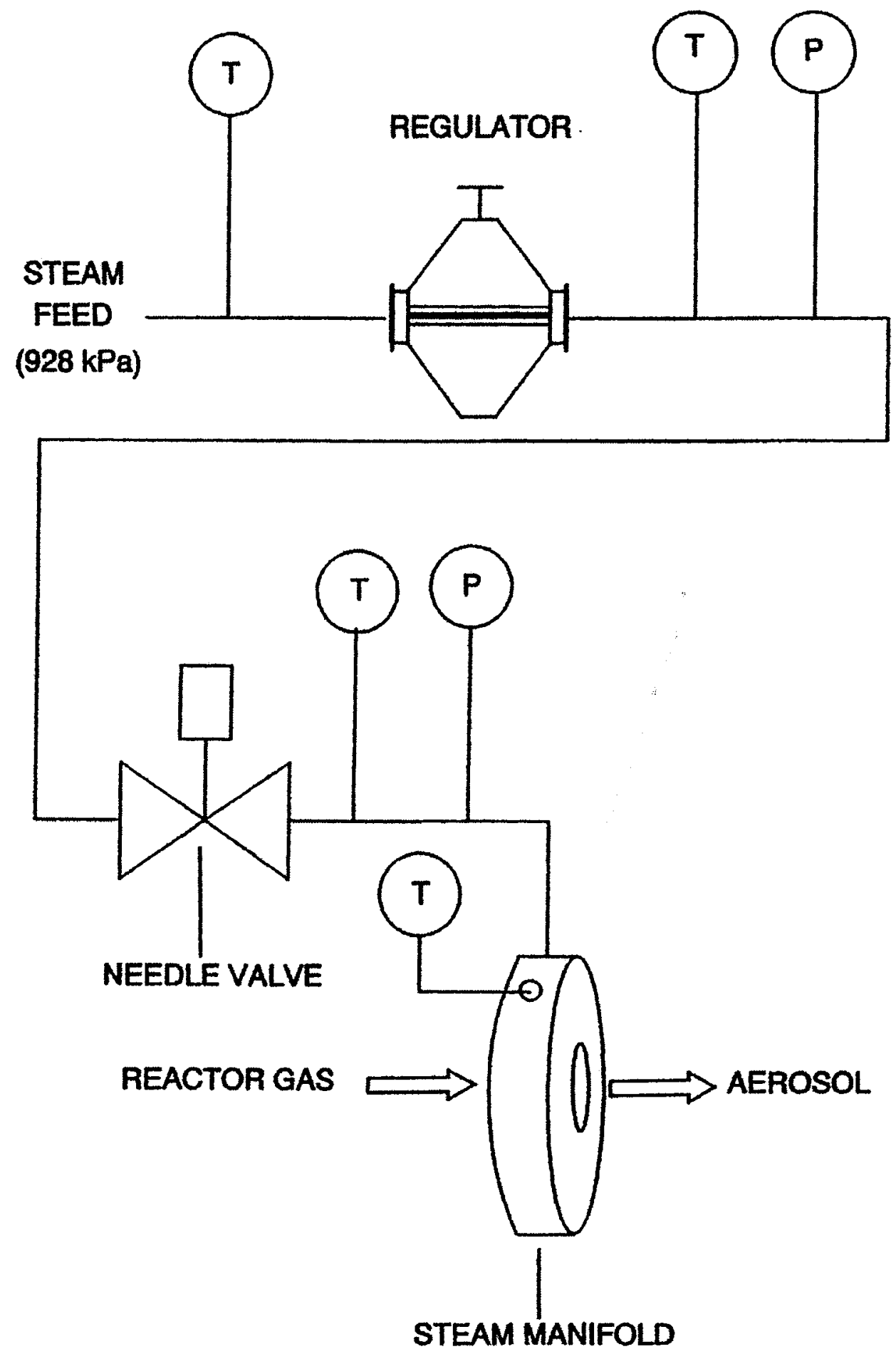

Figure 14. Steam measurement and control system (Addona, 1998) 


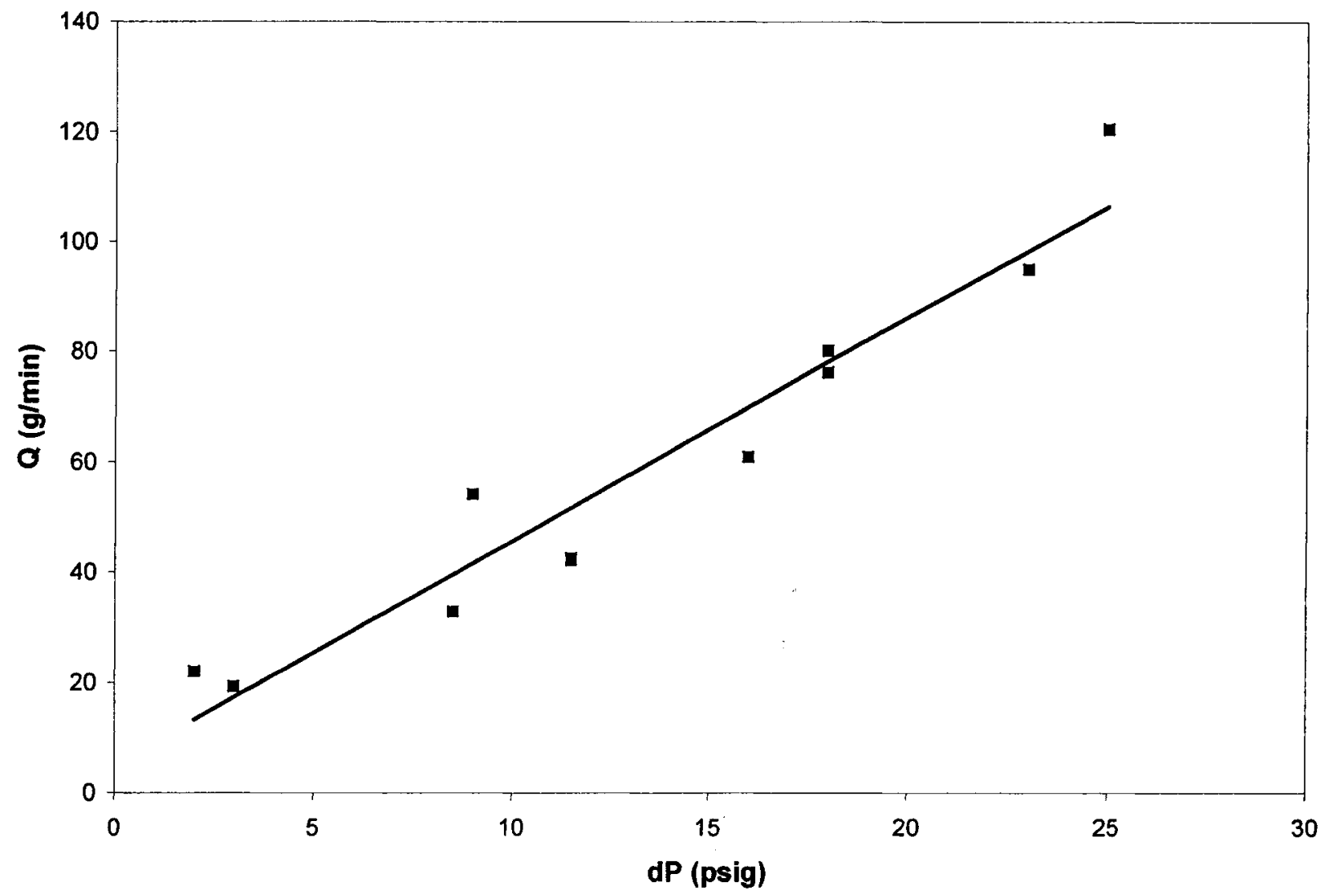

Figure 15. Steam calibration curve 




Figure 16. Baghouse filter used for powder collection (Addona, 1998) 
The power was supplied by eight Miller SRH-444 rectifiers (Miller Electric Mfg. Co.) connected in series. Each rectifier had an open circuit voltage of $75 \mathrm{~V}$ and a power rating of $19.6 \mathrm{~kW}$. The input voltage was 3-phase, $575 \mathrm{~V}$ at $60 \mathrm{~Hz}$. The total open circuit voltage was $600 \mathrm{~V}$. The output rectifier cables were connected to the cathode and anode via a high frequency generator (HF 2000 High Frequency Arc Starter, Miller Electric Mfg. Co.) used for arc ignition. The power was regulated using a remote controller mounted on a control console. The console was also equipped with Ar gas rotameters, a switch to activate the high frequency generator, an emergency button and an analog ammeter and voltmeter.

The voltage was measured using a divider circuit, connected across the cathode and anode at the output of the high frequency generator. Current was measured using a shunt which was placed in series with the anode. The outputs of both devices were connected to the Data acquisition system (DAQ).

A diagram of the electrical equipment is shown in Figure 17.

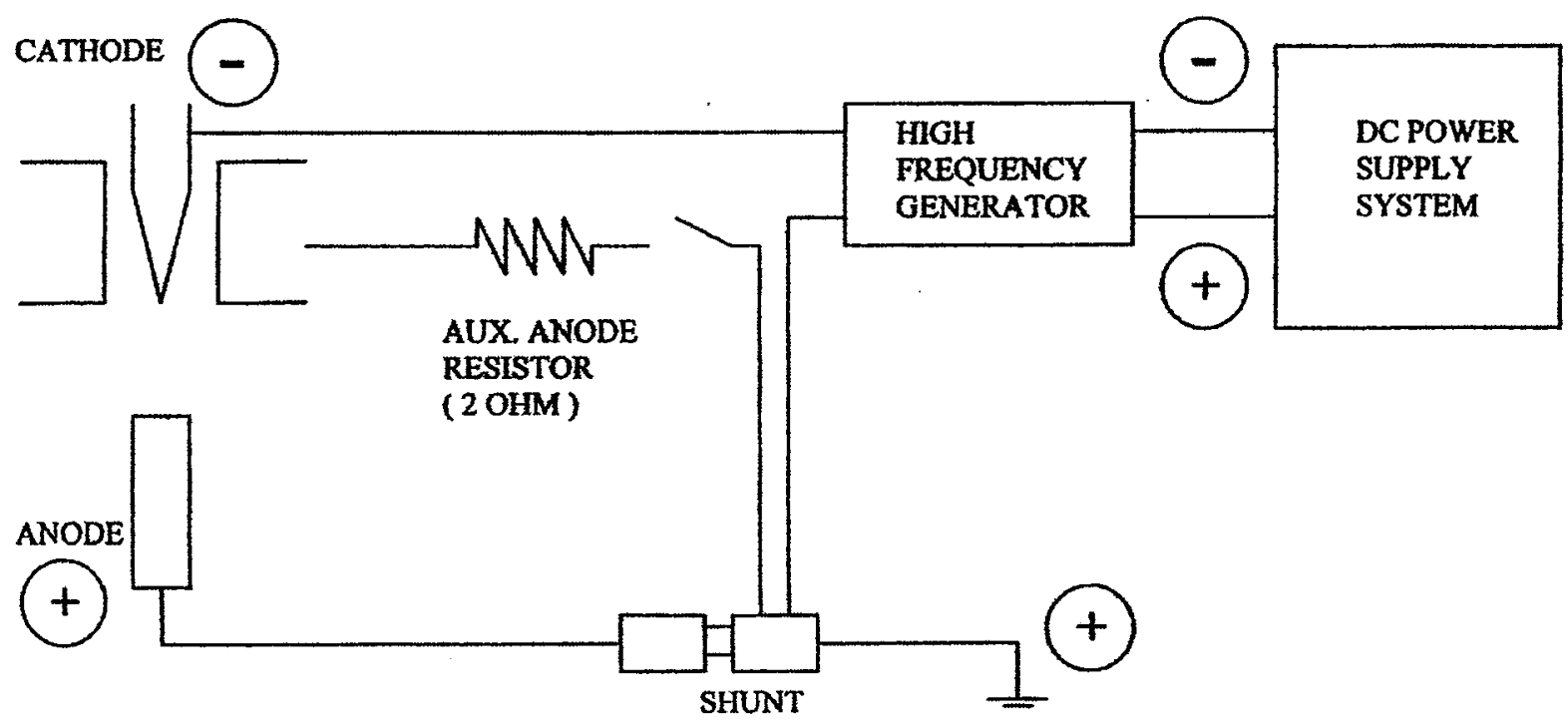

Figure 17. Electrical circuit diagram of the DC power transferred arc reactor (Aquilera \& Silla, 2003) 
The DAQ System consisted of an Input module and a computer. The module is an 8-channel universal Analog Input Module (see Figure 18) with high voltage protection, model I-7019R, from ICP DAS. The module comes with a converter for configuration or connection to PC, model I-7520. It allows different input types: $\mathrm{mV}, \mathrm{V}, \mathrm{mA}$ and thermocouples (J, K, T, E, R, S, B, C, L, M and L2 types). The instrument accuracy is $+/-$ $0.15 \%$ of full scale reading.

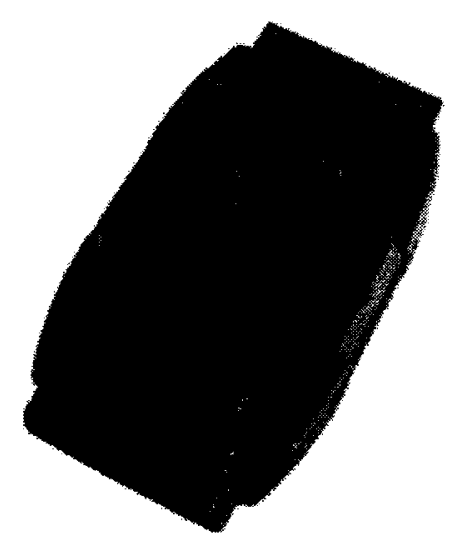

Figure 18. Analog input module for DAQ (www.icpdas.com)

The module was connected to the data acquisition board which was installed in a personal computer. The software used a Lab View interface (see APPENDIXY A), which allowed us to record the temperature in different parts of the system, in ${ }^{0} \mathrm{C}$ and the current (A) and voltage (V) during the experiments. The rate of data acquisition was set at $1 / \mathrm{s}(60$ samples/min). The data acquired were saved to Excel files for later processing (see APPENDICES B and C). 


\subsection{Design of the Agglomerator}

In the flame hydrolysis process for the manufacture of Cab-O-Sil (commercial fumed silica product made by Cabot), an agglomerator is used to accomplish the agglomeration (White and Duffy, 1959) of the powder prior to collection (see Figure 20). The agglomerator consists of a series of aluminum pipes, each 12 inches in diameter and 16 feet long. There are 16 of these pipes, connected in series by $U$ bends. We adapted this type of device to the transferred arc plasma system. The powder, contained in a reservoir, was fed to the system using a Venturi system. A filter was used to collect the powder after agglomeration.

Because the gas temperature at the inlet of the agglomerator shown in Figure 20 is about $320^{\circ} \mathrm{C}$ (which is much below the melting point of silica) it was possible to separate the experiments of fumed silica production and those of agglomeration. Thus, we produced the test material in the refurbished transferred arc reactor and treated in a separate agglomerator.

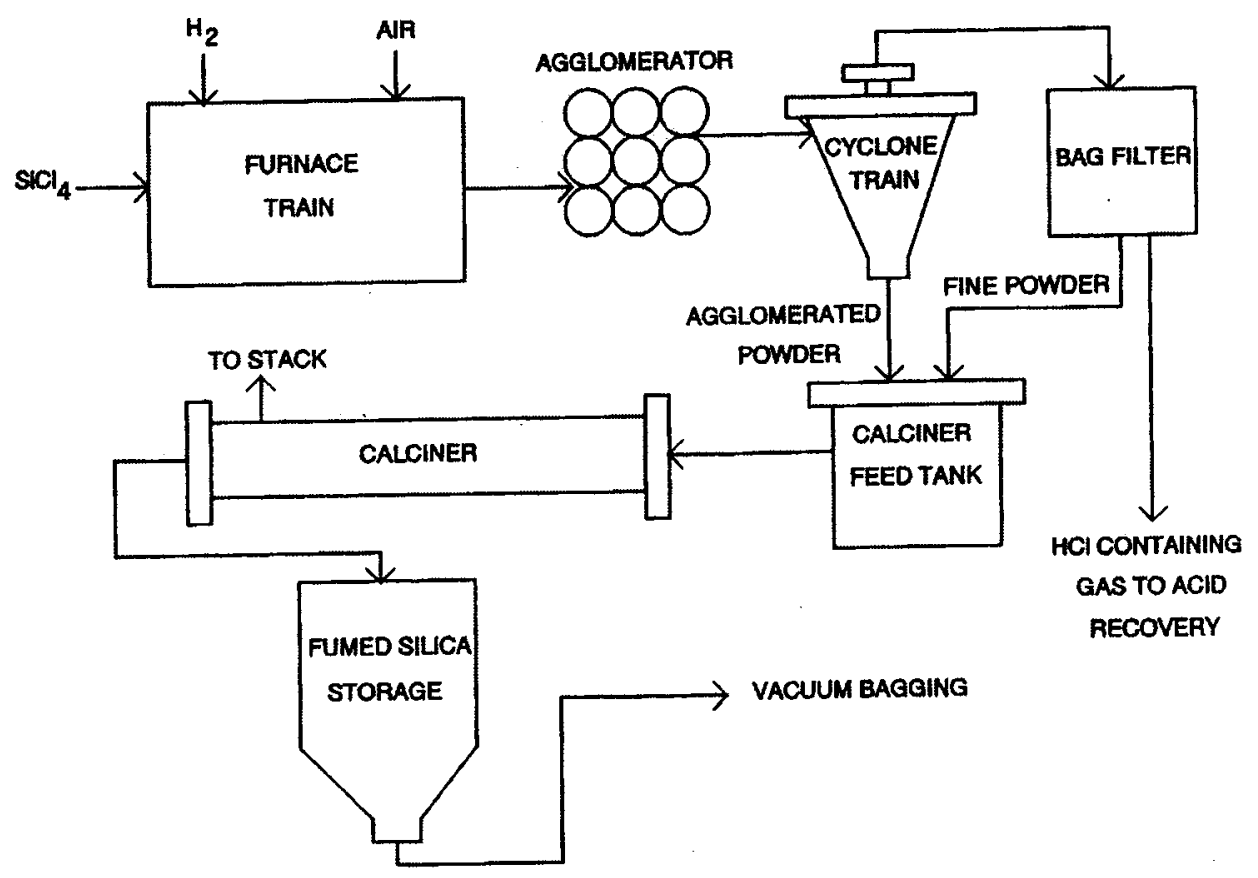

Figure 19. Flame hydrolysis process for fumed silica production (adapted from White and Duffy, 1959) 


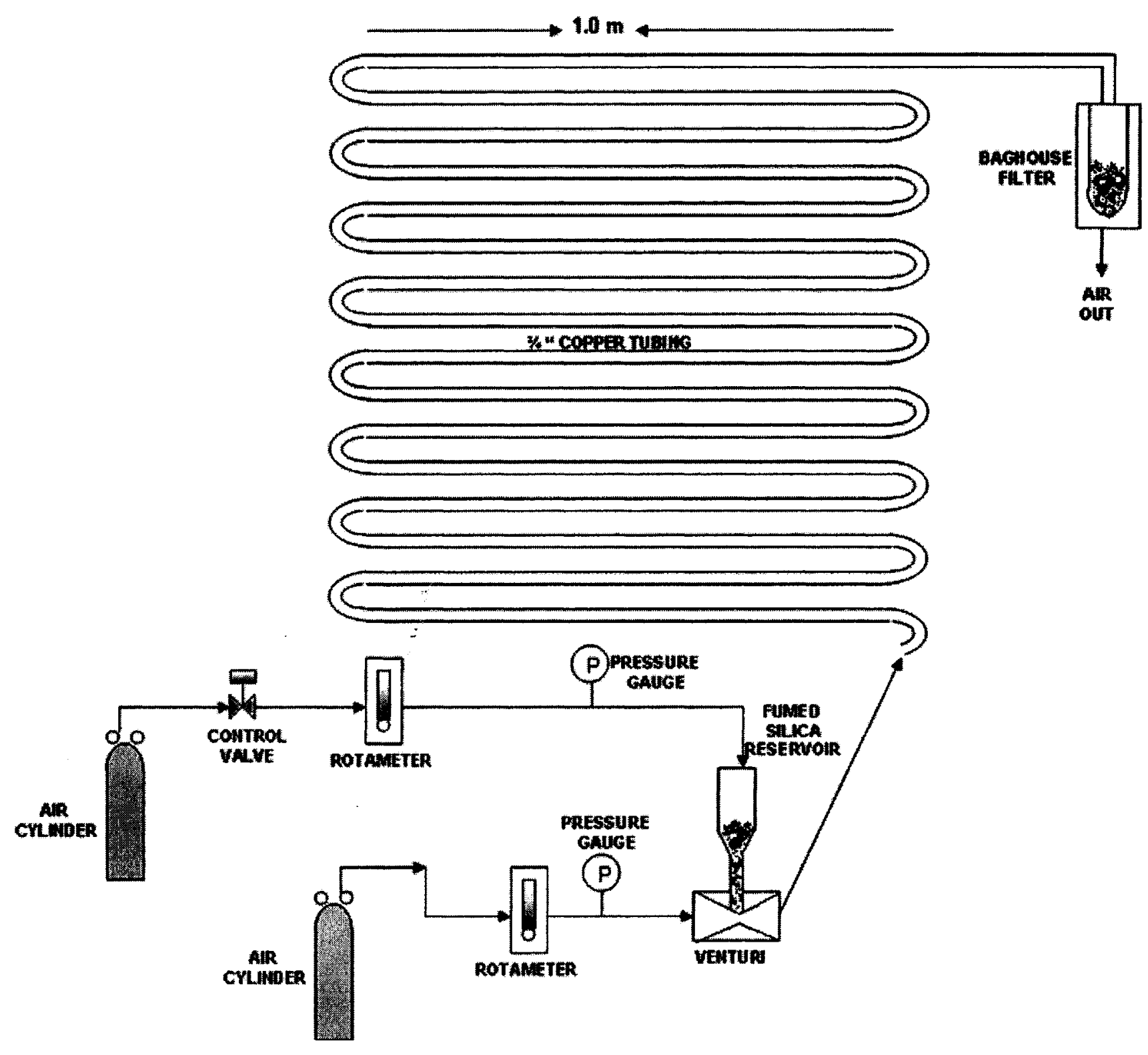

Figure 20. Schematic diagram of the agglomerator used in this work 
The flow rates used were $400 \mathrm{slpm}$ for the venturi and $3 \mathrm{slpm}$ for the feeder. To measure the flows we installed flow meters in both lines. The gas flow rates to the venturi and the feeder were measured by rotameters. The pressure at the venturi entrance and at the feeder entrance were measured by pressure gauges.

The agglomerator was first tested with commercial fumed silica (Aerosil@ 200 from Degussa) to be sure that any problems with the feeding and collection were solved. The operating temperature was the ambient temperature. 


\section{Chapter 5 - EXPERIMENTAL PROCEDURES}

\subsection{Transferred Arc Torch Preparation}

The entire cathode assembly was cleaned before each experiment. Cleaning consisted of removing the condensed silica along the nozzle length. Sand paper was used to sharpen the cathode tip and smooth the surrounding nozzle area. This was important because smooth surfaces allowed easy arc ignition and transfer. The torch insulation was replaced before each experiment. Electrical isolation of the torch was verified.

\subsection{Experimental Procedure for Operating of the Transferred Arc Reactor}

1. Pre-Experimental Preparation:

- clean the inside of the reactor;

- replace all the damaged insulations and other internal parts;

- clean and inspect the torch;

- the apparatus parts (exit tube, window, filter) must be cleaned and reassembled;

- the graphite crucible must be weighted and then filled with $4 \mathrm{~g} \mathrm{NaOH}$ pellets (placed in the center of the crucible, surrounding the graphite rod) and $140 \mathrm{~g}$ quartz; all the quantities must be recorded;

- electrical isolation of the crucible and chamber must be verified;

- place in the feeder (vibrating bowl powder feeder) a known mass of quartz (99.94\% $\mathrm{SiO}_{2}$, irregular in shape, with a nominal size of $\left.1-3 \mathrm{~mm}\right)$;

- seal the reactor and lower the torch to within $1.5 \mathrm{~cm}$ of the top of the crucible.

2. Pressure Test:

- turn on the gas flow and build up a 4 psi pressure inside the reactor;

- turn off the gas flow and check if pressure remains constant for 5 minutes (it means that there are no leaks in the system). 
3. Check the ground cables to see if they are connected to the ground.

4. Check resistance between cathode and ground and cathode and nozzle - in both cases it must be $1 \mathrm{M} \Omega$. If not, it means that the torch is not electricaly isolated and it must be inspected again (replace the electrical tape on the cathode and be sure that the cathode tip and the nozzle do not touch each other).

5. Make sure the exhaust is $\mathrm{ON}$.

6. Turn ON cooling water flows to the reactor and torch and check for leaks (the valves must be fully opened to give the maximum flow rates). Turn ON the booster pump. Check for leaks again.

7. Check if the water flow indicators for cathode and nozzle are working.

8. Turn ON gas flows. Before ignition, Ar must flow for 1 hour, with 5 slpm to purge the system of air. For the experiment, flows of $20 \mathrm{slpm} \mathrm{Ar}$ for torch and 4 slpm Ar for window and feeder are used.

9. Check if the cathode is covered with the plastic cover to avoid accidental human contact during and experiment.

10. Make sure that the cables from power supply to torch do not touch each other

11. Plug in control console and HF power cables.

12. Check if the cables marked "Transferred arc anode" (red plug) and "Transferred arc cathode" (black plug) are attached to the gray box named "Connection box" (located in the hall existing between the laboratories 5310 and 5120, on top of the DC power supply system). 
13. Check if the cable labeled "Transferred arc" is connected to the socket on the blue remote control box (located at the hall existing between the laboratories 5310 and 5120 , near the "Connection box").

14. Turn ON the main circuit breakers marked $1 \& 5,2 \& 6,3 \& 7,4 \& 8$ (located at the hall existing between the laboratories 5310 and 5120 ).

15. Set the rheostat to 0 (control console, laboratory 5310).

16. Turn ON the power switch and the HF power switch on the control console.

17. Turn ON the switch marked DC power supply on the console.

18. Release the emergency button (out position). The voltmeter (on the control console) should indicate $600 \mathrm{~V}$.

19. Press the auxiliary anode relay button (the small red button located under the power supply rheostat).

20. Push to the right the HF toggle switch located under the knob labeled power supply rheostat. A spark is created and it generates an arc between the cathode and nozzle, which then is transferred to the graphite rod in the center of the crucible. When this occurs, the nozzle relay is opened.

21. Increase the power by adjusting the power supply rheostat.

22. Turn ON the steam flow (slowly).

23. To observe the arc use the protective welding glass wear through the side window. 
24. Start the data acquisition system (after $\sim 1 \mathrm{~min}$ from the arc ignition).

25. During the first 15 minutes of operation the filter must be bypassed to prevent the contamination with $\mathrm{NaOH}$. Because of the low melting point $(591 \mathrm{~K}), \mathrm{NaOH}$ is vaporized within a few seconds after arc ignition. The powder collection starts when the temperature in the exit tube is almost constant.

26. Start the particle feeding.

\subsection{Shut-down Procedure}

1. Prior to the termination of an experiment, particle feeding must be stopped and the filter must be bypassed again.

2. Turn OFF the steam.

3. Reduce the gas (Ar) flows.

4. Turn OFF the power switch and simultaneously set the rheostat to 0 .

5. Push the red emergency button (in position).

6. Put the control console power switch and the HF power switch in the DOWN position (OFF).

7. Turn OFF all the main circuit breakers marked $1 \& 5,2 \& 6,3 \& 7$ and $4 \& 8$.

8. Ar and cooling waters flows must continue until the apparatus is cooled.

9. After reactor cooling, turn OFF the Ar and water flows. 


\subsection{Experimental Procedure for Operating of the Agglomerator}

1. Measure and record the mass of the empty feeder (particle reservoir).

2. Pour powder in the feeder and record again its mass.

3. Measure and record the mass of the empty filter bag.

4. Install the feeder and the filter.

5. Turn on the air flow through the agglomerator and set it at $400 \mathrm{slpm}$. The pressure inside the feeder is monitored via a pressure gauge. During the tests the pressure was 4 psig.

6. Open the feeder valve (situated at the bottom of the feeder) to allow the powder to enter the venturi.

7. Turn on the air flow through the feeder and set it to $3 \mathrm{slpm}$. The pressure is increasing in the feeder $(\sim 3.5 \mathrm{psig})$ and the powder starts to flow through the pipes.

8. After the feeder is empty, allow the air to flow one more minute to allow the collection of all the powder into the filter bag.

9. Turn off the air flows and close the feeder valve.

10. Measure the mass of the feeder. The difference between the mass of feeder with powder and the mass of the empty feeder (at the end of experiment) gives the mass of powder fed into the agglomerator.

11. Open the filter and detach the filter bag. 
12. Measure and record the mass of the filter bag with the powder collected. The difference between the mass of the filter bag with the powder and the mass of the empty filter bag gives the mass of powder collected.

13. Clean the agglomerator, the feeder and the filter using a vacuum cleaner.

14. Transfer the powder collected into a beaker, for further testing. 


\section{Chapter 6 - EXPERIMENTAL RESULTS}

We performed two types of experiments:

thermal plasma production of fumed silica samples using different quench conditions

$>$ agglomeration of produced fumed silica powders

In both cases, the powders were analyzed using the techniques enumerated in Chapter 3.

\subsection{Summary of Plasma Experiments Performed}

In our experiments, we tried to use similar conditions to Addona's experiments. An arc current of $170 \mathrm{~A}$ and a voltage of $45 \mathrm{~V}$ were used for most of the experiments. Argon was used for the torch $(20$ slpm), the window ( 4 slpm) and the feeder $(4 \mathrm{slpm})$. The feed material was Sitec quartz $\left(99.94 \% \mathrm{SiO}_{2}\right.$, irregular in shape, with a nominal size of 1-3 $\mathrm{mm}$ ). The mass of quartz added in the feeder at the beginning of each experiment was $400 \mathrm{~g}$ and $140 \mathrm{~g}$ was loaded into the crucible. The total duration of the experiments was approximately 2 hours. All these conditions were selected to obtain good production results.

Different quench conditions were studied by varying the quench gas composition (steam, air and mixtures of both) and the flow rates. The steam used was from a steam line in laboratory, available at a pressure of $105 \mathrm{kPa}$. A filter was installed to remove particulate matter from line corrosion.

The main problems during the tests were to control the pressure in the system and temperature in the exit tube and filter. The pressure increases during the tests were due to the deposition of the powder in the pipes and and collection of powder in the filter. To solve these problems we increased the pipe diameter from $1 / 2$ " to $3 / 4$ " and we installed an 
additional vacuum pump at the end of the process to account for the pressure drop across the filter. During the experiments, thermocouples (Types $\mathrm{C}$ and $\mathrm{K}$ ) were used to measure temperature. Key temperatures measured included the reactor exit gas temperature (just prior to quenching) and the inlet and outlet filter temperature (see Figure 1). To avoid excessive heat loss leading to condensation, the exit tube was insulated during the steam quench experiments. No insulation was used during the air quench experiments and additional cooling air was added at the filter entrance to reduce temperature and avoid damaging the filter bag used for collection (a Nomex filter bag was used).

A summary of the synthesis experiments is presented in Table 2, in which: $t$ is the total experiment time, $I$ is the argon arc current during the steady-state part of the experiments, $\mathrm{V}$ is the voltage, $\mathrm{P}_{\mathrm{r}}$ and $\mathrm{P}_{\mathrm{f}}$ are the pressures in the reactor and filter, $\mathrm{Q}_{\mathrm{Ar}}$ is the argon flow in the torch, window and feeder (W/F), $\mathrm{Q}_{\mathrm{q}}$ is the quench flow, $\mathrm{r}_{\mathrm{D}}$ is the quartz decomposition rate, $\mathrm{m}_{\mathrm{p}}$ is the mass of product collected and $\mathrm{T}_{\mathrm{r}}$ is the temperature of gases leaving the reactor.

The decomposition rate was calculated using the following formula:

$$
r_{D}=\left(m_{q i}+m_{q f}-m_{q i}\right) / t_{f}
$$

where $m_{q i}$ is the mass of quartz in the crucible, at the beginning of the experiment, $m_{q f}$ is the mass of quartz fed during the experiment, $\mathrm{m}_{\mathrm{qt}}$ is the mass of quartz in the reactor (crucible + chamber), at the end of the experiment and $t_{f}$ is the feeding time. The $m_{q t}$ was used instead of the mass of quartz in the crucible at the end of the experiment, because during the feeding not all the quartz fell into the crucible; some fell into the chamber floor.

In the table, the experimental conditions were recorded during the steady-state part of the experiments. We can see that the values for current and voltage were almost the same for all the experiments and we used the same Ar flow rates for torch, window (to prevent condensation of the decomposed silica onto the window) and feeder (to prevent blocking due to partial melting of the quartz particles). For the steam experiments we varied the steam flow rate from $50 \mathrm{gpm}$ to $115 \mathrm{gpm}$, which covers the entire range of 
quench flow rates (low, medium and high) used by Addona in his experiments. We also used air and mixtures of air and steam for the quench. These conditions cover a large range of water vapor concentrations in the quench zone. This zone is where particle nucleation and growth occurs, in addition to surface reactions and aggregate formation (due to the collision and partial fusion of the solidifying molten silica particles).

We can see also in Table 2 that the decomposition rate was approximately constant during experiments where this parameter was measured and torch power was approximately constant. The mass of product collected varied with the experiment duration. The low values of product mass collected in experiments 15 and 17 are due to the fact that we had steam condensing in the filter bag because the insulation was removed around the outside of the filter housing when air quench experiments were commenced (starting with experiment 13). This was done to avoid excessively high temperatures in the filter bag since air quenching resulted in much higher temperatures at the filter inlet. This insulation was not re-installed for experiment 15 (pure steam quench) and it was thought that the use of heating tapes wrapped around the filter housing would be sufficient to compensate for the heat loss during this experiment. These heating tapes were insufficient to prevent steam condensation and as a result much of the powder collected (especially in the bottom portion of the filter bag) was wet and it was not collected. Steam condensation in the filter also occurred during experiment 17 and a similar problem with powder collection resulted.

$T_{r}$ varied with the torch power: by increasing the power, the $T_{r}$ was also increased For the experiments 15 and 16 we have lower values of $T_{r}$ because the thermocouple design was changed. 
Table 2. Summary of experiments

\begin{tabular}{|c|c|c|c|c|c|c|c|c|c|c|c|c|}
\hline \multirow[t]{2}{*}{ Exp. } & \multirow[t]{2}{*}{$\begin{array}{c}t \\
(\min )\end{array}$} & \multirow[t]{2}{*}{$\begin{array}{c}I \\
(A)\end{array}$} & \multirow[t]{2}{*}{$\begin{array}{c}V \\
(V)\end{array}$} & \multicolumn{2}{|c|}{$\begin{array}{c}\text { Pressure } \\
\text { (psig) }\end{array}$} & \multicolumn{2}{|c|}{$Q_{A r}(s l p m)$} & \multicolumn{2}{|c|}{$\boldsymbol{Q}_{q}$} & \multirow[t]{2}{*}{$\begin{array}{c}r_{D} \\
(g p m)\end{array}$} & \multirow[t]{2}{*}{$m_{p}(g)$} & \multirow[t]{2}{*}{$\begin{array}{c}T, \\
P C)\end{array}$} \\
\hline & & & & $\boldsymbol{P}_{r}$ & $\boldsymbol{P}_{f}$ & Torch & $W / F$ & $\operatorname{Air}(\operatorname{slpm})$ & Steam(gpm) & & & \\
\hline 1 & 20 & 200 & 40 & 2.0 & & 15 & 4 & 15 & & NM & NM & $\mathrm{NM}$ \\
\hline$* 2$ & 43 & 200 & 40 & 2.5 & & 15 & 4 & 15 & & NM & NM & NM \\
\hline$* 3$ & 30 & 200 & 42 & 1.0 & & 15 & 4 & & $\mathrm{NM}$ & NM & NM & $\mathrm{NM}$ \\
\hline$* 4$ & 70 & 200 & 50 & 1.0 & & 20 & 4 & & NM & NM & 3.0 & $\mathrm{NM}$ \\
\hline$* 5$ & 94 & 160 & 50 & 1.0 & & 20 & 4 & & NM & NM & 3.5 & $\mathrm{NM}$ \\
\hline$* 6$ & 22 & 160 & 32 & 1.5 & 1.5 & 20 & 4 & & NM & NM & NM & $\overrightarrow{N M}$ \\
\hline$* 7$ & 90 & 200 & 42 & 0.5 & 0.5 & 20 & 4 & & 55 & NM & 4.4 & NM \\
\hline$* 8$ & 120 & 170 & 40 & 1.0 & 1.0 & 20 & 4 & & 62 & 0.50 & 5.3 & NM \\
\hline$* 9$ & 118 & 175 & 41 & 1.0 & 1.0 & 20 & 4 & & 110 & 0.49 & 6.3 & 1260 \\
\hline 10 & 120 & 170 & $\overline{43}$ & 1.0 & 1.0 & 20 & 4 & & 50 & 0.41 & 9.7 & 1130 \\
\hline 11 & 111 & 170 & 46 & 1.0 & 1.0 & 20 & 4 & & 62 & 0.51 & 8.3 & 1400 \\
\hline 12 & 110 & 170 & 47 & 1.0 & 1.0 & 20 & 4 & & 60 & 0.48 & 9.5 & 1320 \\
\hline 13 & 120 & 175 & 47 & 1.8 & 1.8 & 20 & 4 & 27 & 19 & 0.41 & 13.3 & 1260 \\
\hline 14 & 120 & 168 & 48 & 1.5 & 1.5 & 20 & 4 & 33 & & 0.33 & 10.7 & 1300 \\
\hline 15 & 120 & 170 & 48 & 2.0 & 2.0 & 20 & 4 & & 115 & 0.46 & 7.5 & 960 \\
\hline 16 & 90 & 166 & 47 & 2.5 & 2.5 & 20 & 4 & 30 & & 0.32 & 6.7 & 1050 \\
\hline 17 & 110 & 170 & 45 & 2 & 2 & 20 & 4 & 27 & 22 & 0.40 & 3.4 & 1240 \\
\hline
\end{tabular}

Note: $\mathrm{NM}=$ Not Measured

\footnotetext{
${ }^{*}$ For the experiments 1 to 9 , the Current and Voltage values were recorded at the beginning of the experiments, using the voltmeter and ampermeter located on the control board(in lab. 5310), because the Data Acquisition System was not yet installed.
} 
We also calculated the feeding rate $\left(r_{f}\right)$ for the experiments from the initial and final mass of quartz in the feeder and the feeding time:

$$
r_{f}=\frac{m_{q i}-m_{q f}}{t_{f}}
$$

were: $\mathrm{m}_{\mathrm{qi}}=$ mass of quartz in the feeder at the beginning of experiment

$\mathrm{m}_{\mathrm{qf}}=$ mass of quartz in the feeder at the end of experiment

$t_{\mathrm{f}}=$ feeding time

Table 3 gives a comparison of the decomposition rate $\left(\mathrm{r}_{\mathrm{D}}\right)$ and feeding rate $\left(\mathrm{r}_{\mathrm{f}}\right)$ for the experiments 8 to 16 :

Table 3. Decomposition and feeding rates values

\begin{tabular}{|r|r|r|r|}
\hline Exp.number & Quench gas & $r_{D}(\mathrm{~g} / \mathrm{min})$ & $r_{f}(\mathrm{~g} / \mathrm{min})$ \\
\hline 8 & steam & 0.50 & 0.52 \\
\hline 9 & steam & 0.49 & 1.08 \\
\hline 10 & steam & 0.41 & 0.65 \\
\hline 11 & steam & 0.51 & 2.05 \\
\hline 12 & steam & 0.48 & 1.18 \\
\hline 13 & steam + air & 0.41 & 1.05 \\
\hline 14 & air & 0.33 & 0.76 \\
\hline 15 & steam & 0.46 & 1.98 \\
\hline 16 & air & 0.32 & 1.47 \\
\hline
\end{tabular}

The decomposition rate is influenced by the plasma gas flow rate, the type of plasma gas, the arc length and by the power dissipated. For all the experiments we used the same values for these parameters. 
The values of the decomposition rate were constant, except in the cases of experiments 14 and 16, in which air was used as quench gas. We suspect that there was a slight air backflow into the reactor and that decreased the decomposition rate by increasing the oxygen potential in the plasma chamber. The decomposition reaction is a reversible reaction and by Le Chatelier's Principle, the addition of oxygen would reduce the decomposition rate. 


\subsection{Product Analysis of Plasma Experiments}

\subsubsection{X-ray Diffraction (XRD)}

$\mathrm{XRD}$ is a powerful non-destructive technique used to characterize crystalline materials. It provides information on structures, phases, preferred crystal orientations and other structural parameters such as average grain size and crystal defects. The spectrum presents the X-ray diffraction peaks, produced by constructive interference of the beam scattered from each set of planes at specific angles. The absence of these peaks means that the substance is amorphous.

The following figures show the XRD spectra of Aerosil 200 (Figure 21) and two typical plasma produced fumed silica samples (Figure 22) in which steam and air respectively were used in the quench. In all cases, the spectra show that the plasma produced powders are fully amorphous meaning that the quench rates were high.

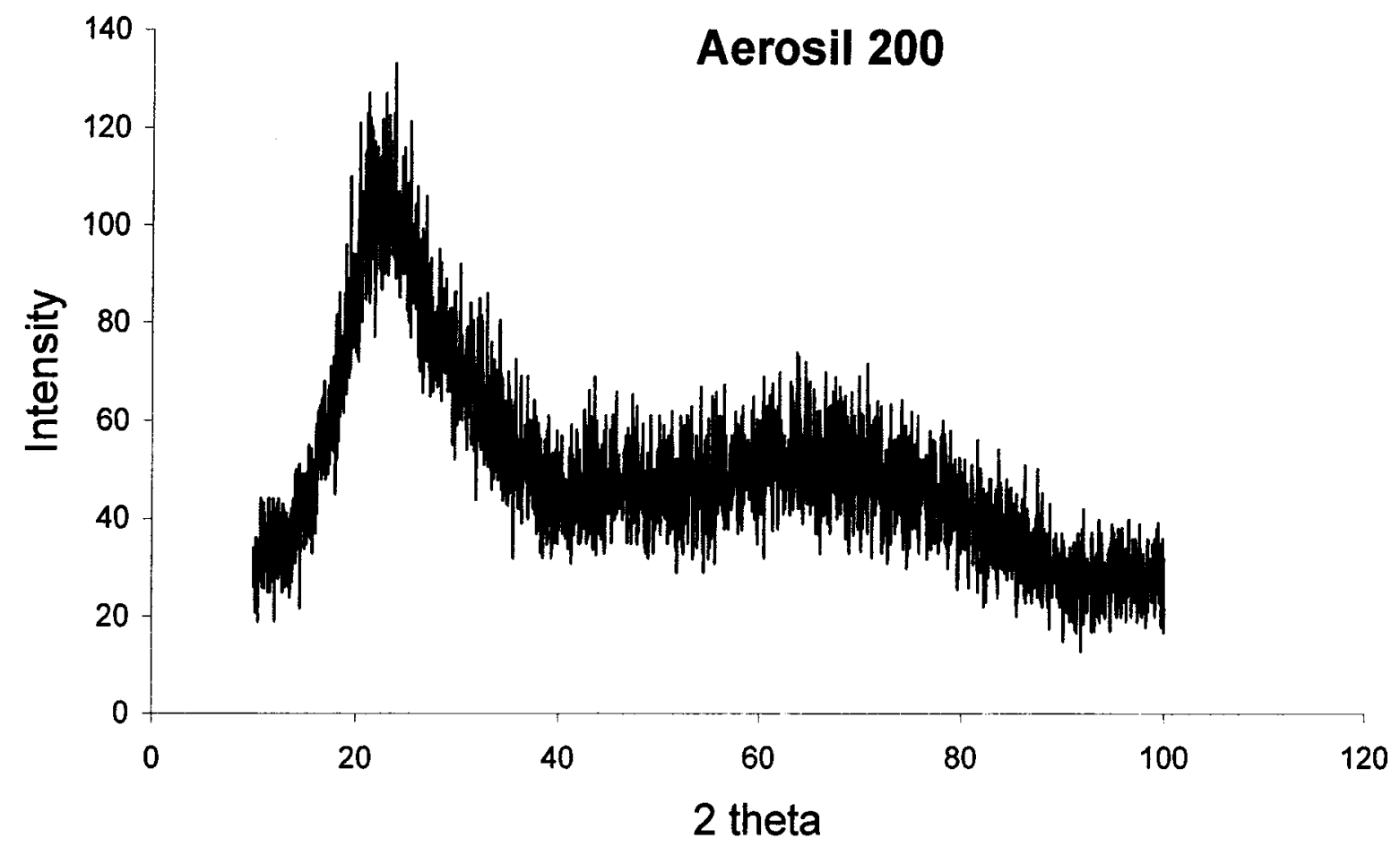

Figure 21. XRD spectrum of Aerosil 200 

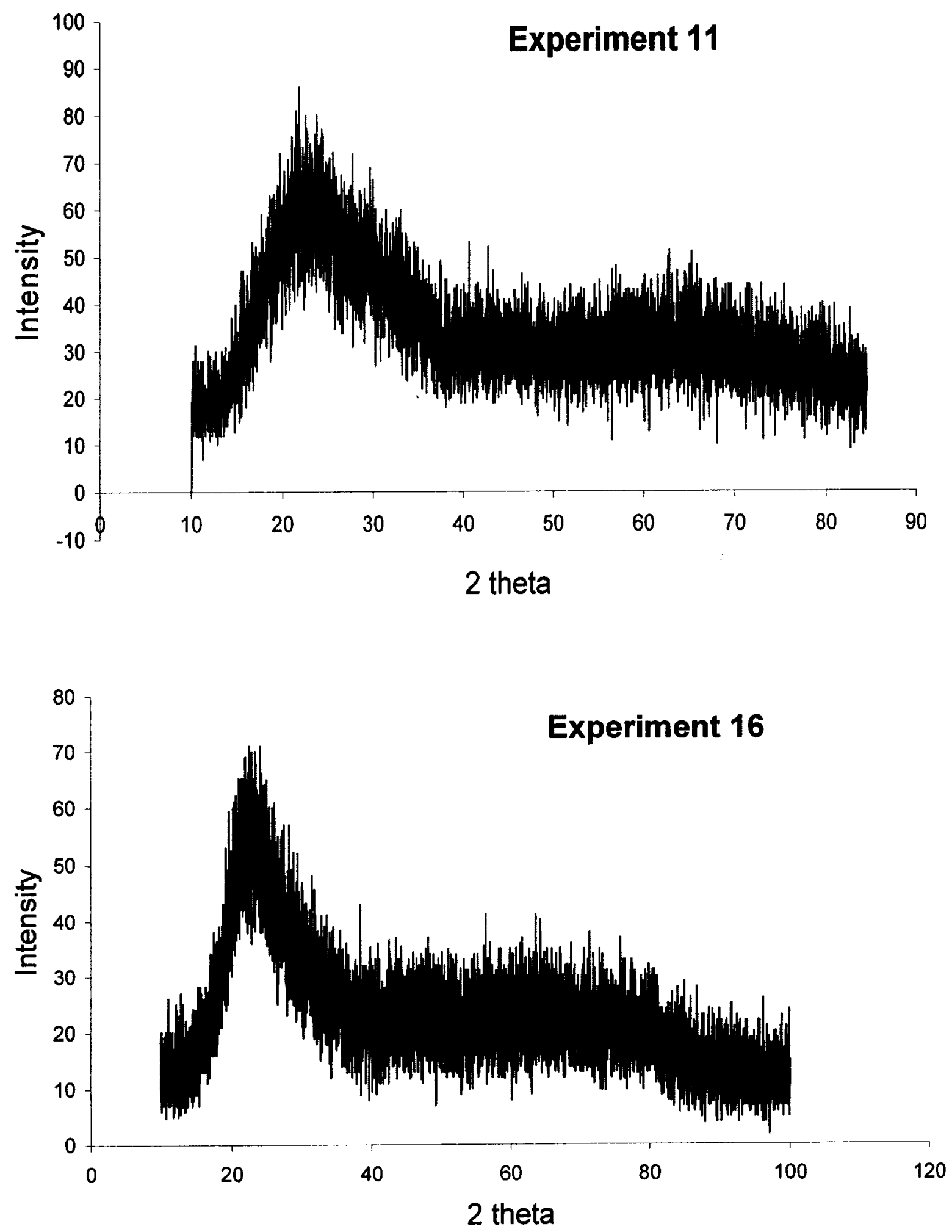

Figure 22. XRD spectrums of experimental powders 


\subsubsection{Scanning Electron Microscopy (SEM)}

SEM uses an energetically well-defined, highly focused beam of electrons scanned across a sample. The apparatus used was a Hitachi 4700 FEG-SEM (Field Emission GunScanning Electron Microscope). The instrument magnification ranges from $30 \mathrm{X}$ to $500,000 \mathrm{X}$ and it is capable of $1.5 \mathrm{~nm}$ resolution at $15 \mathrm{kV}, 12 \mathrm{~mm}$ W.D ${ }^{*}$ and $2.5 \mathrm{~nm}$ resolution at $1 \mathrm{kV}, 2.5 \mathrm{~mm}$ W.D. The electron source is a Cold FE gun producing high brightness $\left(2 \mathrm{X} 10^{9} \mathrm{~A} / \mathrm{cm}^{2} / \mathrm{sr}\right)$ with little energy spread $(0.2-0.3 \mathrm{eV})$.

The powder was spread on a cylindrical mount, using carbon tape. Because the powder is not conductive, the samples were coated with gold. The thickness of the coating was about $20 \mathrm{~nm}$, which was too thin to interfere with dimensions of surface features.

SEM analysis showed that the experimental powders 11 (steam quench) and 16 (air quench), which were typical of plasma produced material, were not the same as Aerosil 200. For Aerosil 200 (Figure 23a) we observed a uniform particles size distribution. In the case of experimental powders (Figure 23b) we obtained a broad particles size distribution and we believe that very big particles (order of 200 - 300 micrometers, like in the case of experimental powder 11, Figure $23 \mathrm{~b}$ ) are present in all the plasma produced powders.

It must be noted that the features shown by SEM do not show the individual nanoparticles since the resolution is too low for this. These are observed in the TEM pictures.

\footnotetext{
W.D. = Working Distance
} 

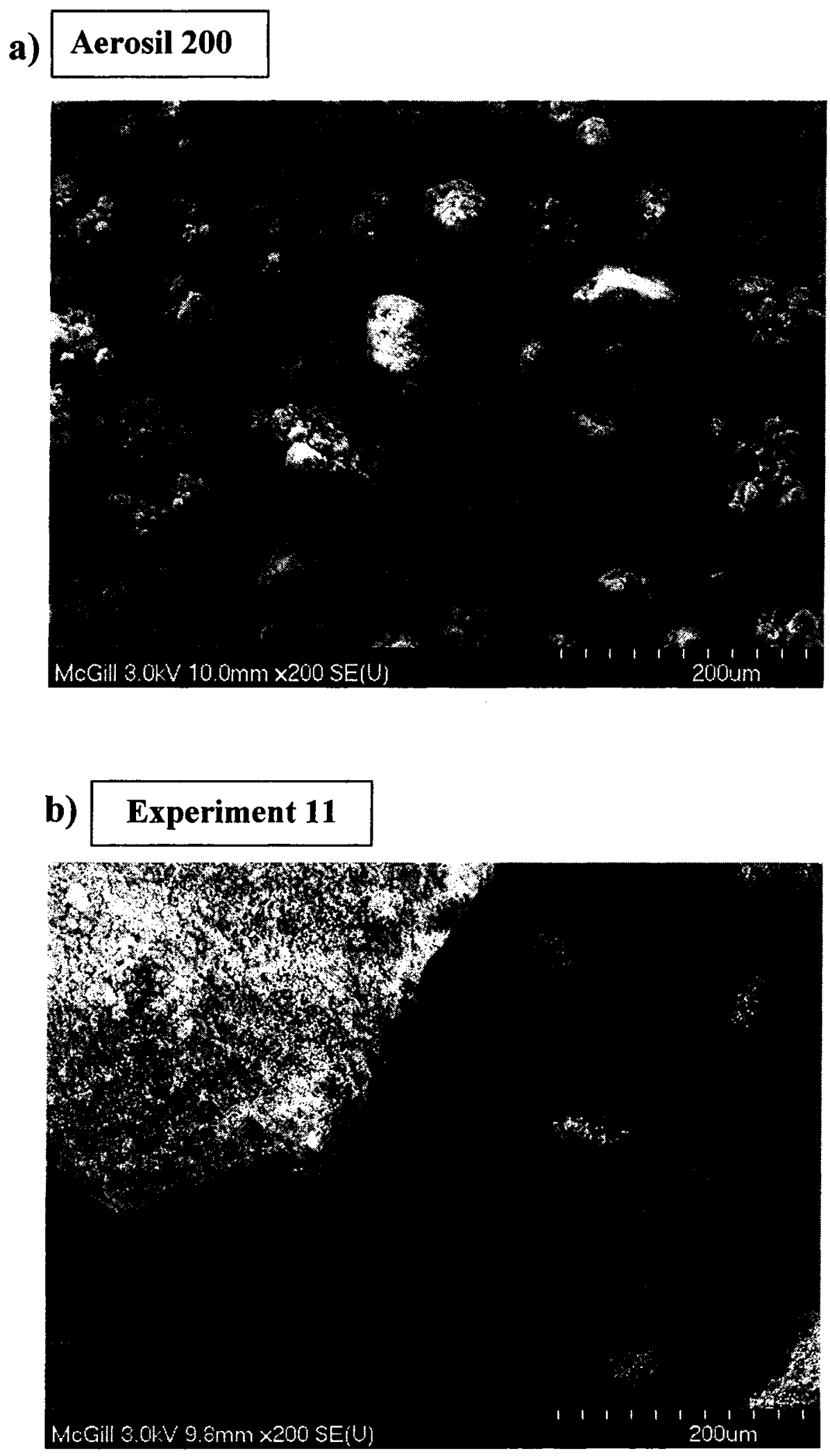
Experiment 16

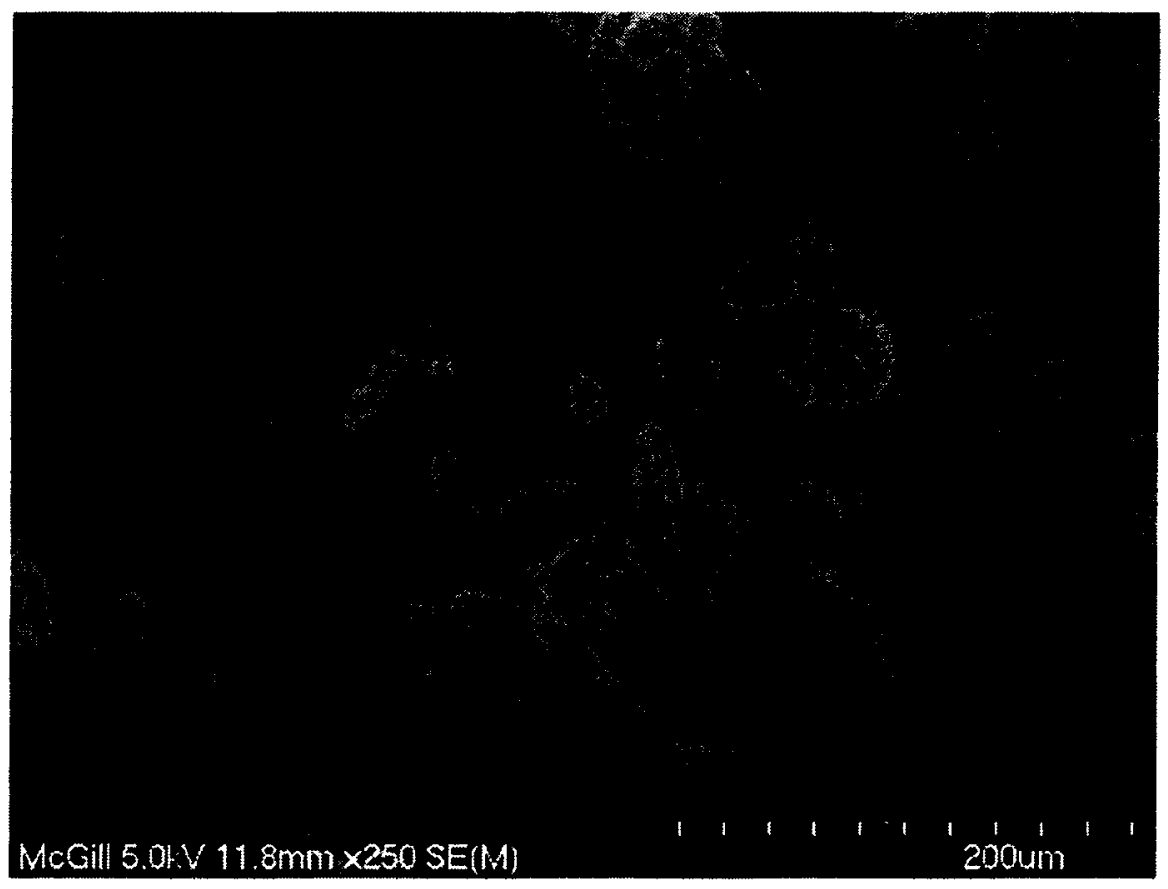

Figure 23. SEM pictures of: a) Aerosil 200 and b) Experimental powders 


\subsubsection{Transmission Electron Microscopy (TEM)}

TEM was used in order to provide information about the primary particles shape and size and also about the aggregate structure.

The samples were prepared by dispersing a small amount of powder in about $2 \mathrm{ml}$ of water using an ultrasonic bath for about 1 minute, then pipetting a drop onto a 300-mesh $\mathrm{Cu}$ grid with carbon film and air drying at room temperature. The samples were imaged in the JEOL JEM-2000FX TEM at an accelerating voltage of $80 \mathrm{kV}$. Images were obtained with the Gatan digital imaging (CCD) system, Model 791. TEM provides twodimensional images of the particles, therefore spherical particles appears as round discs.

The TEM pictures (see Figure 24) showed that fumed silica was built up of many almost spherical primary particles. The primary particles form a network. Practically, no isolated particles were observed; the particles lined up with each other to form irregular chains. We can see in the TEM pictures that we obtained the chain-like aggregate structure (which is a very important property of the powders) with both steam and air quench.

For Aerosil 200 (commercial product from Degussa) the average primary particle size is $12 \mathrm{~nm}$ (Degussa Technical Bulletin). In the case of the experimental powders the particles size distribution is not as uniform as can be seen from the TEM pictures. This wider size distribution of the primary particles in the case of the experimental powders is thought to be due to the fact that the plasma reactor and quench zone conditions such as $\mathrm{SiO}_{(\mathrm{g})}$ concentration, mixing intensity, temperature distribution and residence time have not been optimized. As a result, the experimental powders have a primary particle size, which varies from a few nanometers up to $50 \mathrm{~nm}$ or more. Large primary particles (in the range of $50 \mathrm{~nm}$ ) were not seen in the case of Aerosil 200 during TEM analysis. 




AEROSIL 200

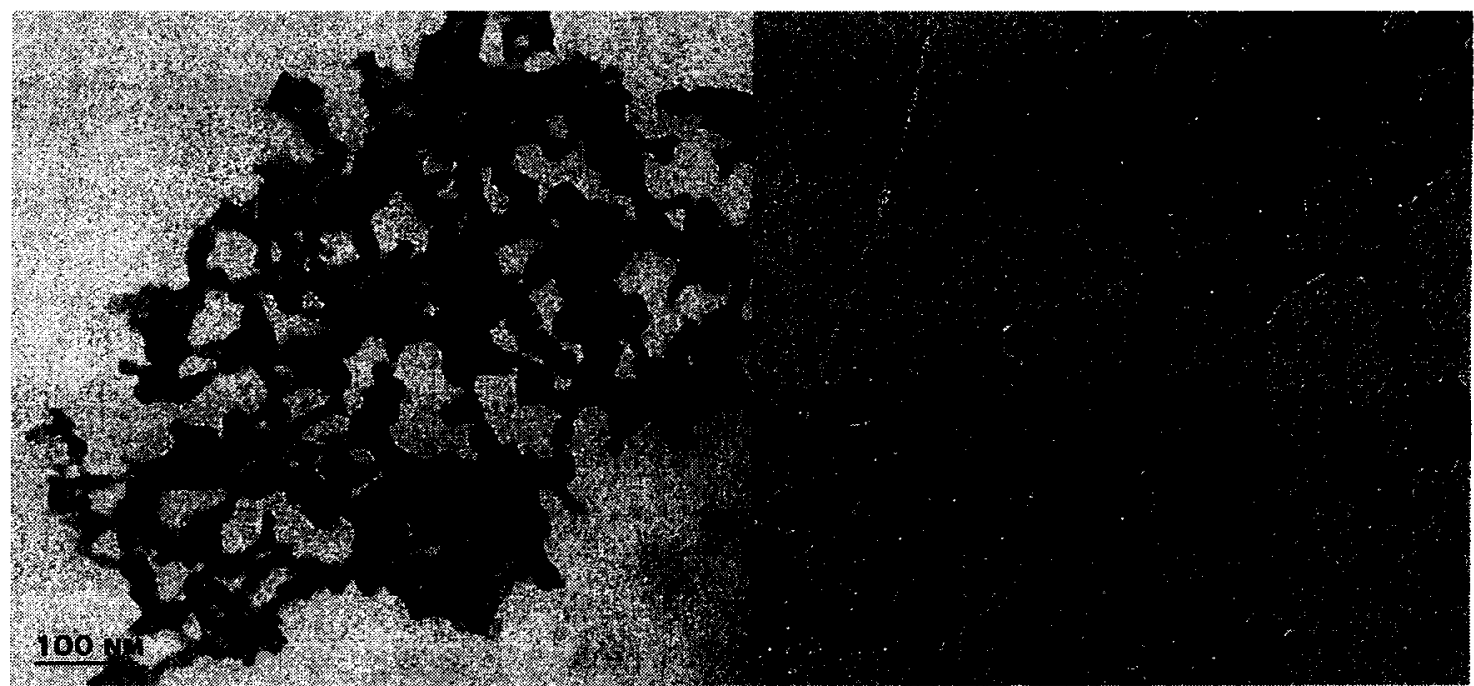

\section{EXPERIMENT 8}

(steam quench)
EXPERIMENT 14

(air quench)

Figure 24. TEM pictures of Aerosil 200 and experimental powders

Note: Powder Exp.8 has a specific surface area of $173 \mathrm{~m}^{2} / \mathrm{g}$ which is close to the specific surface area value of Aerosil $200\left(200 \mathrm{~m}^{2} / \mathrm{g}\right)$. 


\subsubsection{Rheological Tests}

Viscosity is the characteristic of materials to absorb, through tangential deformation, a tangential stress that depends on the velocity gradient. Rheological tests were used in order to characterize the quality of the plasma produced fumed silica as thickening and thixotropic agent. The results were compared with the qualities of the commercial powder.

For the rheological tests, $2 \%$ by weight suspensions in Clearco Pure Silicone Fluid $1000 \mathrm{cSt}$ were prepared. This fluid is a $100 \%$ polydimethylsiloxane (medium to low hydrogen-bonded system) that is clear, colorless and odorless. The mixing time was 10 minutes and was the time required to produce a suspension. The mixer used was a normal kitchen blender for which we modified the pellets to fit to a small volume cup $(30 \mathrm{ml}$ of suspension were prepared for each test). The tests were done using an ASTM Standards Test (D2196 - 05) and a Nametre 1000 Rotary-B Viscometer, at $21^{\circ} \mathrm{C}$. The Nametre Viscometer is a powerful tool for the study of non-Newtonian liquids. The apparatus can measure viscosity values between 50 and $1,000,000 \mathrm{cP}$ in a temperature range from $-55^{\circ} \mathrm{C}$ to $+150^{\circ} \mathrm{C}$. The apparent viscosity values reported by the apparatus are based on Newton's premise that torque is proportional to the shear rate.

The apparent viscosity values were recorded for each rotational speed, at the same number of spindle revolutions ( 30 turns). Table 4 shows the time taken for 30 revolutions at each speed as well as the apparent viscosity values. The apparent viscosity values were recorded for both increasing and decreasing speeds.

When added in a liquid system, fumed silica provides thickening and thixotropic properties, which depend largely on the tendency of the fumed silica aggregates to link together into chains through hydrogen bonding. To form these bonds, the oxygen from the hydroxyl groups must not be involved in another hydrogen bond. For example, in the hydrogen-bonded hydroxyl groups, the oxygen is already involved in a hydrogen bond. Thus, at that point on the fumed silica surface, the aggregate will not link with another aggregate to form a chain. The groups which permit the hydrogen-bonding between 
aggregates are the isolated hydroxyl groups. Here, the oxygen is not involved in a hydrogen bond with another hydroxyl group (see Figure 1, page 4), so at this point on the surface, the aggregate can form a hydrogen bond with another aggregate. In conclusion, for the same particulate structure, the viscosity of the system will be higher if the fumed silica surface has more isolated hydroxyl groups than other types of groups. Conversely, the viscosity values will be low if the isolated hydroxyl groups are absent from the silica surface or if they are involved in a hydrogen-bonding with another molecule.

Table 4. Viscosity test for Aerosil 200

\begin{tabular}{|r|r|r|}
\hline \multicolumn{1}{|c|}{ RPM } & Time (min) & Apparent Viscosity (cP) \\
\hline 5 & 6.00 & 7380 \\
\hline 10 & 9.00 & 5290 \\
\hline 20 & 10.30 & 3860 \\
\hline 50 & 11.06 & 2700 \\
\hline 100 & 11.24 & 2220 \\
\hline 50 & 12.00 & 2700 \\
\hline 20 & 13.30 & 3890 \\
\hline 10 & 16.30 & 5340 \\
\hline 5 & 22.30 & 7330 \\
\hline
\end{tabular}

The Apparent Viscosity values depend on the powder properties (such as specific surface area and surface hydroxyl groups density) but also on the concentration, liquid type, degree of dispersion and temperature. In order to obtain a clear value of the apparent viscosity as a function only of the powder properties, the rest of the factors were kept constant (we used the same concentration of the suspension, the same oil to prepare the suspension, same mixing technique and same concentration, for all the tests).

The Apparent Viscosity curves in Figure 25 show that the apparent viscosity values decrease with increasing speed, which is also true in the case of Aerosil 200 (the 
commercial product from Degussa), which was used as standard. For the experimental powders, the viscosity values are not as high as the ones for Aerosil 200, for which we observed a higher change in the apparent viscosity values at small shearing speed ( 5 to 20 RPM). The drop in apparent viscosity with increasing shear rate is also an indicative of the presence of isolated hydroxyl groups since it is breaking of the hydrogen bonds. That lowers the viscosity.

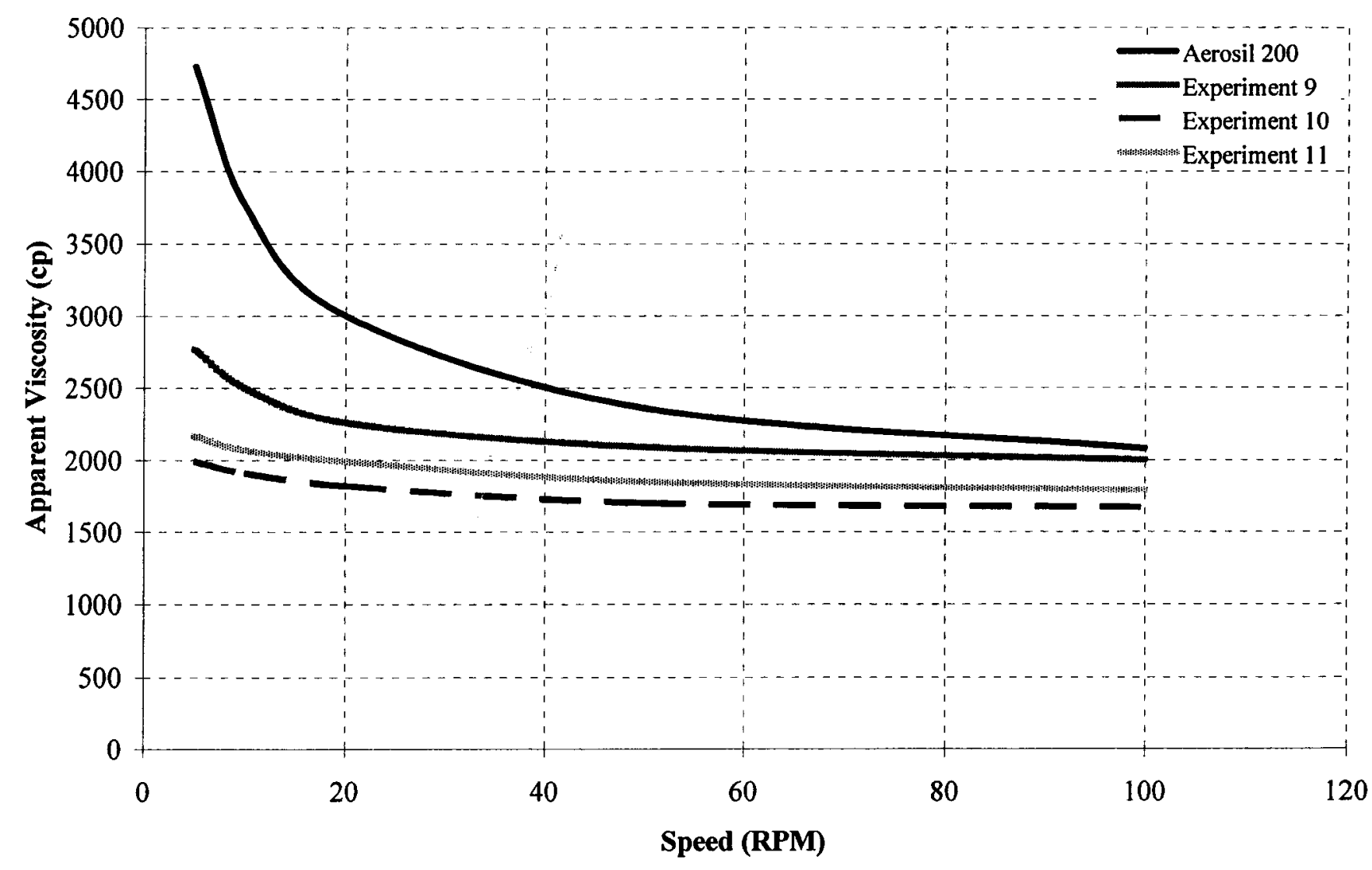

Figure 25. Apparent viscosity values of Aerosil 200 and different experimental powders (different quench steam flows) 
Figure 26 shows that the apparent viscosity at 5 RPM (which is the first measurement taken during a typical rheological test) increases with increasing mixing time in the case of Aerosil 200. This is due to the formation of hydrogen-bonding between the isolated hydroxyl groups from the surface of the fumed silica particles and the liquid particles. In the case of the experimental powders we observed a small decrease of these values. The reason for this may be the fact that in the case of the experimental powders we have water molecules hydrogen-bonded with the surface hydroxyls on the particle surface. These water molecules are linked together via hydrogen-bonding, forming water clusters, which are attached to the fumed silica aggregates. When fumed silica is mixed with oil, to prepare the suspension for the test, the water clusters are detached from the silica surface (water molecules coalesce into droplets). As result, the suspension is diluted and the apparent viscosity value is smaller. Also, it is believed that the experimental powders have less thickening and thixotropic effect because of the absence of the hydroxyl groups from the fumed silica surface.

We also observed that the apparent viscosity values increase with increasing the surface area (Figure 27), because with increasing the surface area, more free hydroxyl groups are present in the system and more hydrogen bonds are formed between the fumed silica particles and the liquid particles. 


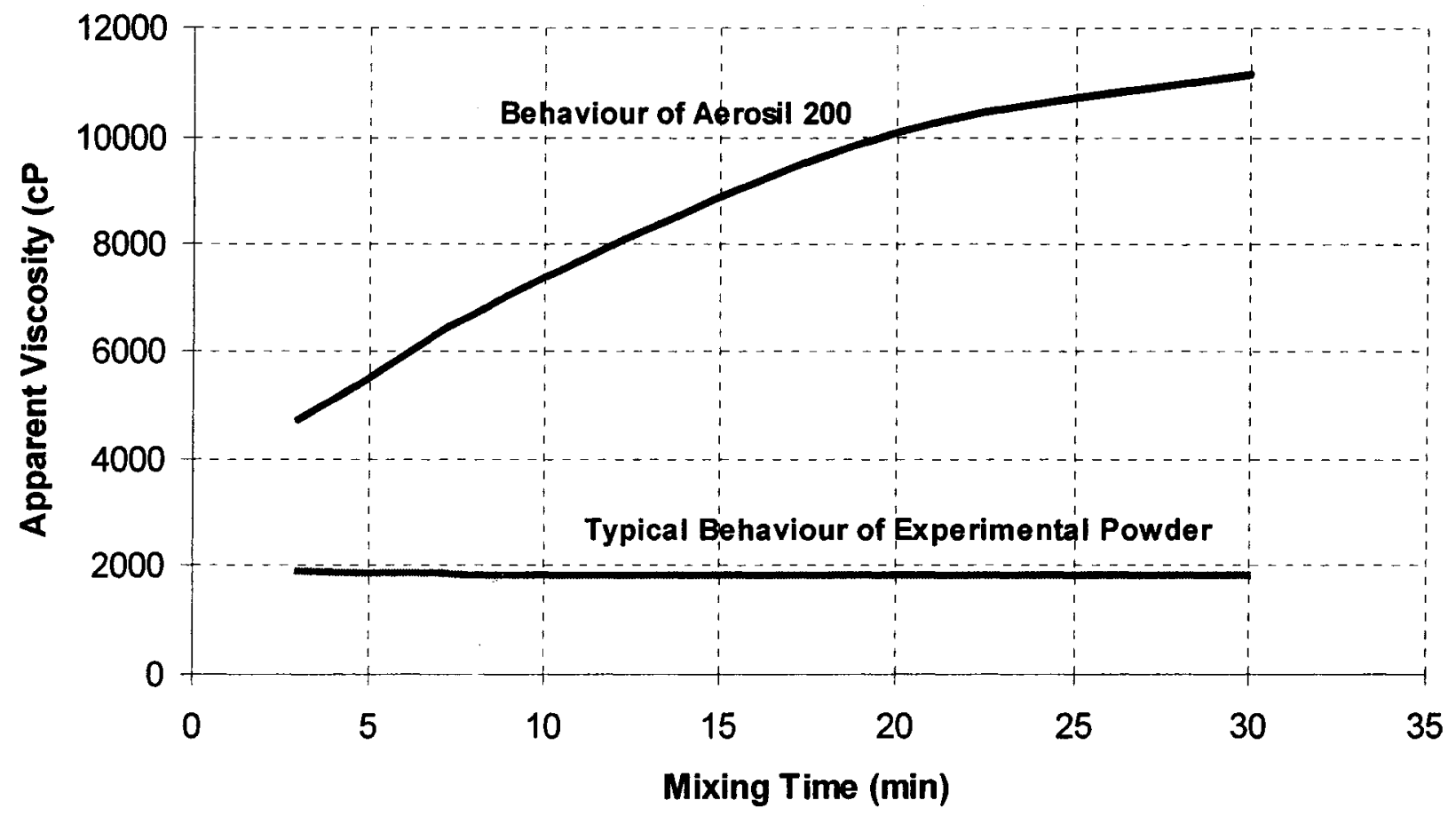

Figure 26. Viscosity profiles of Aerosil 200 and experimental powder with different mixing times (@5 RPM) 


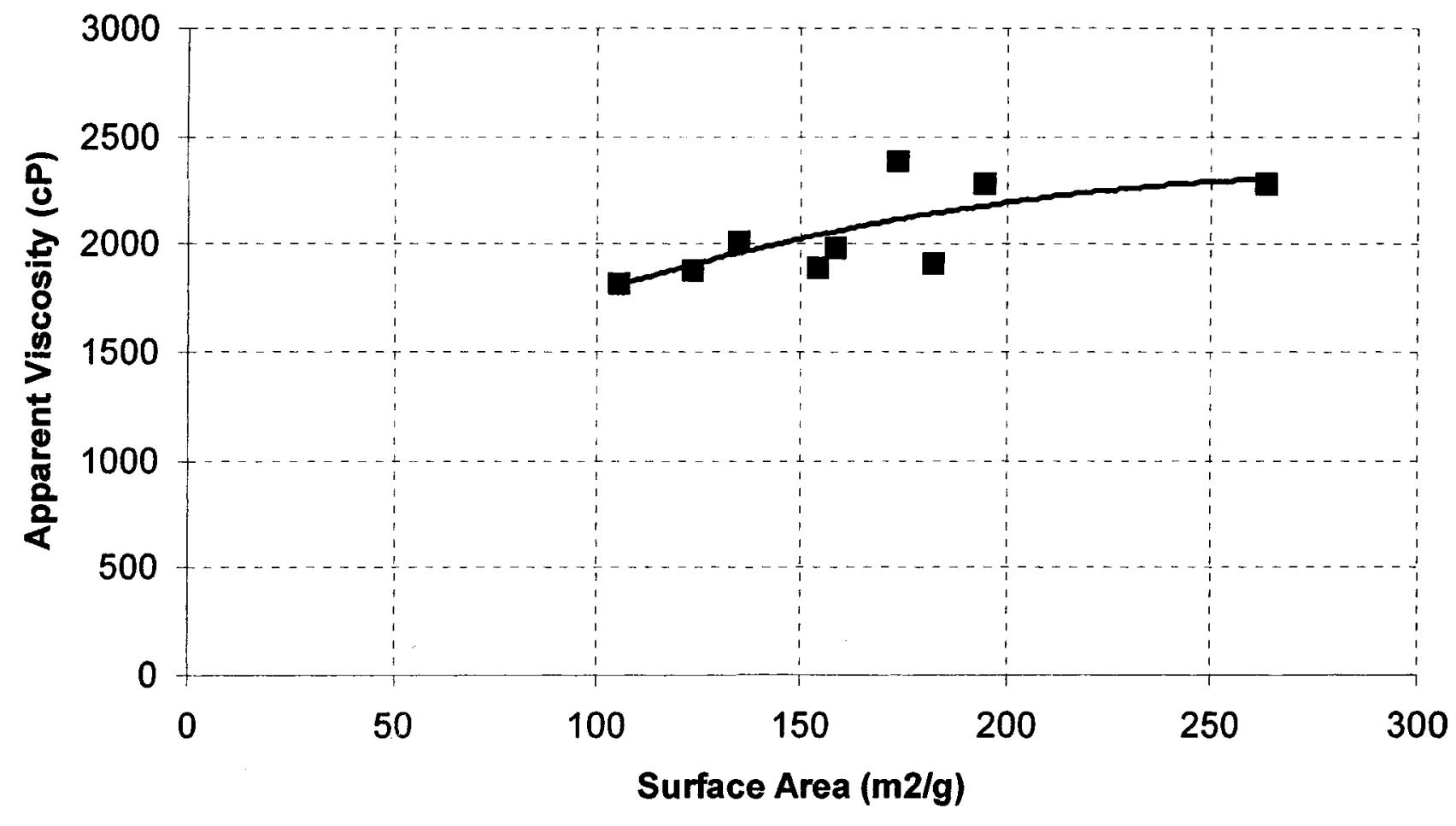

Figure 27. Variation of apparent viscosity values (@ 5RPM) of plasma produced powders with the specific surface area 


\subsubsection{Specific Surface Area Measurements (BET)}

The most reliable method used to determine the specific surface area is the physical adsorption of gases, especially nitrogen. The $\mathrm{N}_{2}$ adsorption isotherms are evaluated according to Brunauer, Emmet and Teller (J. Am. Chem. Soc. 60, 309, 1938). The theory is an extension of the Langmuir theory, which is a theory for monolayer molecular adsorption, to multilayer adsorption with the following hypotheses:

- gas molecules physically adsorb on a solid in layers;

- there is no interaction between each adsorption layer;

- the Langmuir theory can be applied to each layer.

A total surface area $S_{\text {total }}$ and a specific surface area $S$ are evaluated by the following equations:

$$
\begin{aligned}
S_{\text {total }} & =\frac{\left(\tau_{m} N s\right)}{M} \\
S & =\frac{S_{\text {total }}}{a}
\end{aligned}
$$

where $\mathrm{N}$ is Avogadro's number, $\mathrm{v}_{\mathrm{m}}$ is volume of gas adsorbed, $\mathrm{s}$ is the adsorption cross section, $M$ is the molecular weight of adsorbate and $a$ is the weight of the solid sample.

Using this method in three tests, the specific surface area of Aerosil (B) 200 was found to be 200 with a standard deviation of $20 \mathrm{~m}^{2} / \mathrm{g}$.

We also used BET analysis to determine the specific surface area of the experimental fumed silica powders produced during this study. The values of the specific surface area of different plasma produced powders are presented in the Table 5. 
We observed that the surface area varies with the quench flow rate (see Figure 28): by increasing the quench flow rate the surface area also increases. This can be explained by the fact that by increasing the quench flow rate, more gas enters the oxidation zone and the temperature decreases and this leads at the nucleation of the particles. The smaller the particle size, the larger the surface area. We also observed that at high flow rates the obtained values are far from the curve. This suggests that at high flow rates we are dealing with a mixing limitation within the oxidation zone.

Table 5. Specific surface area of experimental powders

\begin{tabular}{|r|r|r|r|c|}
\hline \multicolumn{1}{|r|}{ Exp. } & $\mathrm{T}_{\mathbf{r}}\left({ }^{\circ} \mathbf{C}\right)$ & $\begin{array}{c}\text { Surface Area } \\
\left(\mathbf{m}^{2} \mathbf{l g}\right)\end{array}$ & $\begin{array}{c}\text { Quench flow } \\
\text { rate (gpm) }\end{array}$ & Quench Gas \\
\hline 8 & $\mathrm{NM}$ & 173 & 62 & steam \\
\hline 9 & 1260 & 263 & 110 & steam \\
\hline 10 & 1130 & 158 & 50 & steam \\
\hline 11 & 1400 & 194 & 62 & steam \\
\hline 12 & 1320 & 154 & 60 & steam \\
\hline 13 & 1260 & 123 & 27 & air+steam \\
\hline 14 & 1300 & 135 & 7.3 & air \\
\hline 15 & 960 & 182 & 115 & steam \\
\hline 16 & 1050 & 105 & 6.6 & air \\
\hline
\end{tabular}

Note: $N M=$ Not Measured 


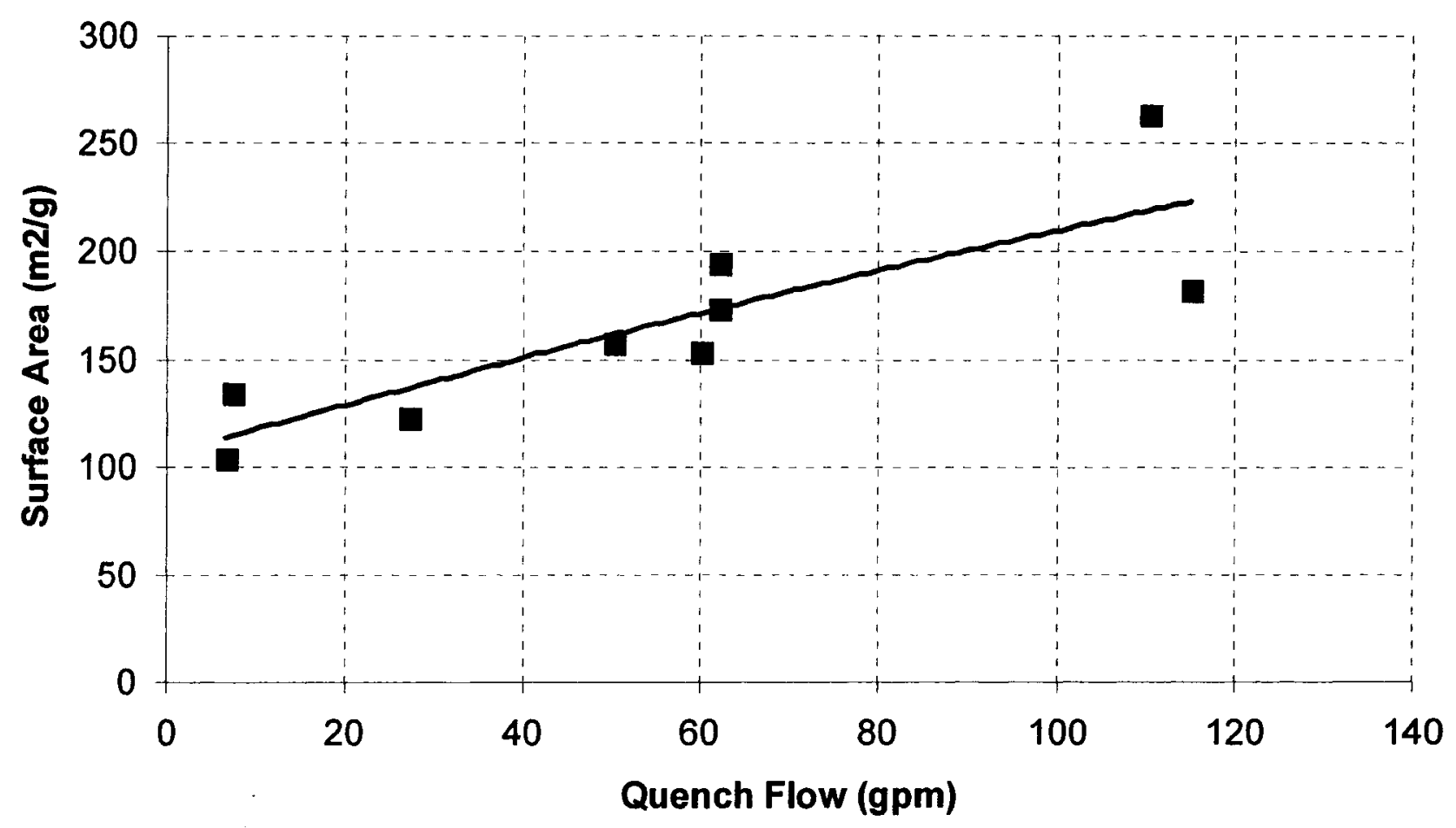

Figure 28. Variation of specific surface area of plasma produced powders with the quench flow rate 


\subsubsection{Diffuse Reflectance Infra-Red Fourier Transform (DRIFT) Spectroscopy}

DRIFTS uses a light beam to analyze a powder sample. This light is partially reflected and transmitted. Light that passes into the material may be absorbed or reflected out again. Hence, the radiation that reflects from an absorbing material is composed of surface-reflected and bulk re-emitted components, which summed are the diffuse reflectance of the sample.

The instrument used was a DiffusIR ${ }^{\mathrm{TM}}$ ( model EasiDiff ${ }^{\mathrm{TM}}$ ) from Pike Technologies. The software used was OPUS, which allowed us to record the sample spectrum and analyse it with operations such as: baseline corrections, conversion of the absorbance spectrum into a transmission spectrum, peak positioning etc.

The experimental fumed silica powders were analyzed by diluting in a transmitting matrix, which in our case was $\mathrm{KBr}$ powder. The sample was ground with the $\mathrm{KBr}$, until an evenly dispersed mixture was obtained. The mixture is then placed in the sample holder. The sample concentration was $5 \%$ by mass of fumed silica in $\mathrm{KBr}$.

The most important peaks in the silica spectrum are presented in the Table 6 .

Table 6. Important peaks in the silica spectrum

\begin{tabular}{|l|c|}
\hline$-\mathrm{OH}$ (isolated) & $3750 \mathrm{~cm}^{-1}$ \\
\hline$-\mathrm{OH}$ (bridged) & $3000-3800 \mathrm{~cm}^{-1}$ \\
\hline$-\mathrm{SiOH}$ (combination oscillation) & $4550 \mathrm{~cm}^{-1}$ \\
\hline$-\mathrm{SiO}$ & $1500-1900 \mathrm{~cm}^{-1}$ \\
\hline
\end{tabular}

The fumed silica spectrum presents two regions of interest: the $400-1400 \mathrm{~cm}^{-1}$ region, where the $\mathrm{SiO}$ stretching vibrations are present, and the $1400-4000 \mathrm{~cm}^{-1}$ region marked by the presence of the specific functional groups (hydroxyl groups). 
The FT-IR spectrums of Aerosil 200 and the experimental powders were found to be different. The differences are in the $3000-3800$ regions of the spectrums and are believed to be due to the differences in the type and amounts of surface hydroxyl groups present.

The peak at around $3750 \mathrm{~cm}^{-1}$ is due to the free hydroxyl groups. This peak is present in the case of Aerosil 200 (see Figure 29), but is very weak or not present (see Figures 30 and 31) in the case of the experimental powders. This suggests that the experimental powders have much less free surface hydroxyl groups. This can also explain the reason for the lower viscosity values obtained for the experimental powders during the rheological tests.

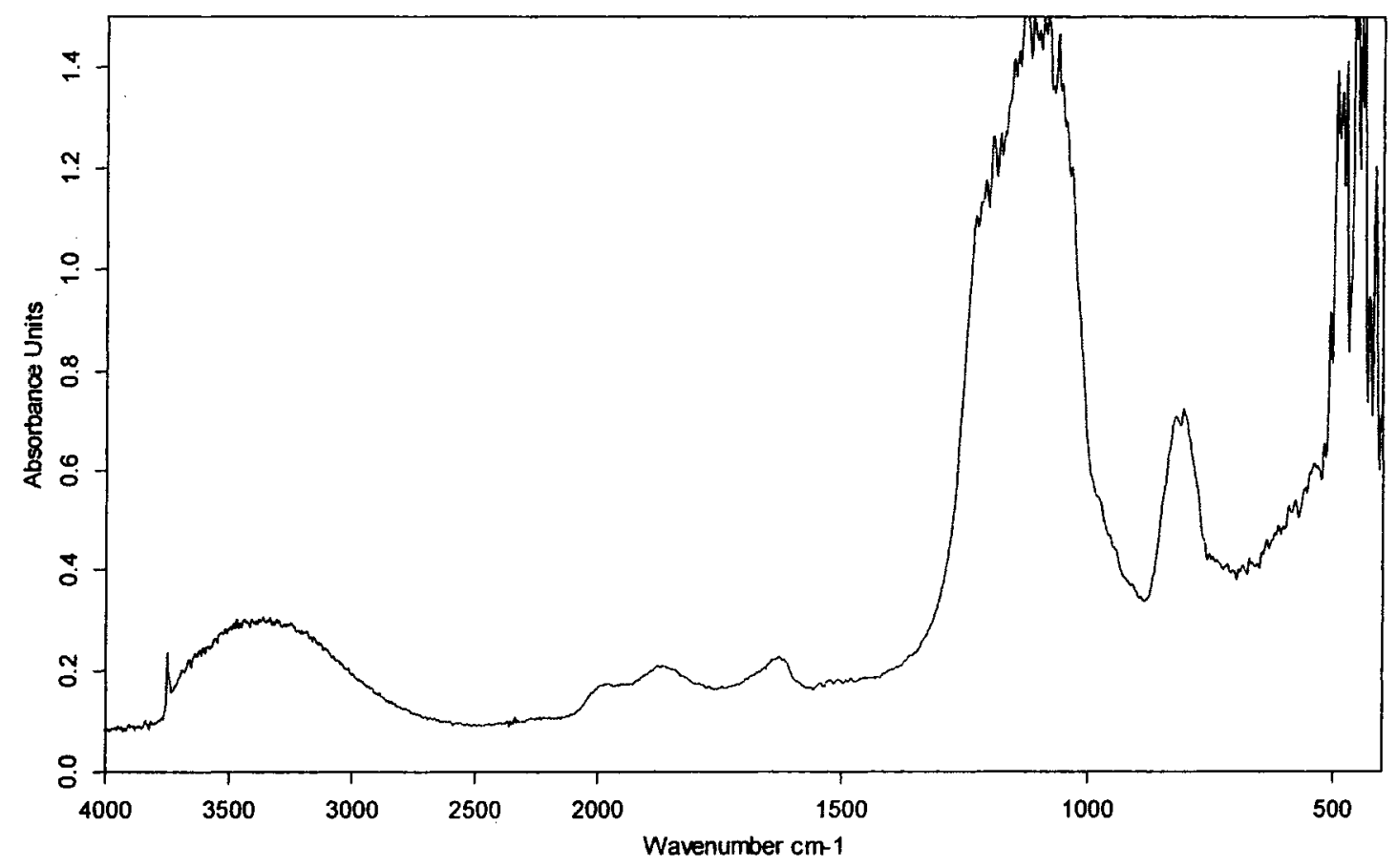

Figure 29. IR spectrum of Aerosil 200 


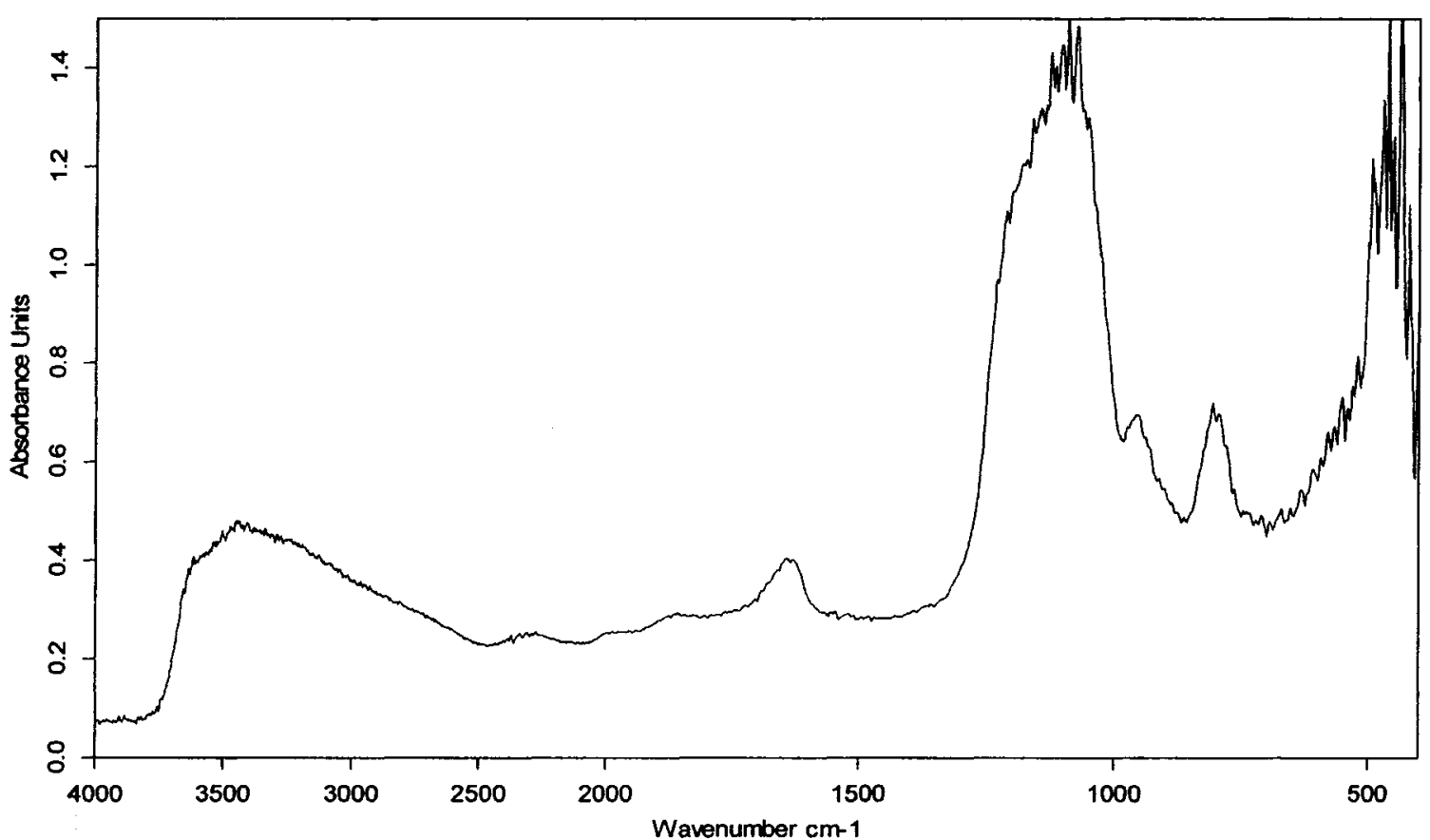

Figure 30. IR spectrum of powder exp. 12 (steam quench)

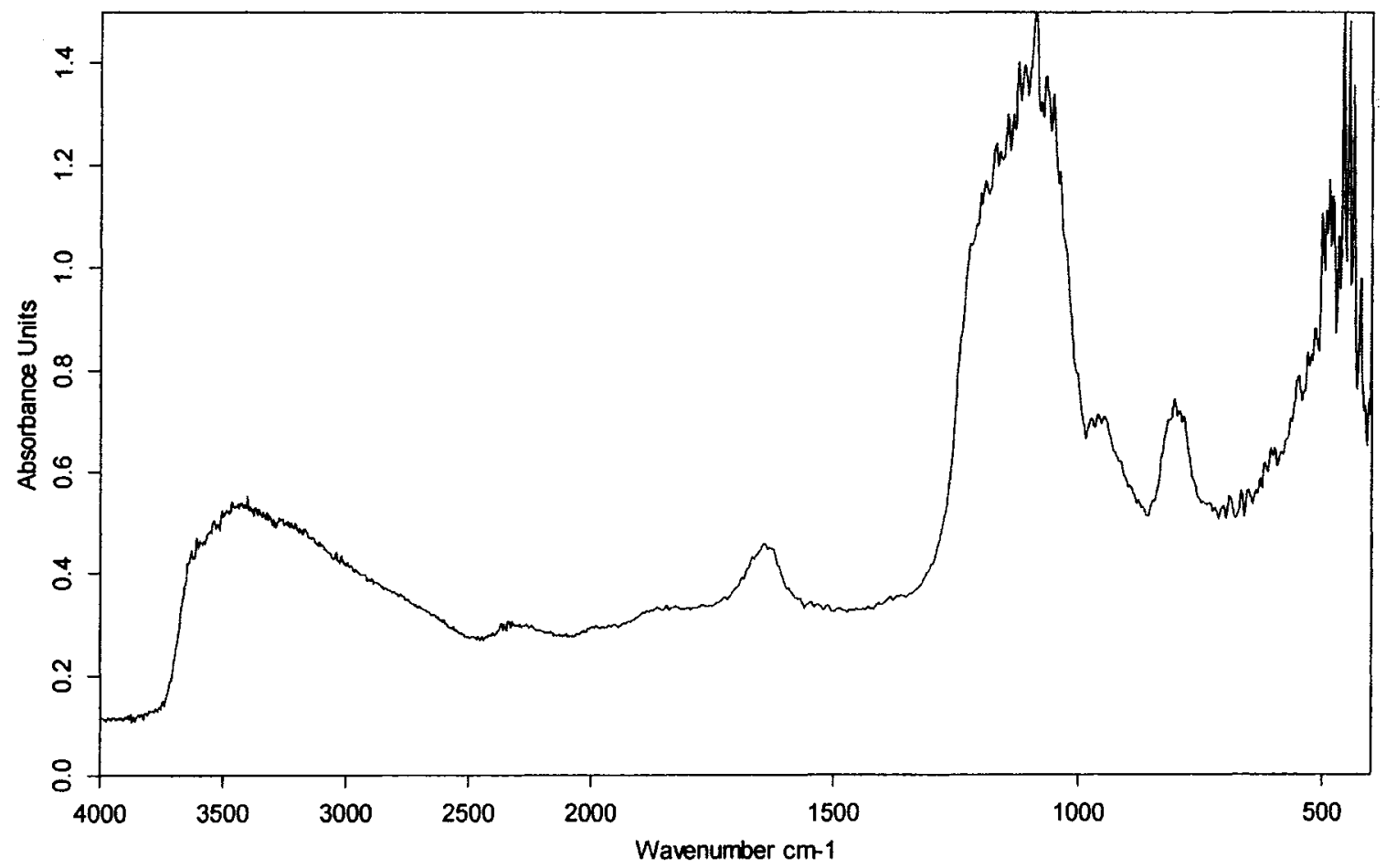

Figure 31. IR spectrum of powder exp.13 (steam + air quench) 
In Figure 32 we can see that by varying the quench conditions (the flow rate and type of gas) we were able to vary the hydroxyl group content, but not enough to get the rheological properties needed (i.e. similar to those of Aerosil 200). The best results were obtained in the case of Experiment 14, in which we used an air quench. The air had a RH $>14 \%$. For this experiment we can see that a small amount of free hydroxyl groups were present on the surface of the particles (the small peak from around $3750 \mathrm{~cm}^{-1}$ ). We think that we obtained the best results with air quench because there were not many water molecules in the system to form hydrogen-bond with the free hydroxyl groups.

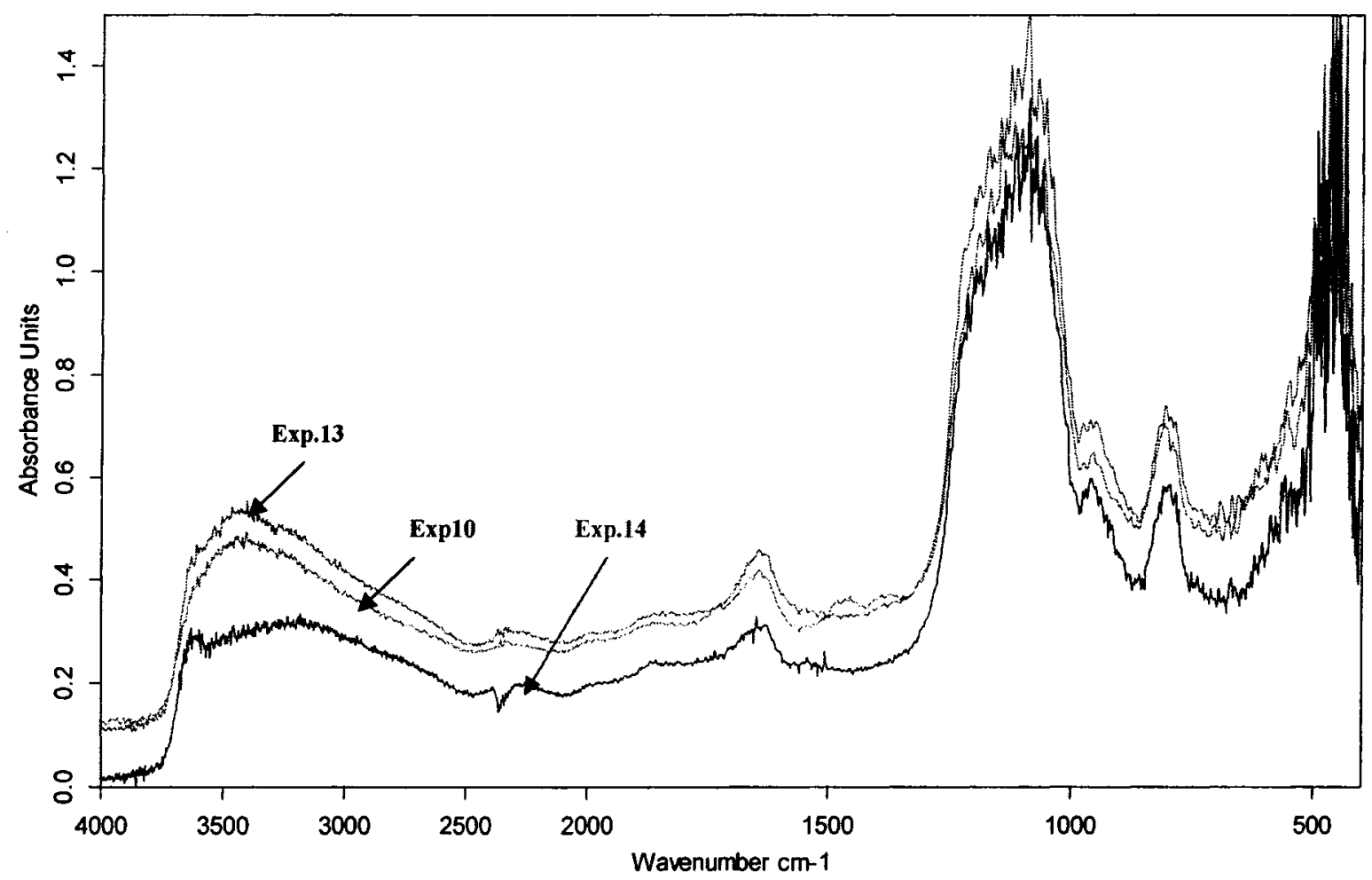

Figure 32. IR spectrum of powder exp. 10 (steam quench), 13 (steam + air quench) and 14 (air quench) 


\subsubsection{Thermogravimetric analysis (TGA)}

TGA measures changes in the weight of a sample with increasing temperature. This technique can be used to detect the loss of volatile components from our product as a function of temperature.

The instrument used was a Perkin Elmer TGA7 with Pyris software, which is capable of simultaneously recording the weight loss curve and the first derivative of weight loss. The tests were done in nitrogen atmosphere $(40 \mathrm{mlpm}$ flow $)$, using a heating rate of $5^{\circ} \mathrm{C} / \mathrm{min}$, up to $800^{\circ} \mathrm{C}$. No sample preparation was necessary.

TGA tests (see Figure 33) show that the mass loss in the temperature range $50^{\circ} \mathrm{C}$ to $800^{\circ} \mathrm{C}$ in the case of experimental powders ( $>8 \%$ ) is higher than in the case of Aerosil $200(4 \%)$. We can see that in the case of Aerosil 200 we have no mass loss up to around $120^{\circ} \mathrm{C}$, so no water is evaporated from the samples. At around $450^{\circ} \mathrm{C}$ we can see a mass loss, which, according to Khalil (1981), is due to the loss of the free hydroxyl groups, in the form of water molecules.

In the case of the experimental powders, we can observe that the sample loss mass up to $120^{\circ} \mathrm{C}$, due to the elimination of the water and we do not observe any mass loss due to the elimination of the free hydroxyl groups.

The first derivative (see Figure 34) shows in the case of Aerosil 200 a broad negative peak starting at $450^{\circ} \mathrm{C}$ which is due to the loss of free hydroxyl groups. In the case of the experimental powders we can observe the negative peaks around $120^{\circ} \mathrm{C}$ but no negative peaks after $450^{\circ} \mathrm{C}$.

The experiments represented in Figures 33 and 34 were chosen because they represent different quench conditions. In experiment 8 , steam was used as quench gas, in experiment 13 air and steam were used, while in experiment 16, only air was used as quench gas (the air had a $\mathrm{RH}>14 \%$ ). Only two experimental powders were presented in Figure 34 (instead of three) for the simplicity of the figure. 


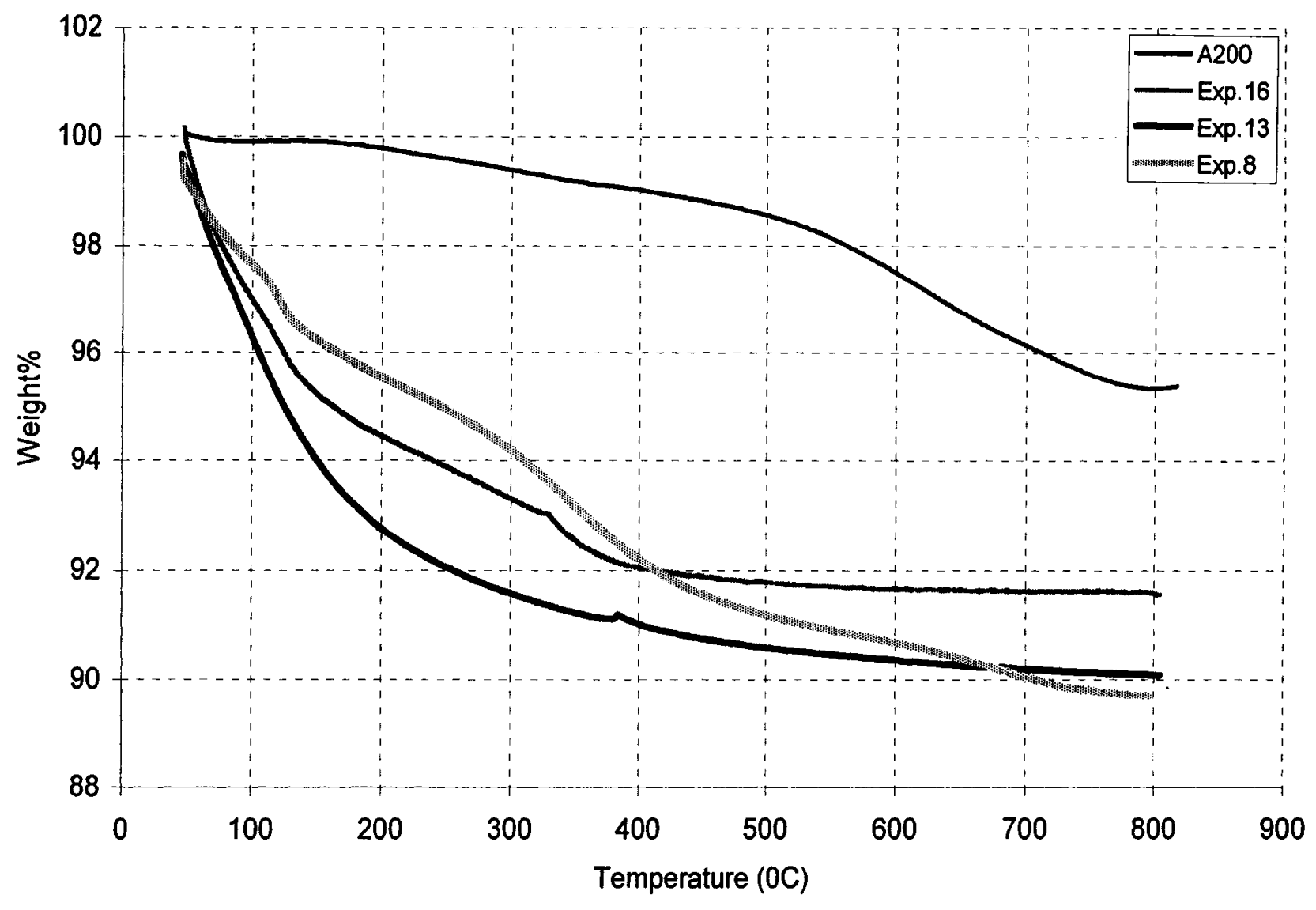

Figure 33. TGA curves for Aerosil 200 and experimetal powders 8 (steam quench), 13 (steam + air quench) and 16 (air quench) 


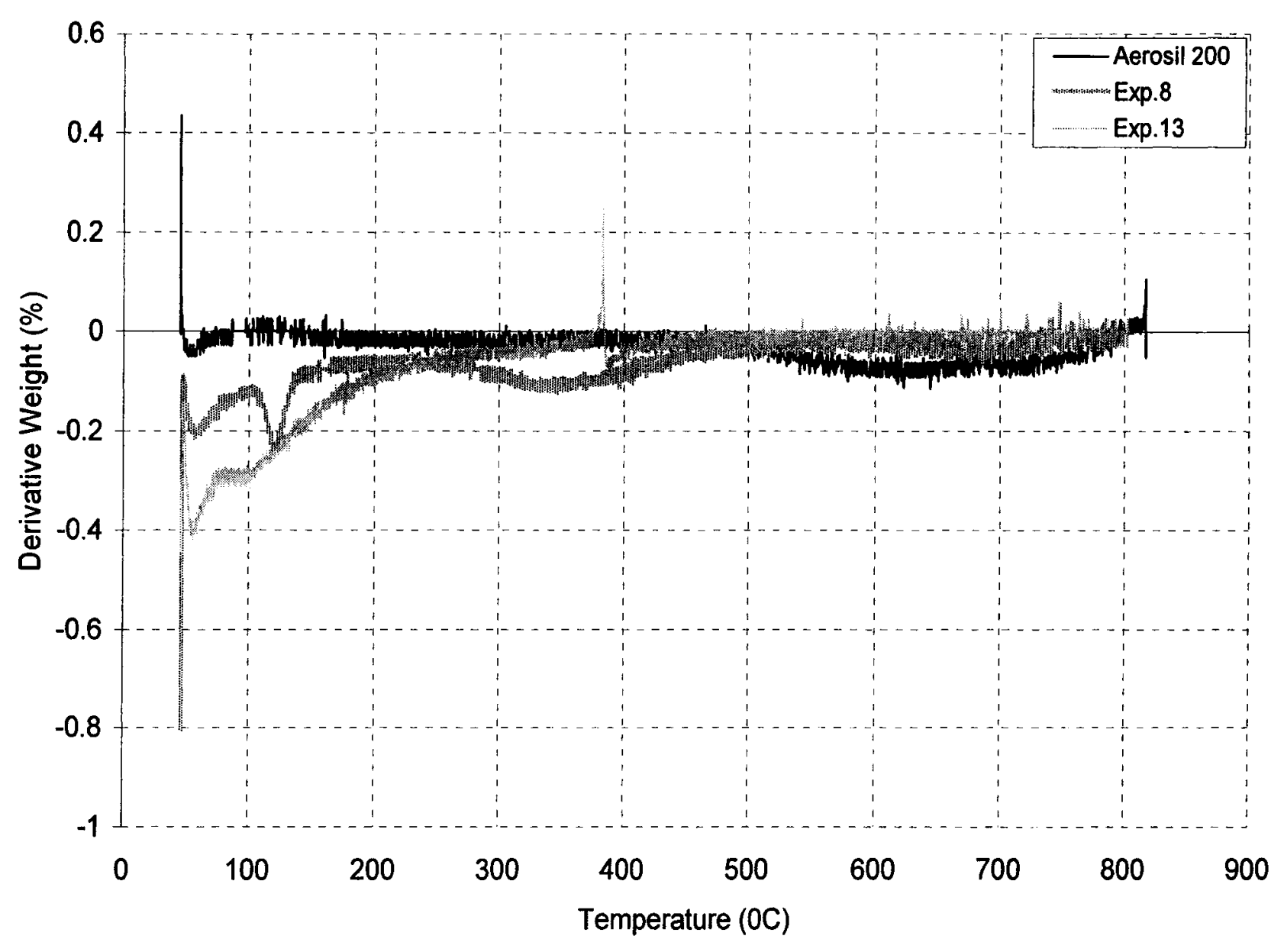

Figure 34. TGA derivative curves for Aerosil 200 and experimetal powders 8 and 13 (different quench conditions)

Note: The TGA program starts at $50^{\circ} \mathrm{C}$ and the false peaks at around this value are due to the starting conditions. 


\subsection{Experimental Results of Agglomeration Tests}

The agglomeration tests were done using the system presented in Figure 20. The conveying gas was air, supplied from regulated high pressure cylinders (MEGS). An air line was also installed to the feeder, because in the preliminary tests it was show that the particles would not flow from the feeder to the venturi without a small flow through the feeder.

The preliminary tests were done using the commercial product (Aerosil 200). The scope of these tests was to determine appropriate operating conditions for the agglomerator. Then, a number of experiments were performed with Aerosil 200 and experimental powders to examine the effect of the agglomerator on the powder properties.

A summary of these tests is presented in the Table 7, where $Q_{v}$ is the air flow rate entering the venturi, $Q_{f}$ is the air flow rate entering the feeder, $M_{f}$ is the mass of powder fed and $\mathrm{M}_{\mathrm{c}}$ is the mass of powder collected after the agglomeration.

Tests number 6 and 7 were done with experimental powders, experiment 11 represented a typical steam experiment and experiment 16 was used as a typical air experiment.

After agglomeration, the powders were analyzed using TEM, SEM, DRIFT and Viscosity tests. 
Table 7. Summary of conditions for the agglomeration tests

\begin{tabular}{|r|r|r|r|r|r|}
\hline Test \# & Powder & $\mathbf{Q}_{\mathbf{v}}(\mathbf{s l p m})$ & $\mathbf{Q}_{\mathbf{f}}(\mathbf{s l p m})$ & $\mathbf{M}_{\mathbf{f}}(\mathbf{g})$ & $\mathbf{M}_{\mathbf{c}}(\mathbf{g})$ \\
\hline 1 & Aerosil 200 & 400 & 4 & 4.7 & 3.0 \\
\hline 2 & Aerosil 200 & 400 & 4 & 3.0 & 2.3 \\
\hline 3 & Aerosil 200 & 400 & 4 & 3.4 & 2.6 \\
\hline 4 & Aerosil 200 & 400 & 4 & 3.2 & 2.1 \\
\hline 5 & Aerosil 200 & 400 & 4 & 3.0 & 2.4 \\
\hline 6 & Exp.11 & 400 & 4 & 3.5 & 3.0 \\
\hline 7 & Exp.16 & 400 & 4 & 3.0 & 2.6 \\
\hline
\end{tabular}




\subsubsection{SEM Analysis}

The SEM pictures taken at low magnification show distinct differences in the experimental powders before and after treatment by the agglomerator. In comparing Figure $35 \mathrm{a}$ and $\mathrm{b}$, we see fewer single small particles in Figure $35 \mathrm{~b}$. This is seen more clearly in Figure 36 which is taken at higher magnification. It is clear that the large particle shown is made up of many smaller particles with diameters of the order of ten to 15 microns. It must be noted that at these magnifications it is not possible to see the individual primary particles or the chain structure which have dimensions of the order of tens of nanometers. Certainly on the scales examined with SEM, it may be concluded that agglomeration has occurred in the experimental powders.

\section{a. Before Agglomeration}

b. After Agglomeration

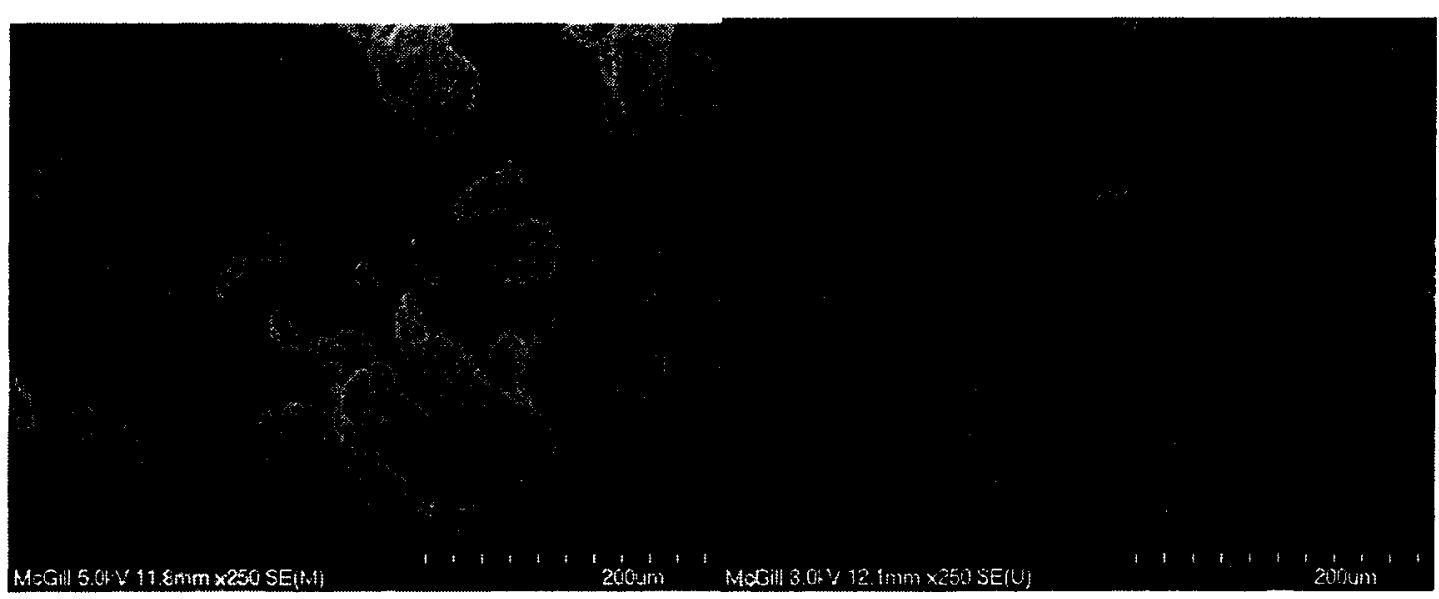

Figure 35. SEM pictures of experimental powder 16 (steam quench) 


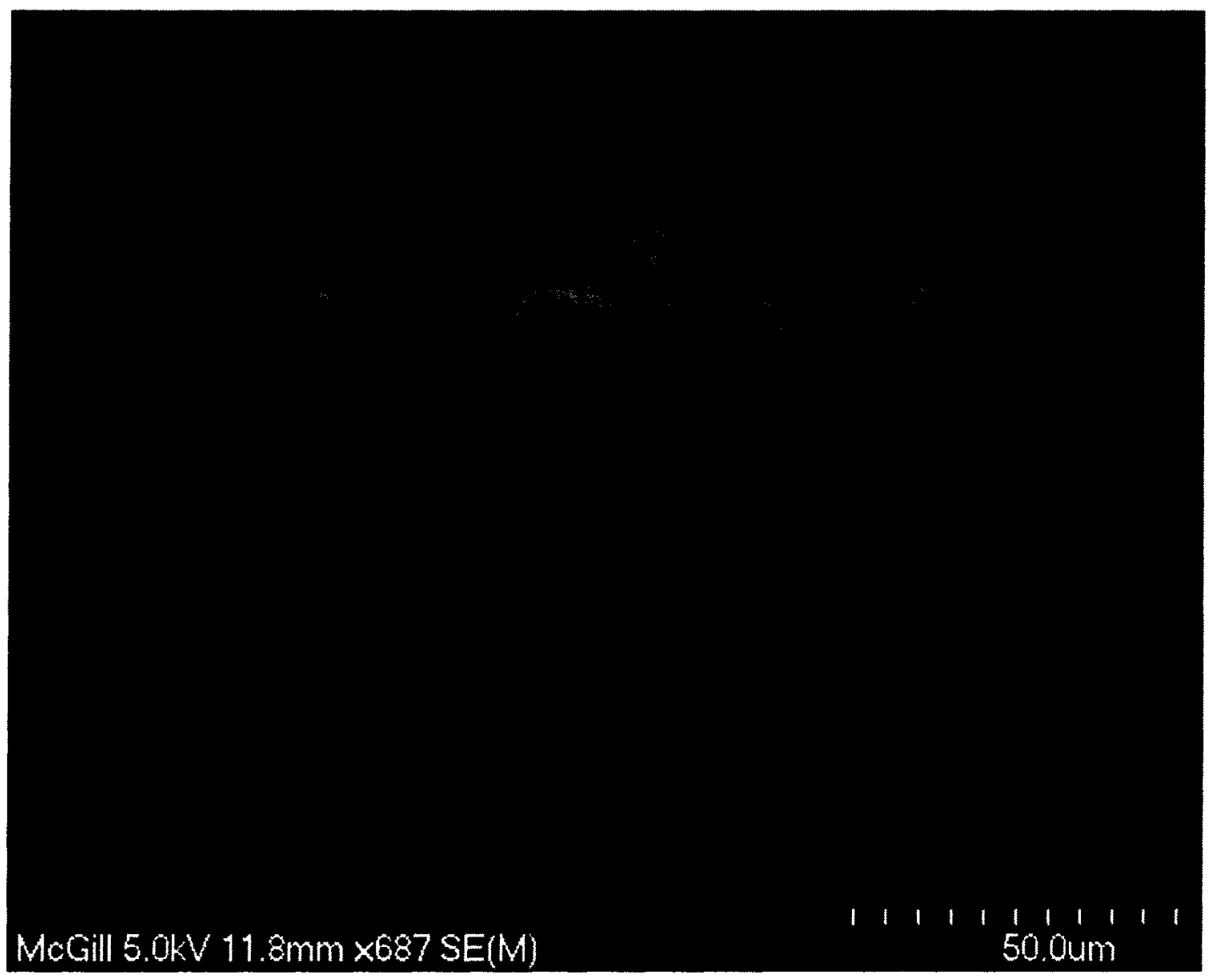

Figure 36. Agglomerated particles (experiment 16, air quench) 


\subsubsection{TEM Analysis}

TEM pictures (Figure 37) shows that the agglomeration had no effect on the particle fine structure; the chain-like structure of the initial product has been preserved.

\section{Before Agglomeration}

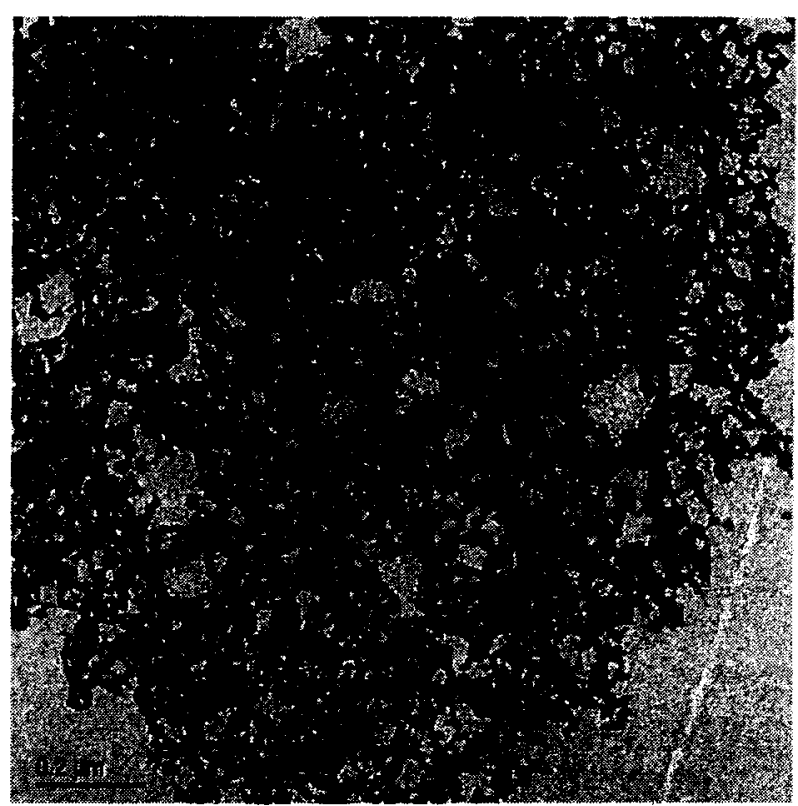

\section{After Agglomeration}

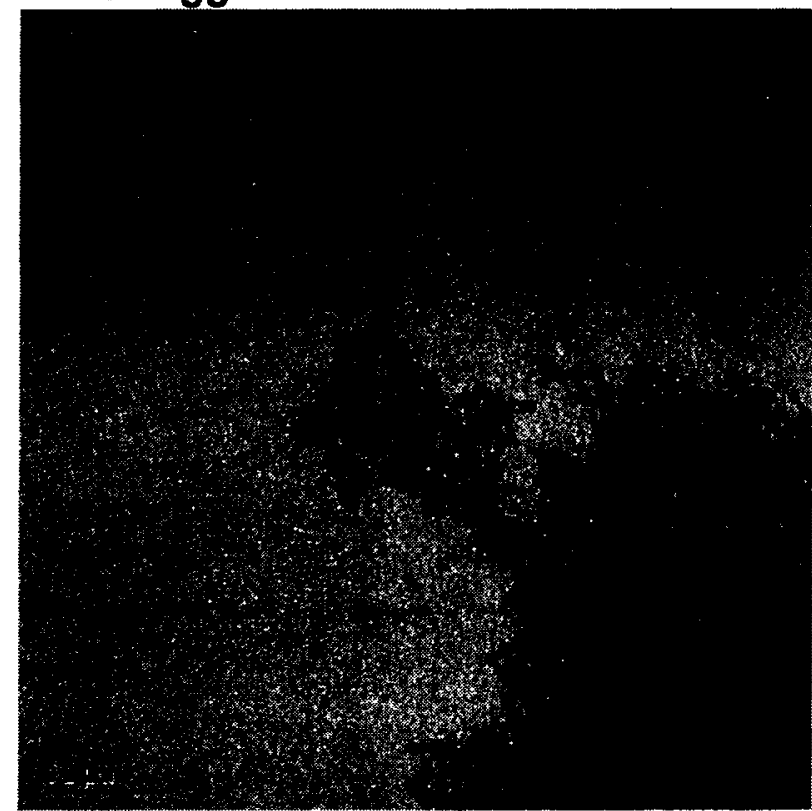

Figure 37. TEM pictures of experimental powder 11 (steam quench) 


\subsubsection{DRIFT Spectroscopy Analysis}

DRIFT spectra of the experimental powders (Figures 38 and 39), before and after agglomeration, show no significant change in the type and amount of groups present on the particle surface (i.e. the agglomeration process does not significantly alter the surface chemistry to the fumed silica) as was expected. This is due to the fact that the agglomeration took place at room temperature $\left(21^{\circ} \mathrm{C}\right)$, which did not allow any modification in the particles surface chemistry. For this kind of modification, the system needs a lot of energy (high temperature) and humid air. The air used for the agglomeration tests was supplied from gas cylinders and had a relative humidity $<4 \mathrm{ppm}$.

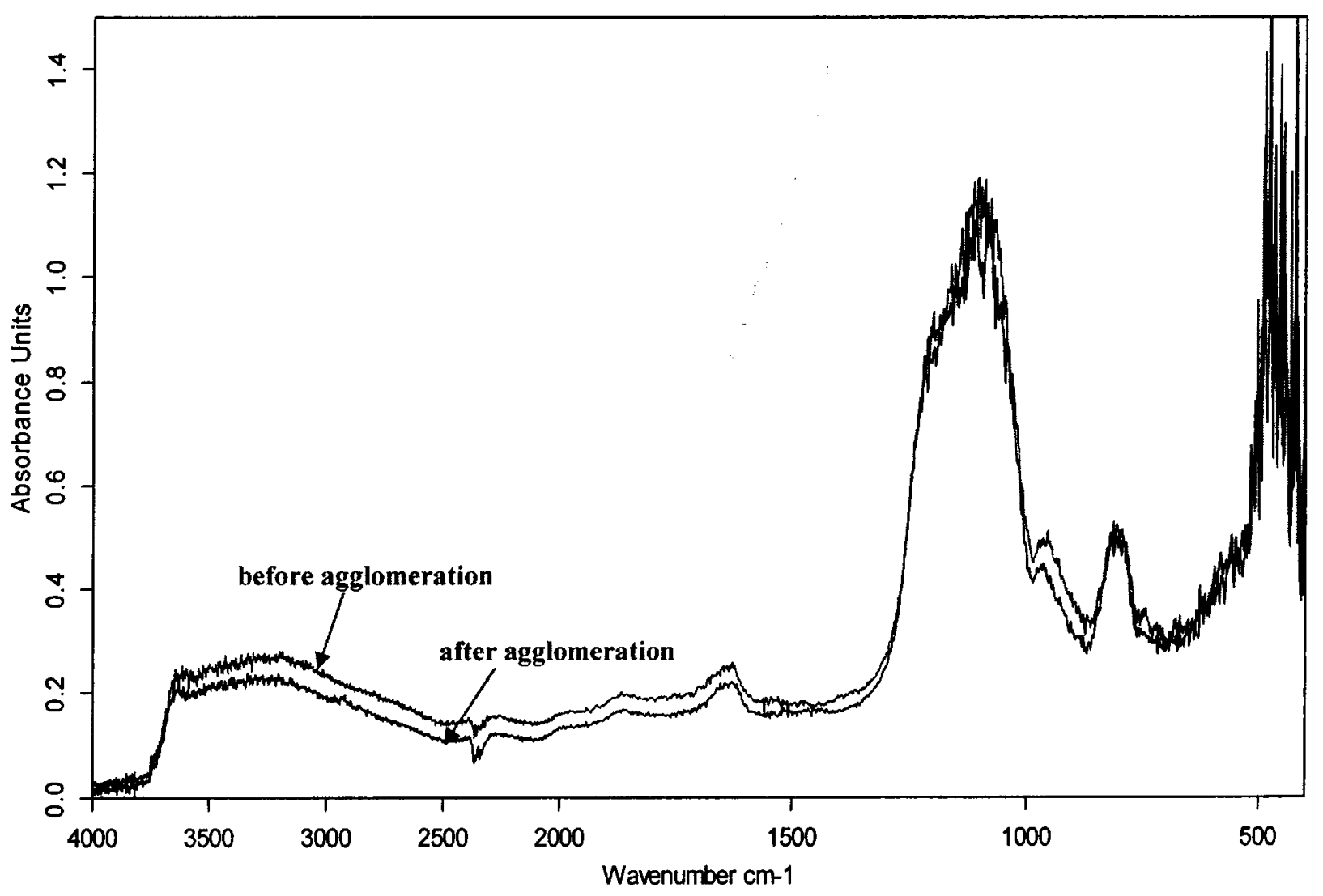

Figure 38. DRIFT spectra of experimental powder 11 (steam quench) 


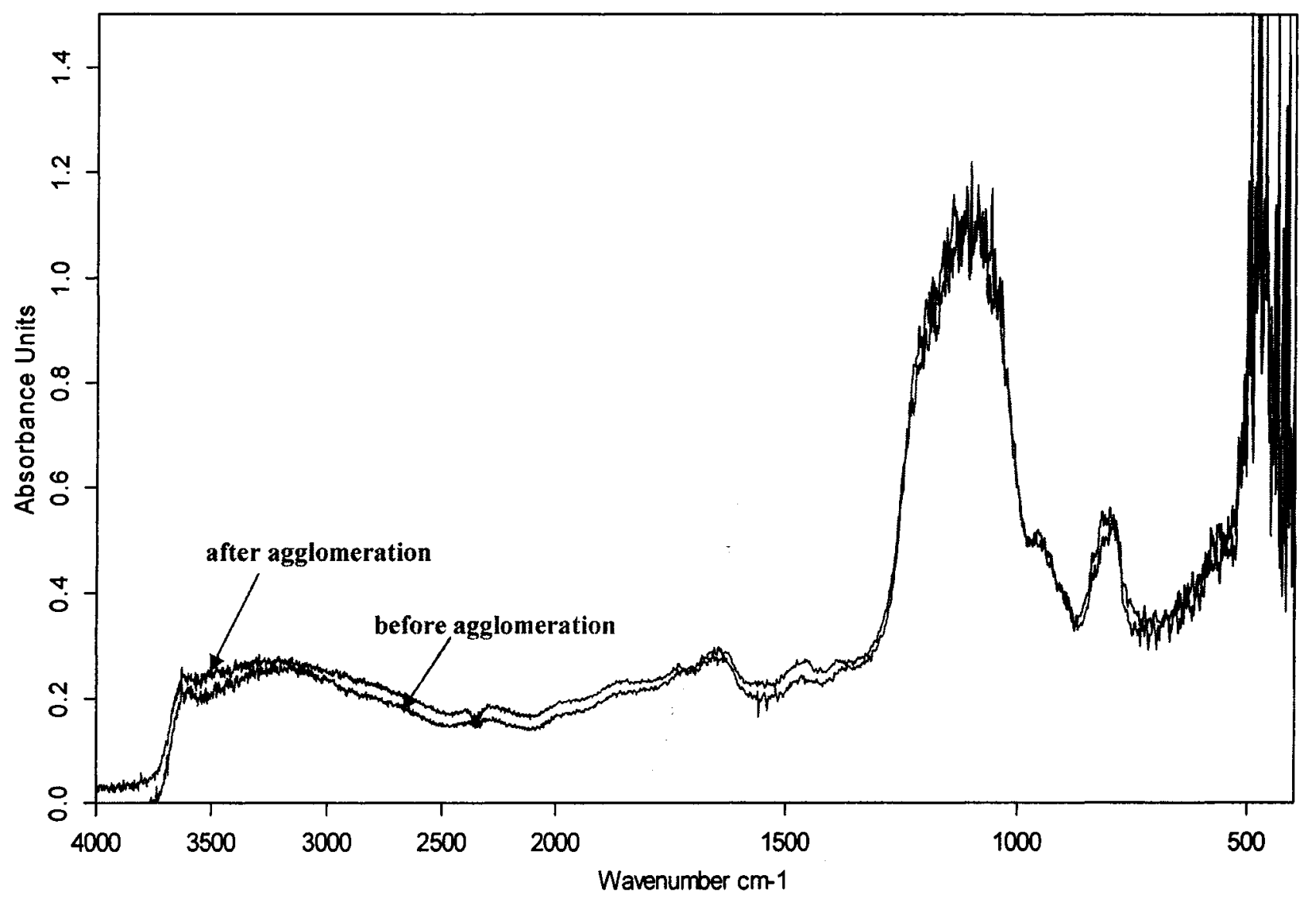

Figure 39. DRIFT spectra of experimental powder 16 (air quench) 


\subsubsection{Rheological tests}

The same type of rheological tests were performed before and after the agglomeration tests, in order to determine if we obtained any improvement in the rheological properties of the plasma produced fumed silicas.

At the beginning of the project, two hypotheses were considered for the study of the rheological properties of the powders. The first was Dr. Addona's hypothesis, in which he assumed that the thickening ability of the system depends on the degree of entanglement of the fumed silica aggregates; in other words, it depends on the degree of agglomeration of the system. The second hypothesis was that the thickening ability of the system depends on the surface chemistry of the particles, especially on the number of free hydroxyl groups present on the surface of the fumed silica particles.

Table 8, below gives the apparent viscosity values for two plasma produced fumed silica suspensions, before and after agglomeration. The values of apparent viscosity are very close. A two-sample hypothesis test showed that at the $95 \%$ confidence level, the initial viscosities of the samples before and after agglomeration were the same as were the variances in these viscosities (see Appendix $\mathrm{E}$ for details). The slight differences before and after agglomeration were thus to do experimental uncertainties. This analysis supports the hypothesis that the enhanced rheological properties are due to the presence of hydroxyl groups on fumed silica, which are not present to a sufficient degree in the plasma produced powders.

In the flame process, based on the plant operating data at full capacity and stoichiometric flow rates, the solids/gas mass loading ratio in the agglomerator was 0.14 . In our laboratory scaled agglomerator, we used a solids/gas loading ratio of 0.025 , which was much lower than in the flame process. This ratio was limited by the feed rate to the venturi. To verify if the loading ratio has any effect on the particle agglomeration and on the powder's rheological properties, we also used a small volume $(200 \mathrm{ml})$ mechanical blender to agglomerate the powders. For these tests we used the same loading ratio like 
the flame process, which was $\sim 0.14$. The necessary amount of powders was poured into the blender and mixed with the air for $1 \mathrm{~min}$. Viscosity tests were done after these tests and the same apparent viscosity values, like before the tests were obtained. That means the loading ratio had no influence on the rheological properties of the agglomerated powders.

Table 8. Apparent viscosity values before and after agglomeration tests

\begin{tabular}{|r|r|r|r|r|r|}
\hline \multirow{2}{*}{ RPM } & \multirow{2}{*}{ Time (min) } & \multicolumn{2}{|c|}{$\begin{array}{c}\text { Apparent Viscosity values } \\
\text { before agglomeration (cP) }\end{array}$} & \multicolumn{2}{c|}{$\begin{array}{c}\text { Apparent Viscosity values } \\
\text { after agglomeration (cP) }\end{array}$} \\
\cline { 3 - 6 } & & Exp.11 & Exp.16 & Exp.11 & Exp.16 \\
\hline 5 & 6.00 & 2290 & 1870 & 2400 & 2100 \\
\hline 10 & 9.00 & 2110 & 1750 & 2110 & 1890 \\
\hline 20 & 10.30 & 2000 & 1650 & 1940 & 1730 \\
\hline 50 & 11.06 & 1860 & 1570 & 1760 & 1630 \\
\hline 100 & 11.24 & 1790 & 1530 & 1670 & 1570 \\
\hline 50 & 12.00 & 1830 & 1570 & 1730 & 1600 \\
\hline 20 & 13.30 & 1930 & 1650 & 1900 & 1700 \\
\hline 10 & 16.30 & 2050 & 1730 & 2090 & 1830 \\
\hline 5 & 22.30 & 2240 & 1850 & 2290 & 2050 \\
\hline
\end{tabular}




\section{Chapter 7 - CONCLUSIONS}

This project was a follow-up of a previous work done by Addona and Munz (1998) which demonstrated the technical feasibility of producing fumed silica in a transferred arc reactor but was unable to demonstrate the special rheological properties of the powder. It was hypothesized that the lower viscosity values obtained for the suspensions in which plasma produced powders were dispersed were due to a lower degree of agglomeration of the particles. In the flame process an agglomerator is used in order to generate large agglomerates, which helps at the collection of the powder. In the plasma process, the powder is collected immediately after the oxidation.

According to literature, the presence of the isolated hydroxyl groups on the surface of the fumed silica particles, along with the number of these groups, are the powder properties that determine high apparent viscosity values for the suspensions.

The objectives of the present work were to produce samples of fumed silica using different quench conditions and to correlate the effect of these conditions with the powder properties. We also wanted to agglomerate the plasma produced fumed silica by using a laboratory scaled agglomerator and to examine the effect of agglomeration on the rheological properties of the product.

All the objectives of this project have been completed. We produced samples of fumed silica using a refurbished transferred arc reactor. The best conditions identified by Addona for the evaporation of the quartz (the raw material used) were used along with different quench conditions (different flows and different quench gases: steam, air and mixtures of both). The products of each experiment were characterized using X-ray diffraction, scanning and transmission electron microscopy (SEM and TEM), BET specific surface measurements, diffuse reflectance infrared Fourier transform spectroscopy (DRIFT), thermogravimetric analysis (TGA) and rheological tests. The results were compared with a commercial product (Aerosil 200 from Degussa). 
The analyses performed demonstrated that the plasma produced material had all the physical properties of the commercial product (amorphous morphology, chain-like structure of the aggregates, large surface area, small particles size) but its apparent viscosity was much lower that the commercial product. For the plasma produced fumed silica the apparent viscosity was only about $40 \%$ of the apparent viscosity of the commercial product, measured at the smallest shearing rate (5 RPM).

An agglomerator system which simulates the one used in the flame process was designed, built and used for the agglomeration of the plasma produced fumed silica. Because the operating temperature of the commercial device is much lower than the sintering temperature of the silica, the laboratory scale agglomerator was operated at room temperature. The gas used was dry air $(\mathrm{RH}<4 \mathrm{ppm})$.

Agglomeration tests demonstrated that althought there was physical agglomeration of the fumed silica particles, this agglomeration did not improve the rheological properties of the plasma produced powders. Statistical tests showed that within $95 \%$ confidence interval the apparent viscosity of plasma produced fumed silica was the same before and after agglomeration.

The laboratory scale agglomerator operated at lower solid/gas ratios than the commercial unit, because of limited feed rates to the venturi. Further tests were done using a laboratory blender and identical loading ratio and residence time to the commercial system. We observed no significant effect on the rheological properties of the plasma produced powders.

It was also shown by DRIFT spectroscopy that by using different quench conditions, the hydroxyl groups content also varied. We were able to produce a small amount of free hydroxyl groups on the surface of the experimental powders 8 (steam quench), 14 (air quench) and 16 (air quench), but not enough to produce a significant increase in the apparent viscosity values. The information from literature indicated that the chlorine present in the commercial process but absent in the plasma process may be required for producing these isolated hydroxyl groups (peak at around $3750 \mathrm{~cm}^{-1}$ in the IR spectrum). 
Thermogravimetric analysis showed that plasma produced powders lost more than $8 \%$ of their mass compared to $4 \%$ for the commercial product. The loss for plasma produced fumed silica occurred at low temperatures consistent with adsorbed water. For the commercial product the mass loss occurred at around $450^{\circ} \mathrm{C}$ which is characteristic of the loss of isolated hydroxyl groups. These test results suggest that in the case of the plasma produced product, the water molecules attached themselves on the surface of the fumed silica particles by hydrogen-bonding rather than forming a hydroxyl group on the surface.

Taking in consideration all these results, the conclusion is that the inferior rheological properties of the plasma produced fumed silica are due to the lack of isolated hydroxyl groups on the surface of the powders and not to the lack of agglomeration. 


\section{REFERENCES}

1. Addona, T., "The Study of a Novel Plasma Process For The Production of Fumed Silica", Ph. D. Thesis, McGill University, Department of Chemical Engineering, Montreal (1998)

2. Addona, T. and Munz, R.J., "Silica Decomposition Using a Transferred Arc Process", Ind.\& Eng. Chem. Research, 38 , 2299-2309 (1999)

3. Biegler, H., W. Neugebauer and H. Kempers, German Patent, DE 1180 723, 1963

4. Gans, I. and Gauvin W. H., "The Plasma Production of Ultrafine Silica Particles", Can. J. of Chem. Eng. 66, 438-444 (1988)

5. Illigen, A. and Neugebauer W., German Patent, DE 1933 291, 1969

6. Ferch, D., "Amorphous Synthetic Silica Products in Powder Form. Production and Characterization", Progress in Organic Coatings, 9, 135-163, 1981

7. Parisi, P.J., “A Novel Transferred-Arc Reactor", M.Eng. Thesis, McGill University, Department of Chemical Engineering, Montreal (1984)

8. Everst, D. A., Sayce, I. G. and Selton, B., "Preparation of Ultrafine Silica Powders by Evaporation Using a Thermal Plasma", Symposium on Electrochemical Engineering, Institution of Chemical Engineers, London, 2, 2.108-2.121, 1973

9. Degussa, "Technical Bulletin Fine Particles" no.11, United States (2004)

10. Cabot Corporation, "Cab-O-Sil Properties and Functions", Information Brochure, United States (1994) 
11. Cabot Corporation, "Cab-O-Sil Untreated Fumed Silica: General Application Guid", www.cabot.com

12. White, L.J. and Duffy, G.J., "Vapor-Phase Production of Colloidal Silica", Ind. Eng. Chem. 51, 232-238 (1959)

13. Young, R.M. and Pfender, E., "Generation and Behavior of Fine Particles in Thermal Plasmas - A Review", Plasma Chem. Process. 5, 1-37 (1985)

14. Hannebauer, B. and Menzel, F., "The Combustion of $\mathrm{SiCl}_{4}$ in $\mathrm{Hot} \mathrm{O}_{2} / \mathrm{H}_{2}$ Flames", Z. Anorg. Allg. Chem. 629, 1485-1490 (2003)

15. Sheka, E., Khavryutchenko, V. and Nikitina, E., "From molecules to particles: Quantum-chemical view applied to fumed silica", Journal of Nanoparticle Research $1,71-81,1999$

16. Khavryutchenko, V., Khavryutchenko, Al. and Barthel, H., "Fumed Silica Synthesis: Influence of Small Molecules on the Particle Formation Process", Macromol. Symp. 169, 1-5 (2001)

17. Khavryutchenko, V., Barthel, H. and Nikitina, E., "Fumed Silica Synthesis: From Molecules, Protoparticles and Primary Particles to Aggregates and Agglomerates", Macromol. Symp. 169, 7-18 (2001)

18. Khavryutchenko, V., Khavryutchenko, Al., "Fumed Silica Synthesis: Influence of Hydrogen Chloride on the Fumed Silica Particle Formation Process", Macromol. Symp. 194, 253-268 (2003)

19. Khalil, A.M., "Thermal Treatment of Aerosil 200 Silica: Induced surface Porasity and Surface Chemistry Relative To The Heat of Immersion In Water", Surface Technology 14, 383-390 (1981) 
20. Berthel, H., Heinemann, M., Stintz, M. and Wessely, B., "Partcle Sizes of Fumed Silica", Part. Part. Syst. Charact. 16, 169-176 (1999)

21. Balabanova, E., "Silica Nanoparticles Produced by Thermal Arc Plasma. Modelling", Journal of Optoelectronics and Advanced Materials Vol.5, No.3, 679686, September 2003

22. Aquilera, L. and Silla, V., "Procedure for the Operation of the Transferred Arc Reactors", CRTP, Dept. Chemical Engineering, McGill University, 2003 


\section{APPENDIXES}

\section{A. LabView INTERFACE of DAQ}

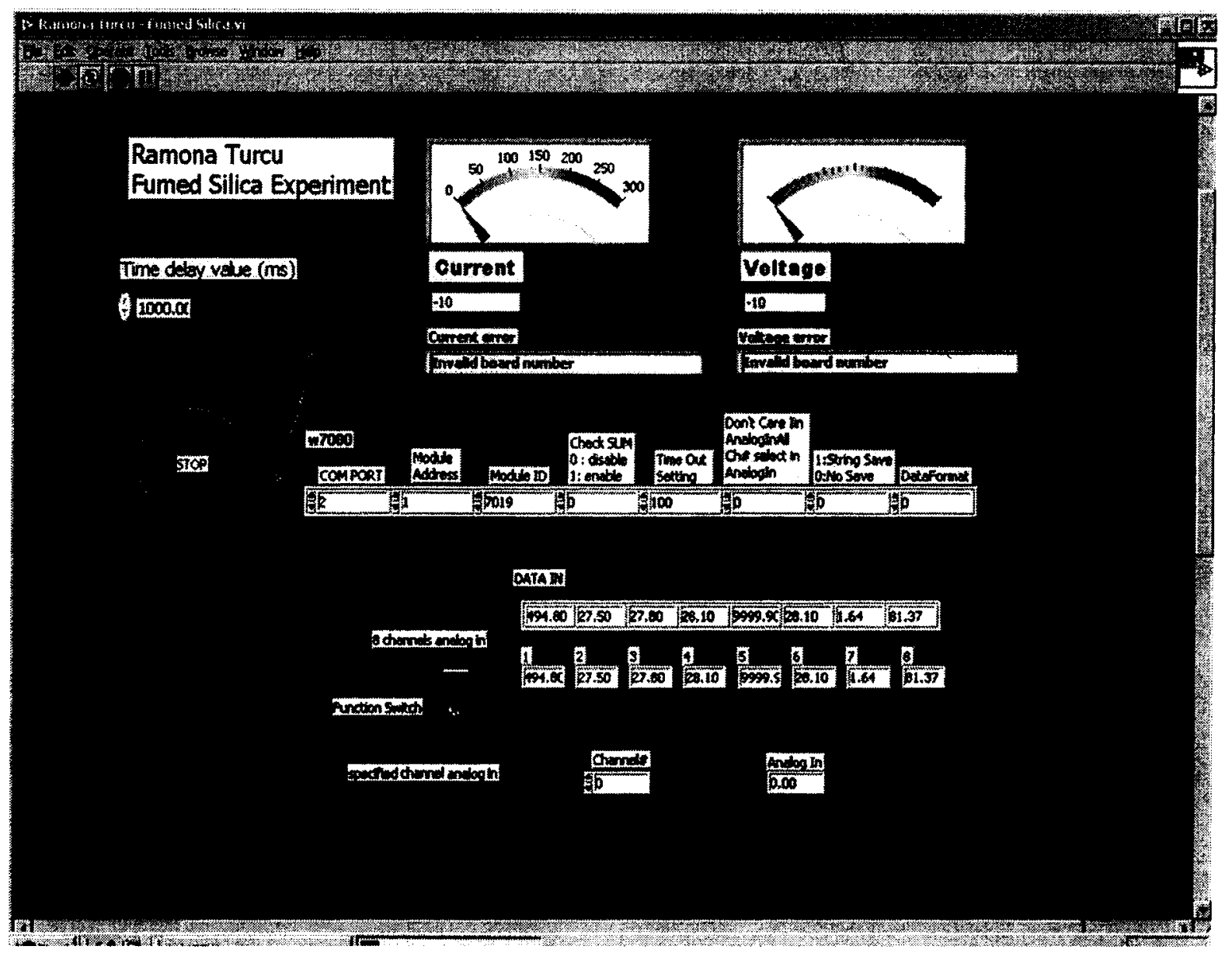




\section{B. VOLTAGE AND CURRENT PROFILES}

FOR EXPERIMENTS 10 TO 16

\section{Experiment 10 - Voltage and Current profiles}

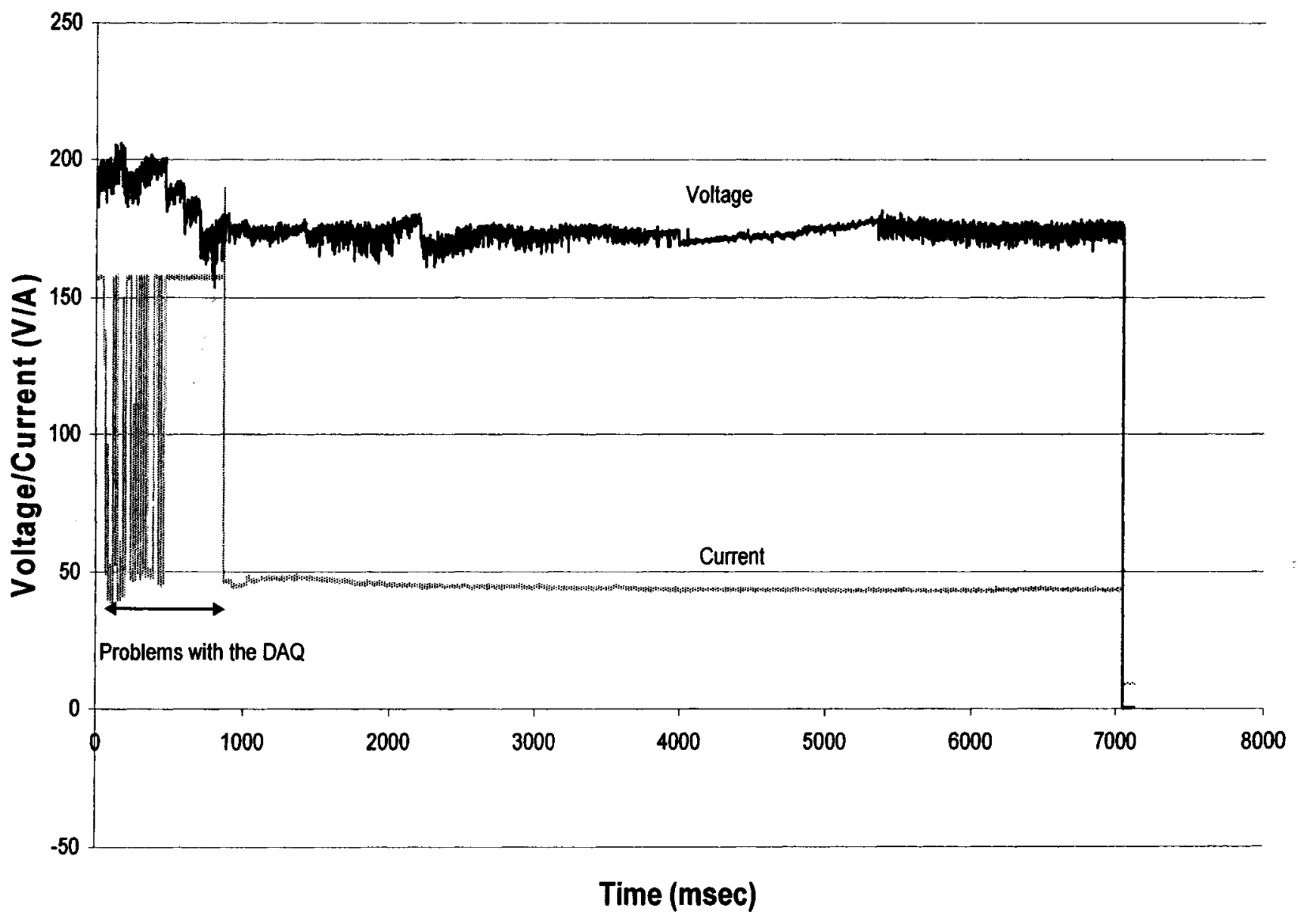


Experiment 11 - Voltage and Current profiles






\section{Experiment 12 - Current and Voltage profiles}



Time(s) 


\section{Experiment 13 - Current and Voltage profiles}

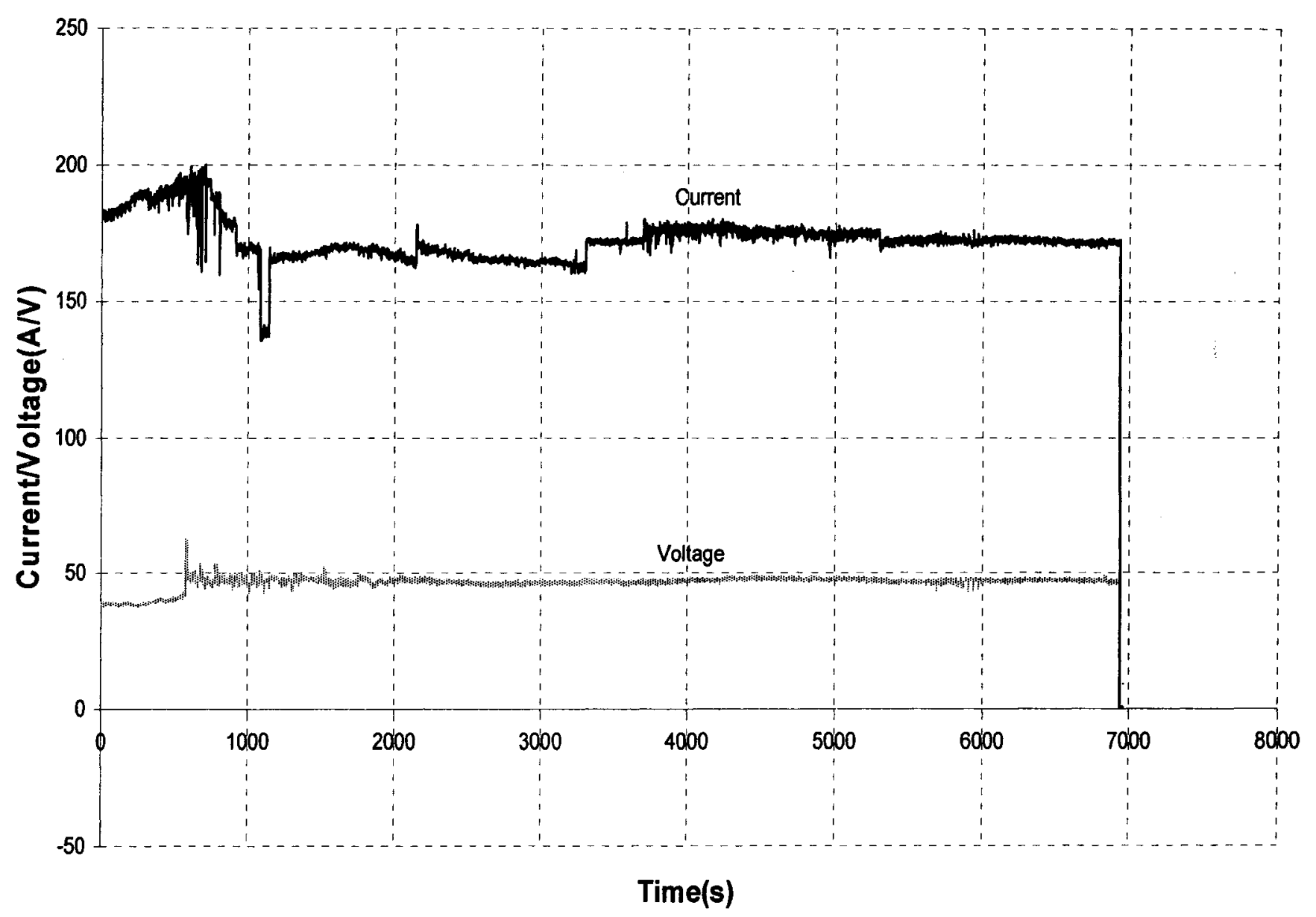




\section{Experiment 14 - Current and Voltage profiles}

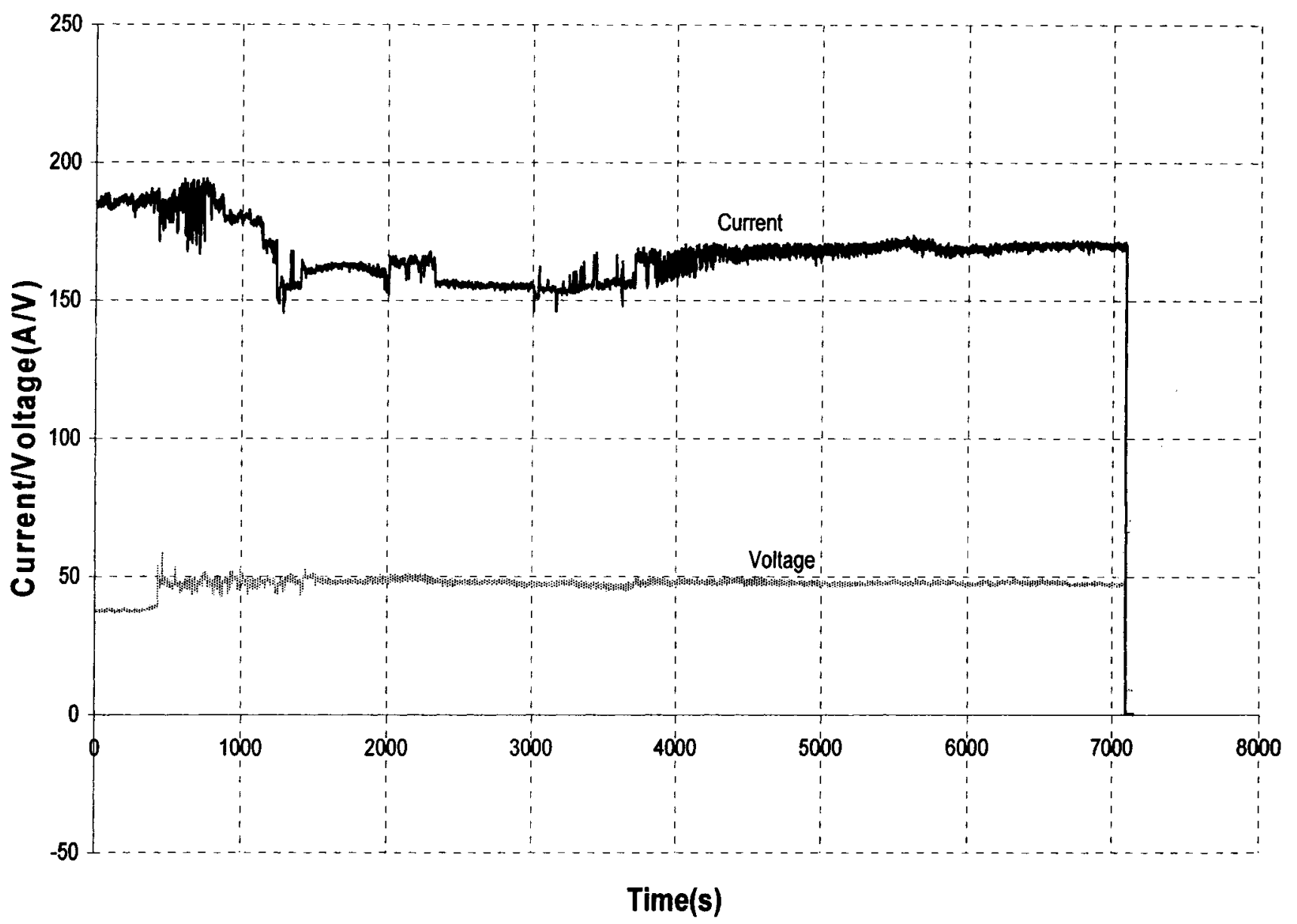




\section{TEMPERATURE PROFILES OF EXIT TUBE, QUENCH ZONE, STEAM LINE AND FILTER FOR EXPERIMENTS 10 TO 16}

\section{Experiment 10 - Temperature profiles}

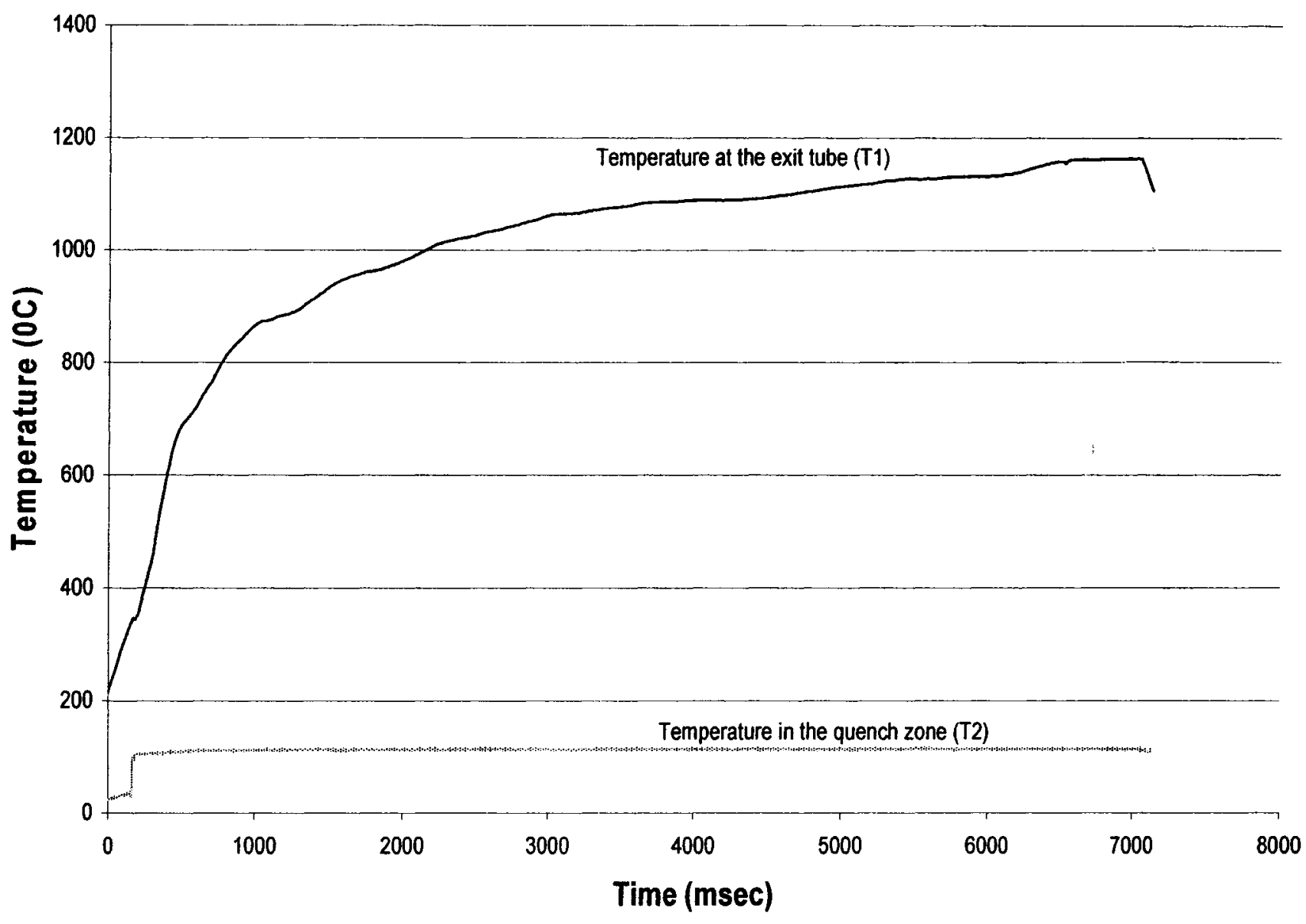




\section{Experiment $10-\mathrm{T} 3$ and T4}

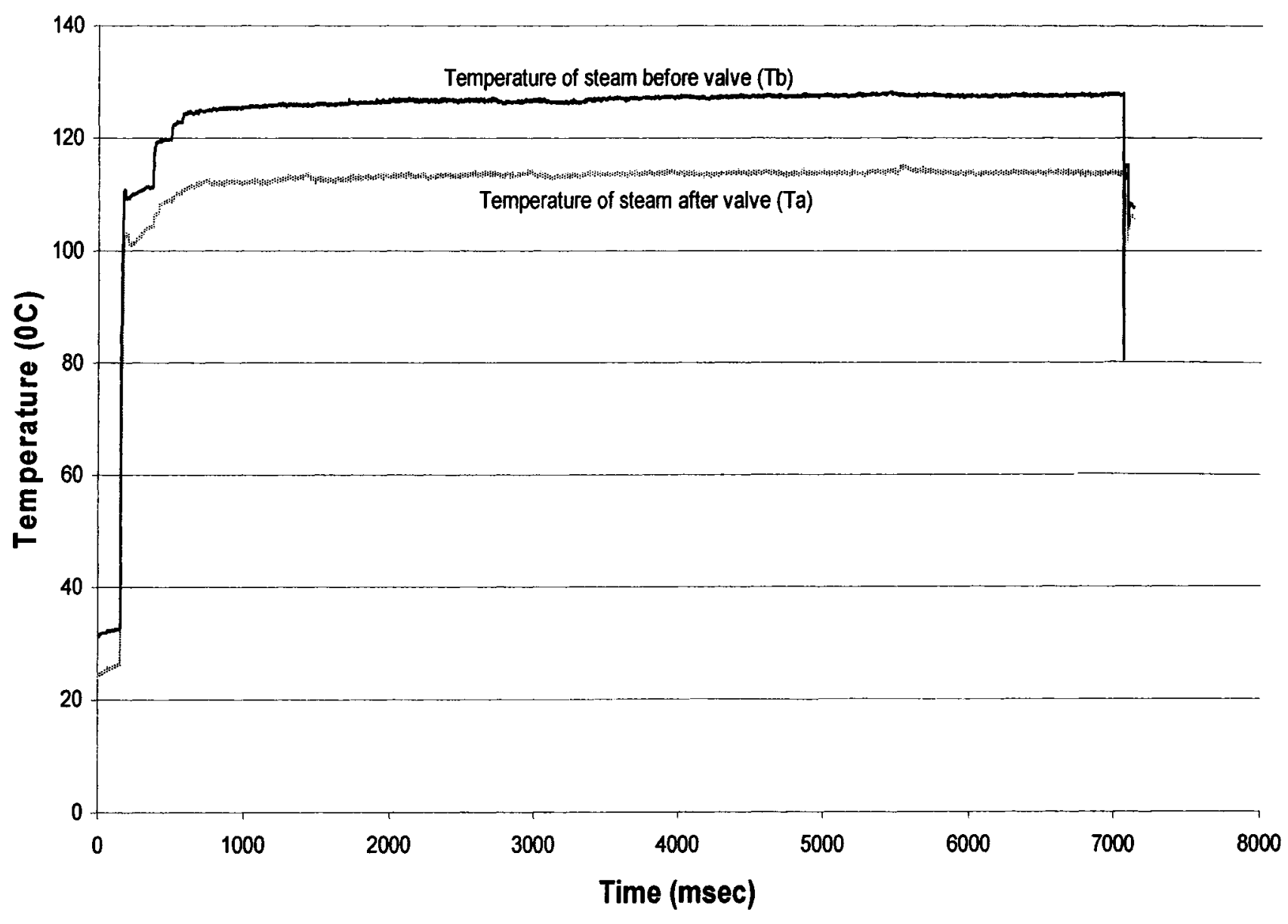




\section{Experiment $10-\mathrm{T} 5$ and $\mathrm{T} 6$}

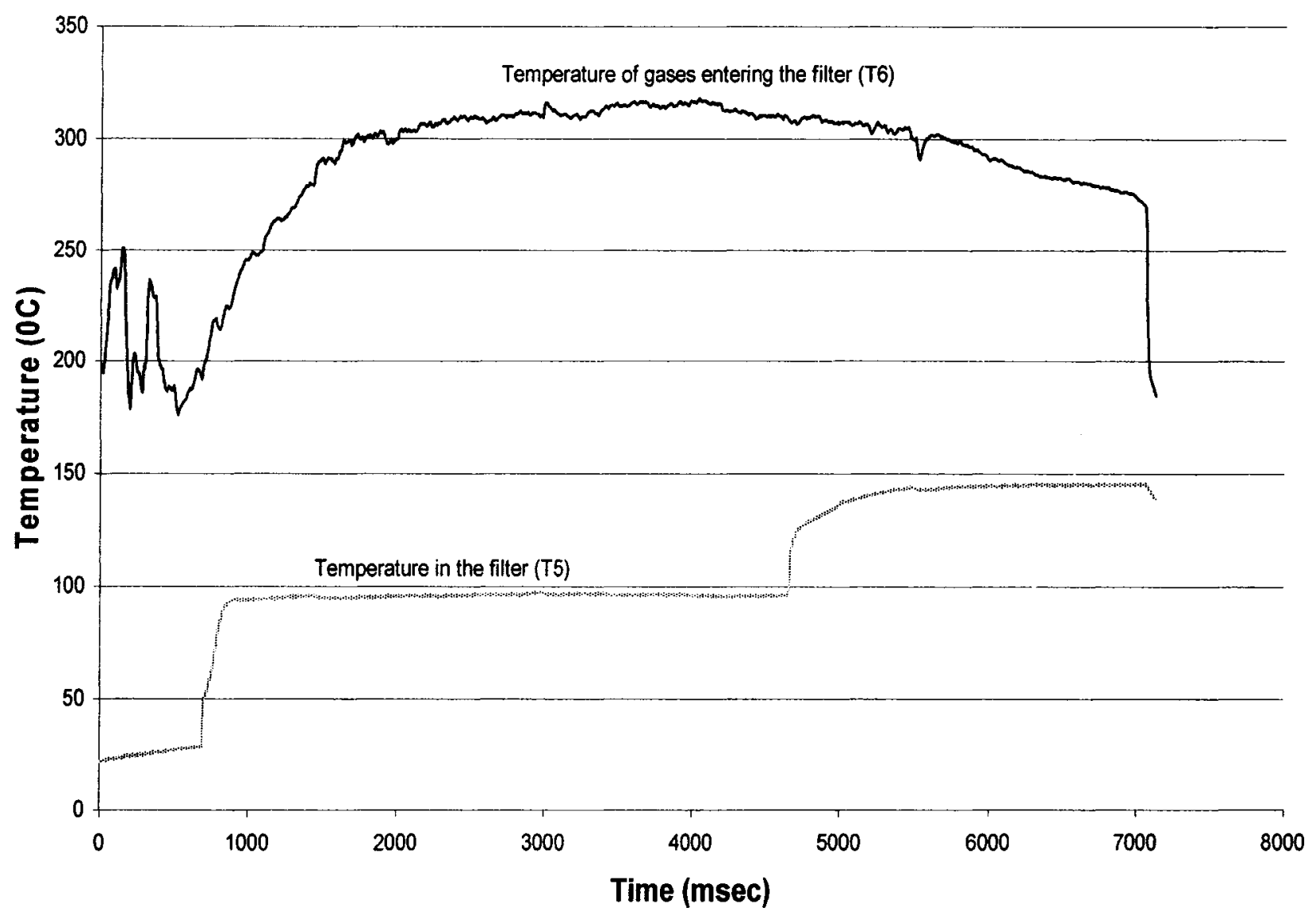




\section{Experiment 11 - Temperature profiles}

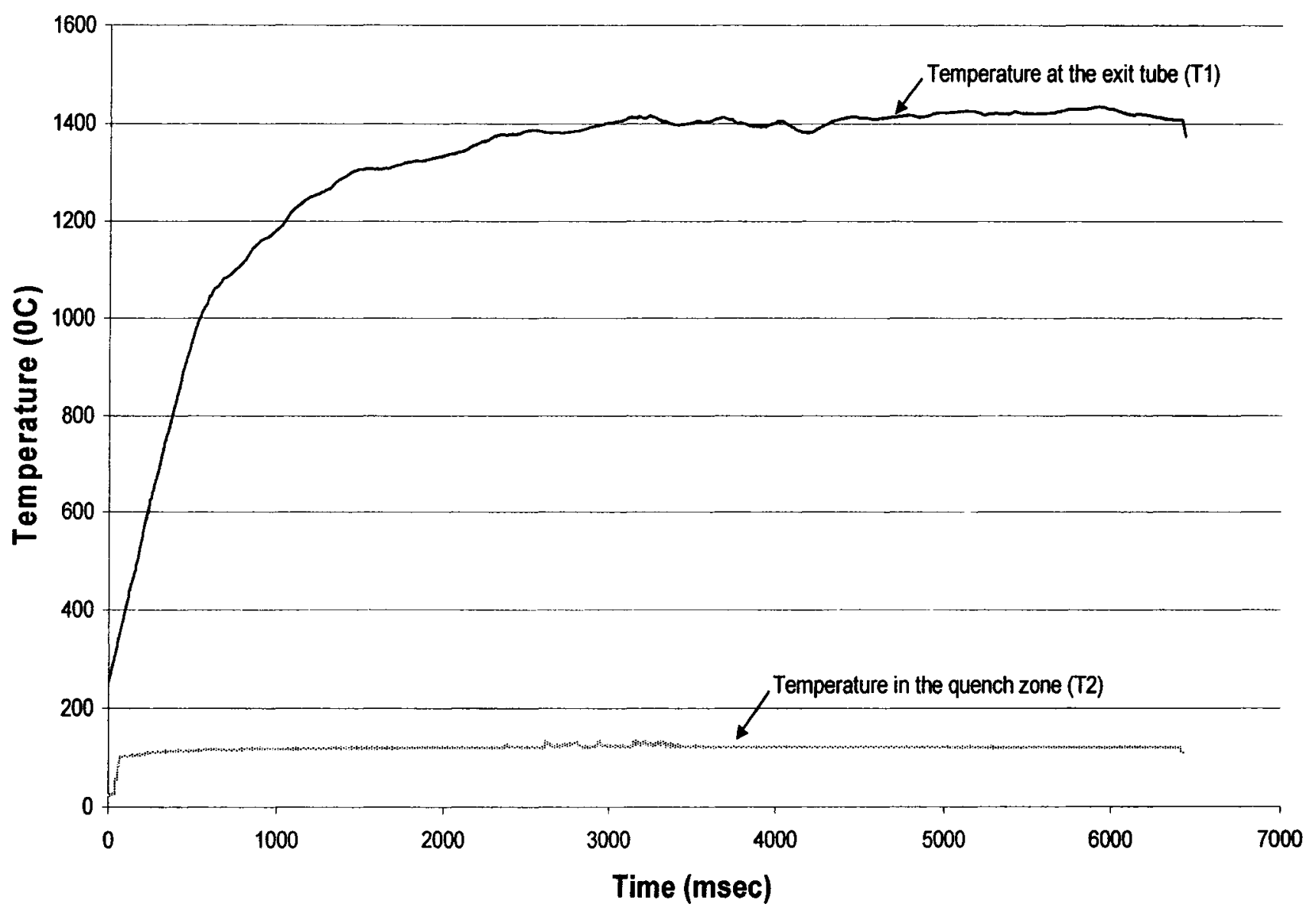




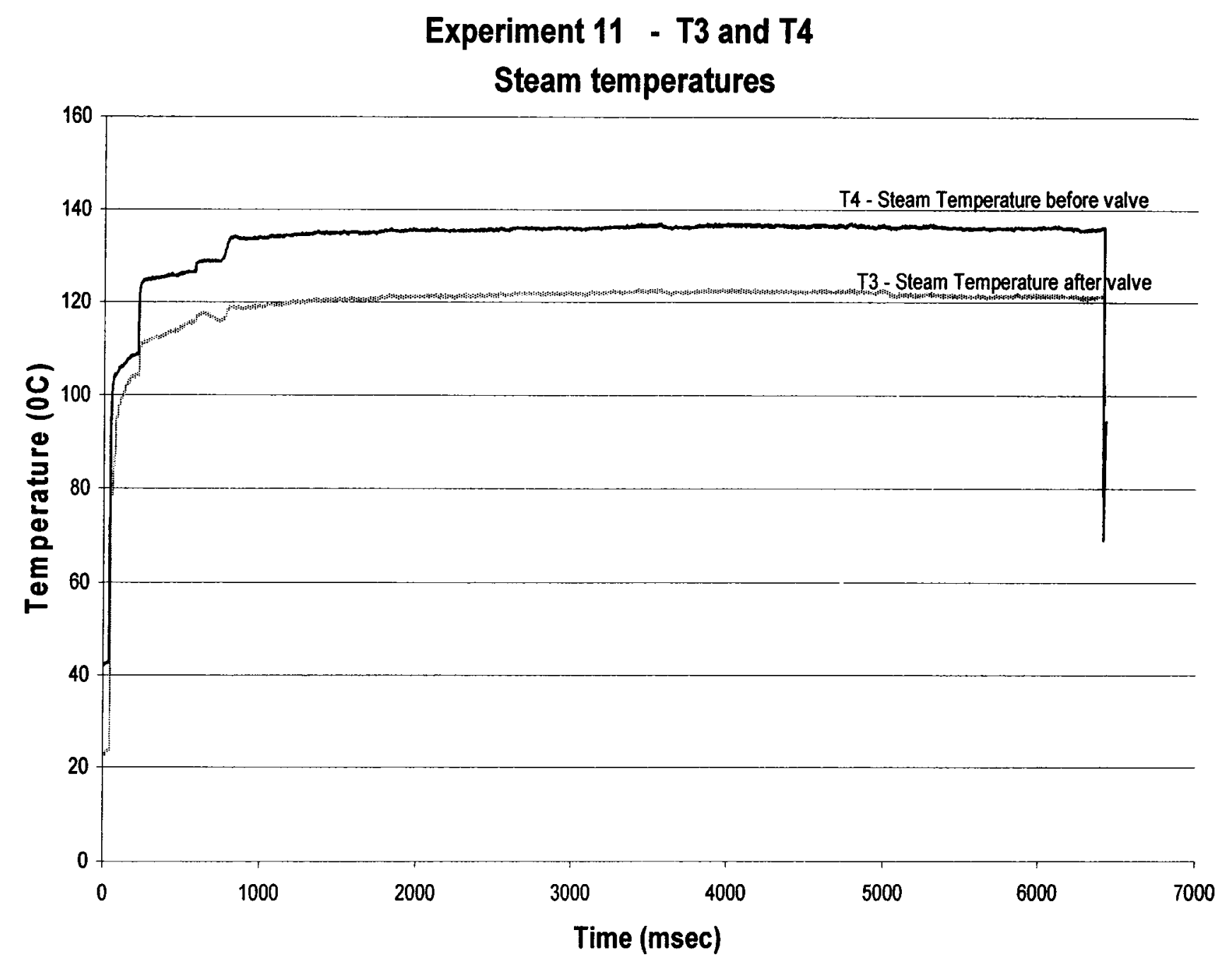




\section{Experiment $11 \quad-\mathrm{T} 5$ and T6}

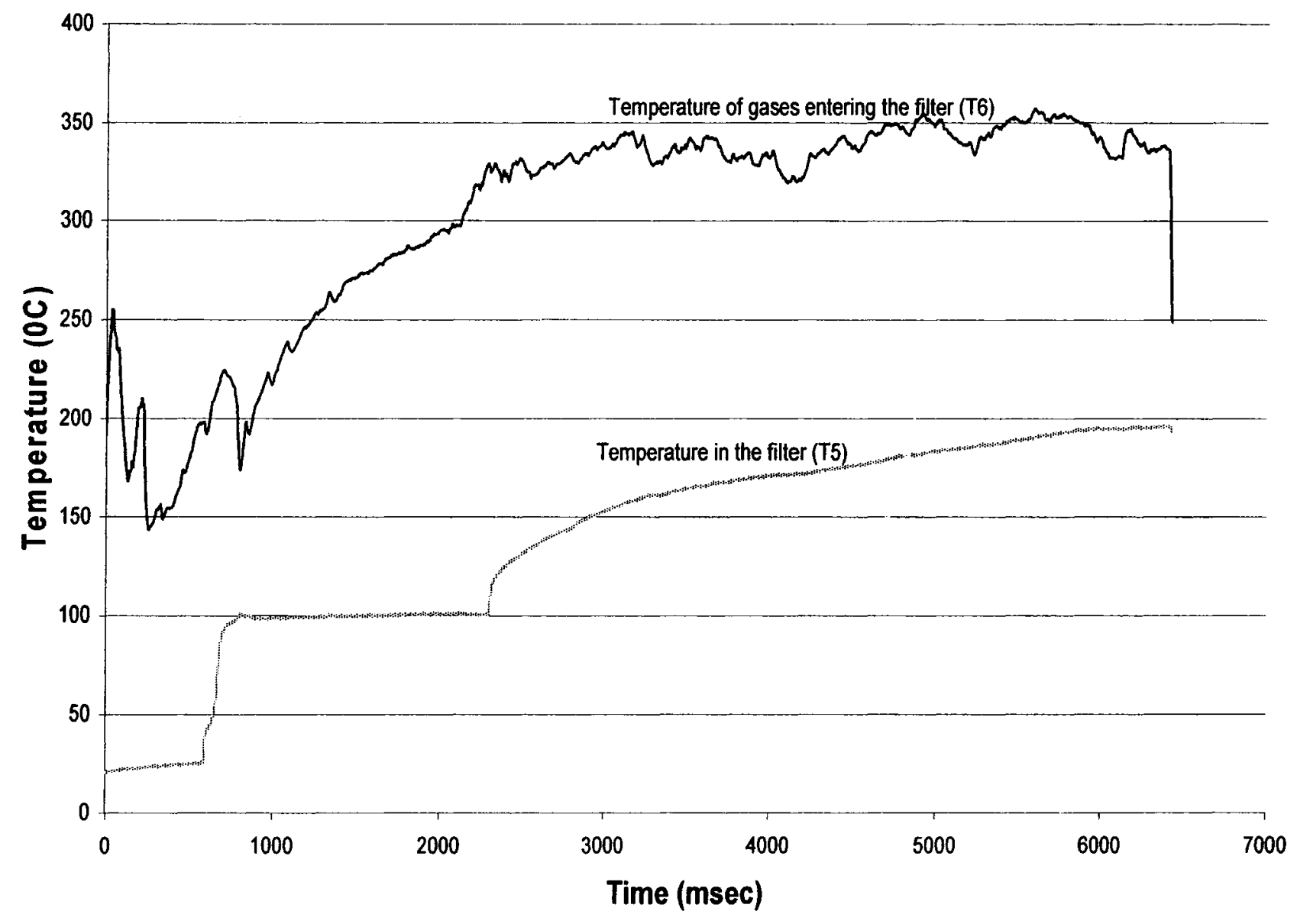




\section{Experiment 12 - Temperatures profiles}

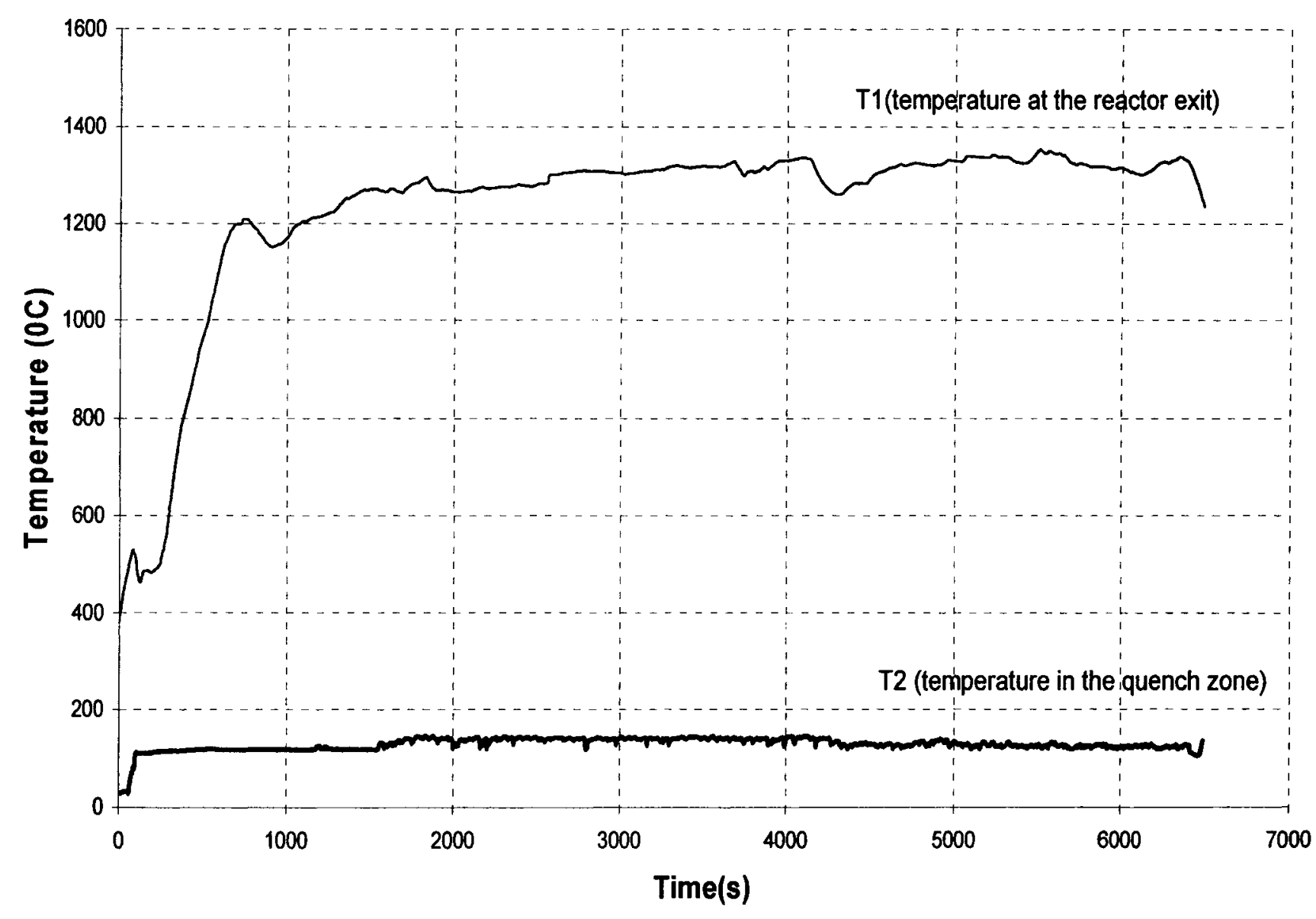




\section{Experiment 12 - Steam temperatures}

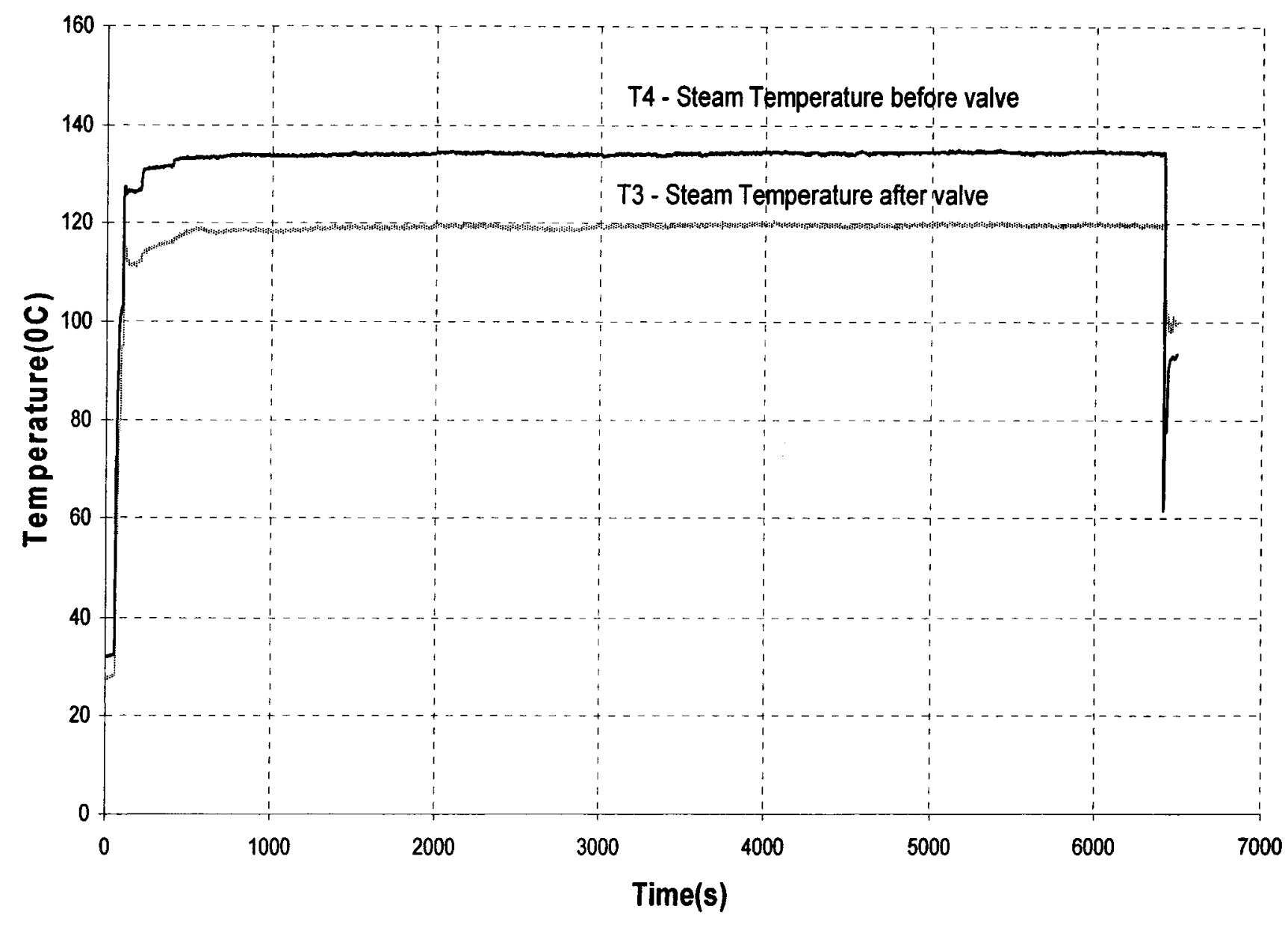




\section{Experiment $12-\mathrm{T} 5$ and T6}

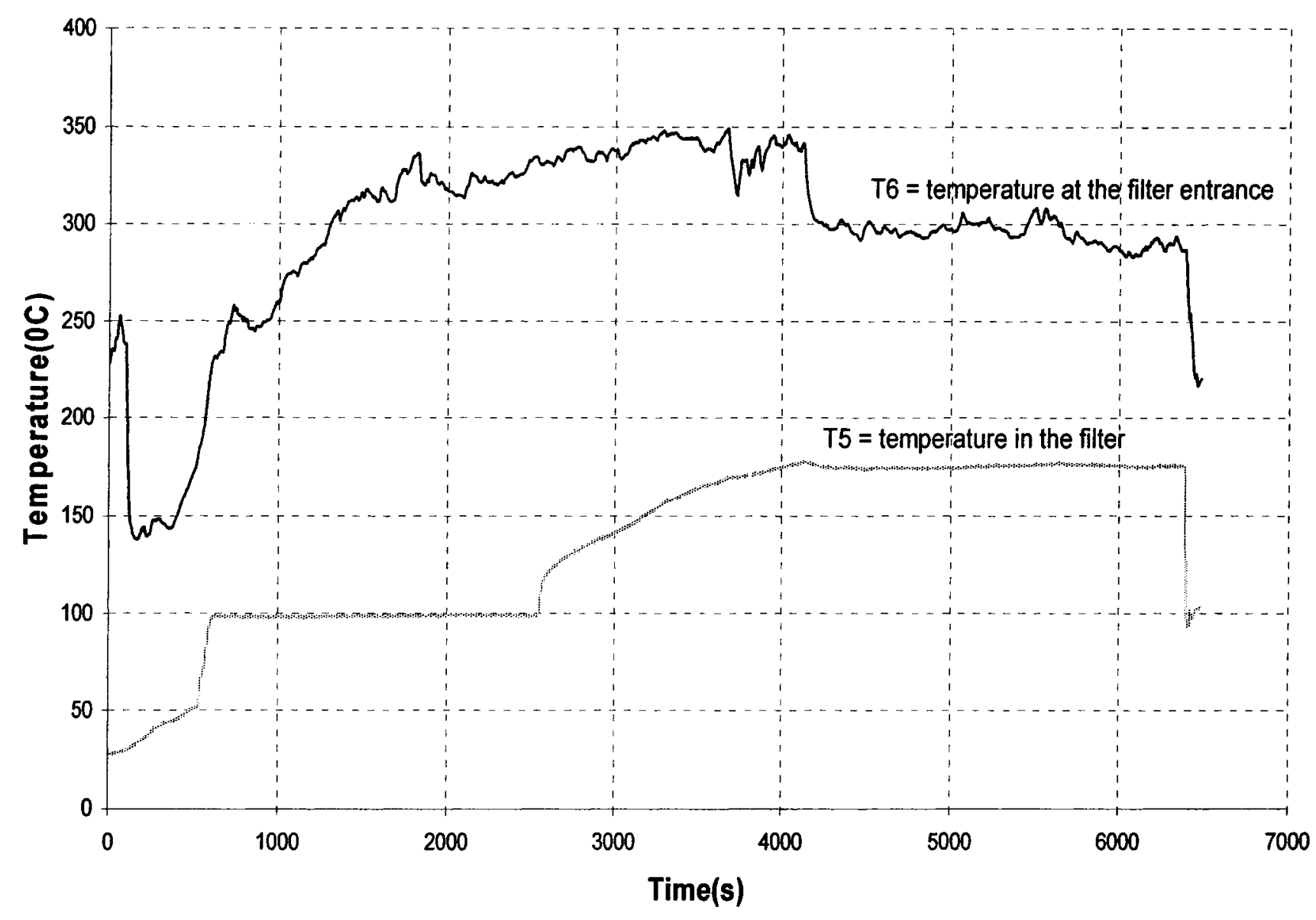




\section{Experiment 13 - Temperature profiles}

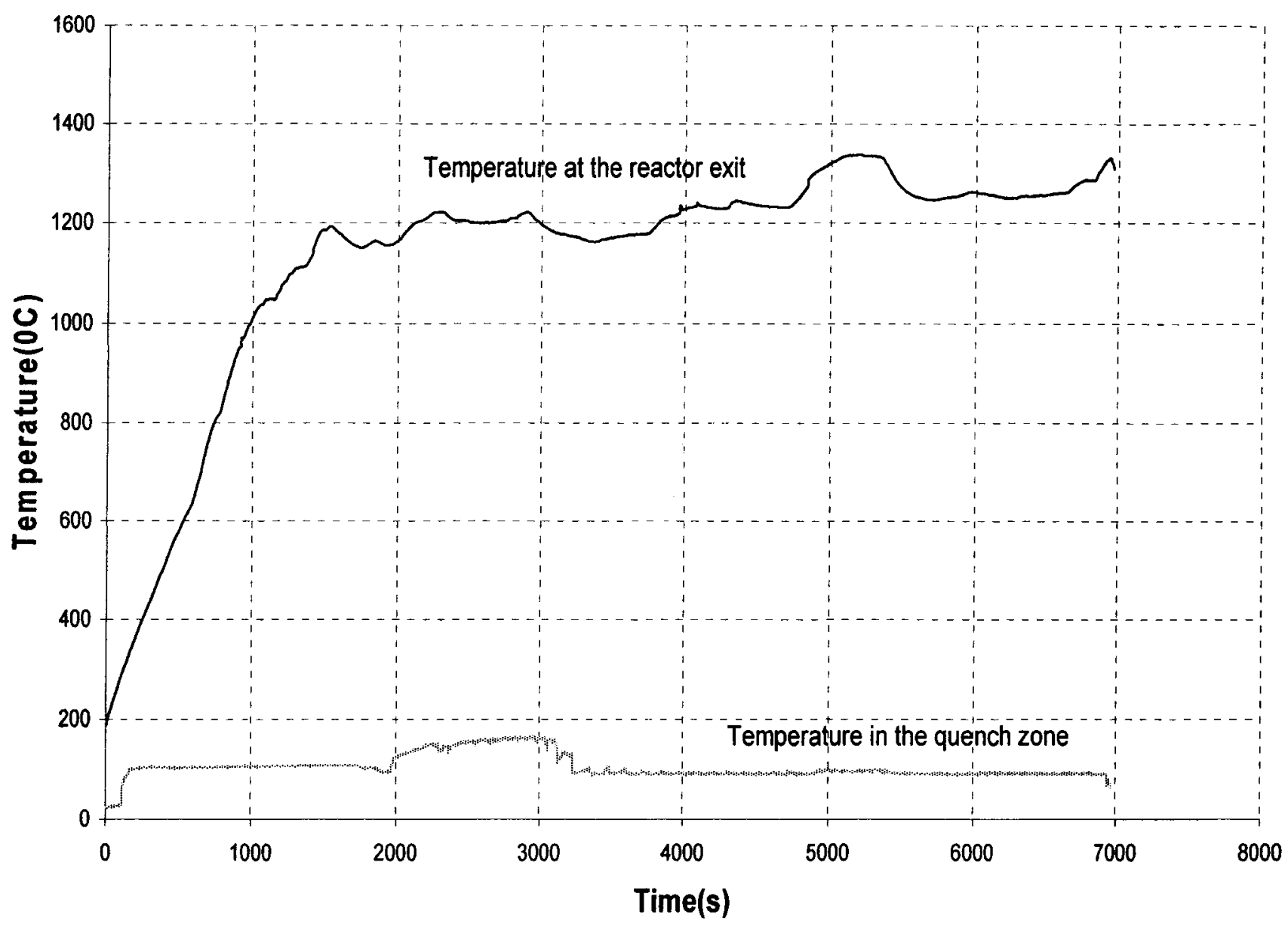




\section{Experiment 13 - Steam temperatures}

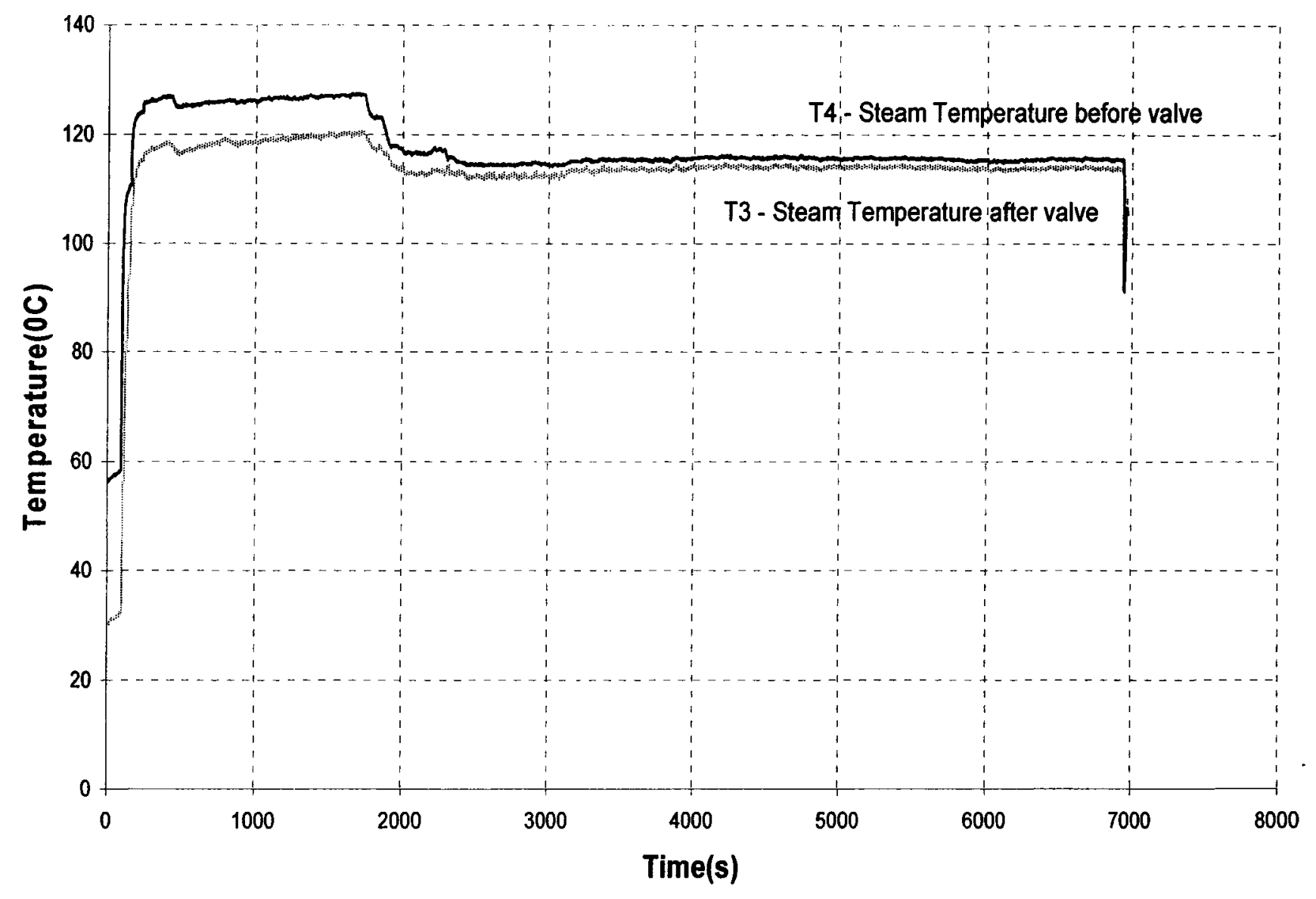




\section{Experiment $13-\mathrm{T} 5$ and $\mathrm{T} 6$}

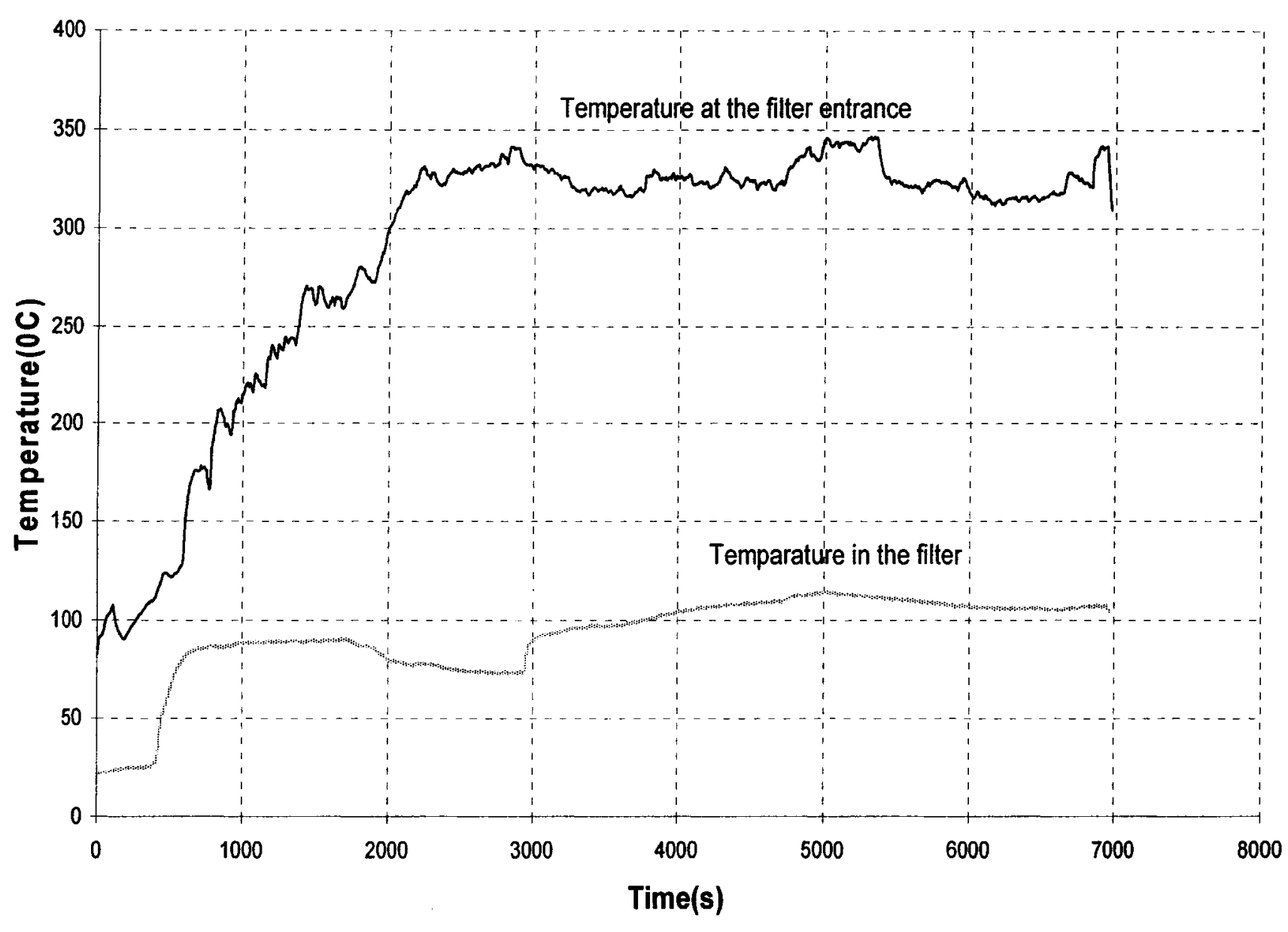




\section{Experiment 14 - Temperatures profiles}

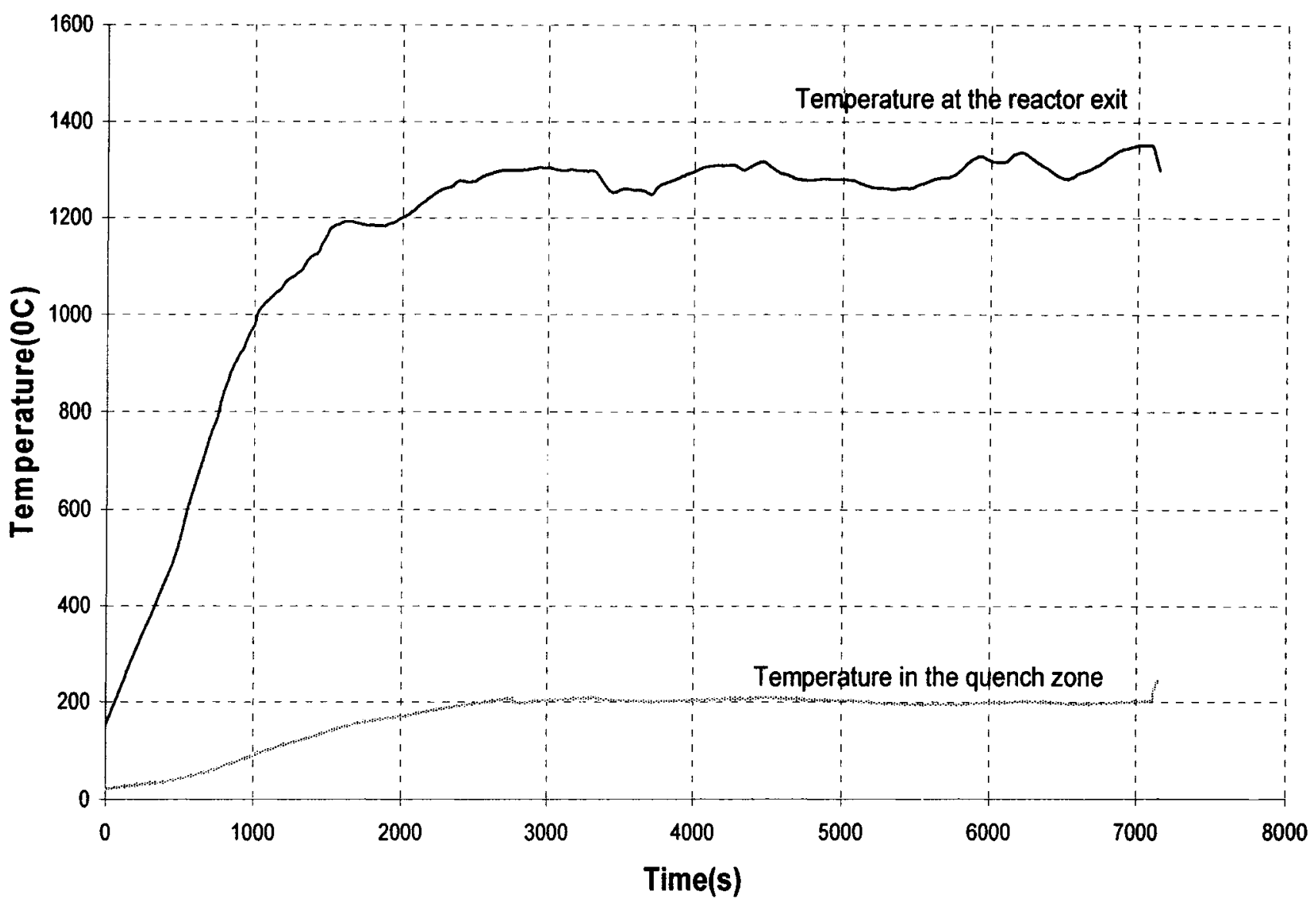




\section{Experiment $14-\mathrm{T} 5$ and $\mathrm{T} 6$}

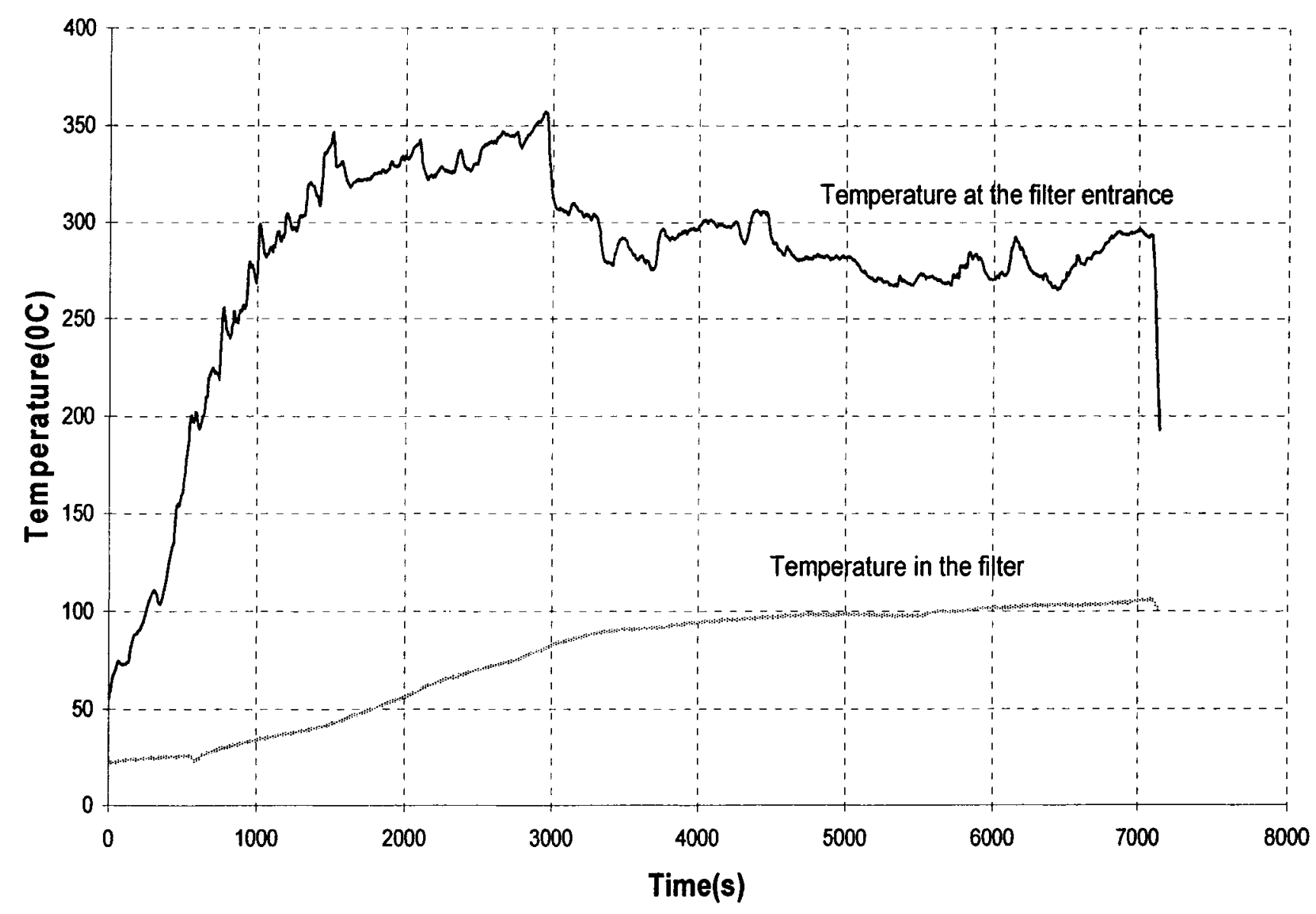


D. DRAWINGS OF GRAPHITE PARTS

TOP VIEW

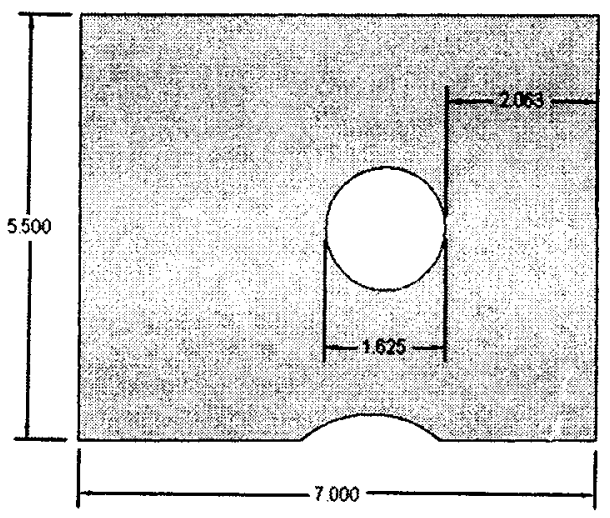

SIDE VIEW

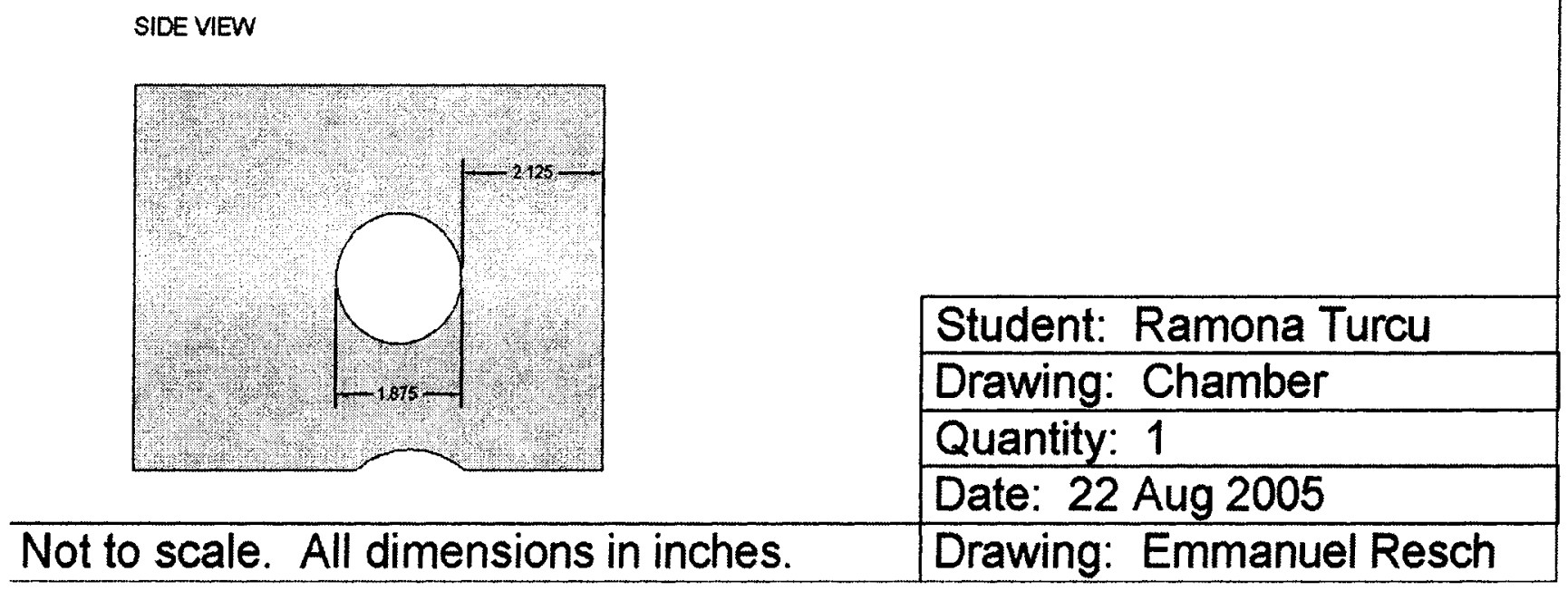

FRONT VIEW

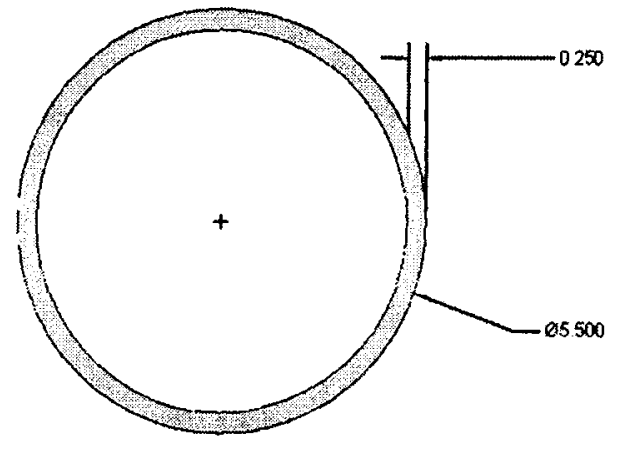


TOP VIEW

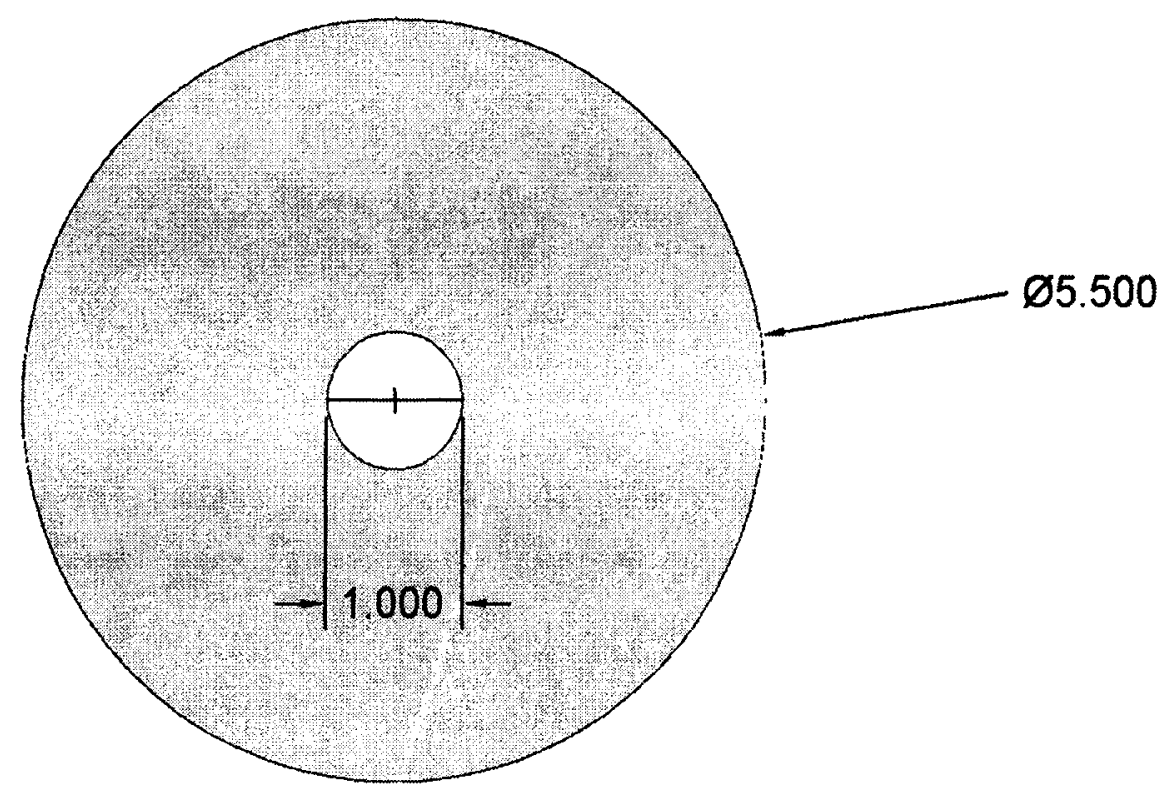

\begin{tabular}{l|l|l}
\multicolumn{1}{c|}{ SIDE VIEW } & & Student: Ramona Turcu \\
& & Drawing: Bottom Plate \\
& Quantity: 1 \\
& Date: 22 Aug 2005 \\
\hline Not to scale. All dimensions in inches. & Drawing: Emmanuel Resch \\
\hline
\end{tabular}


TOP VIEW

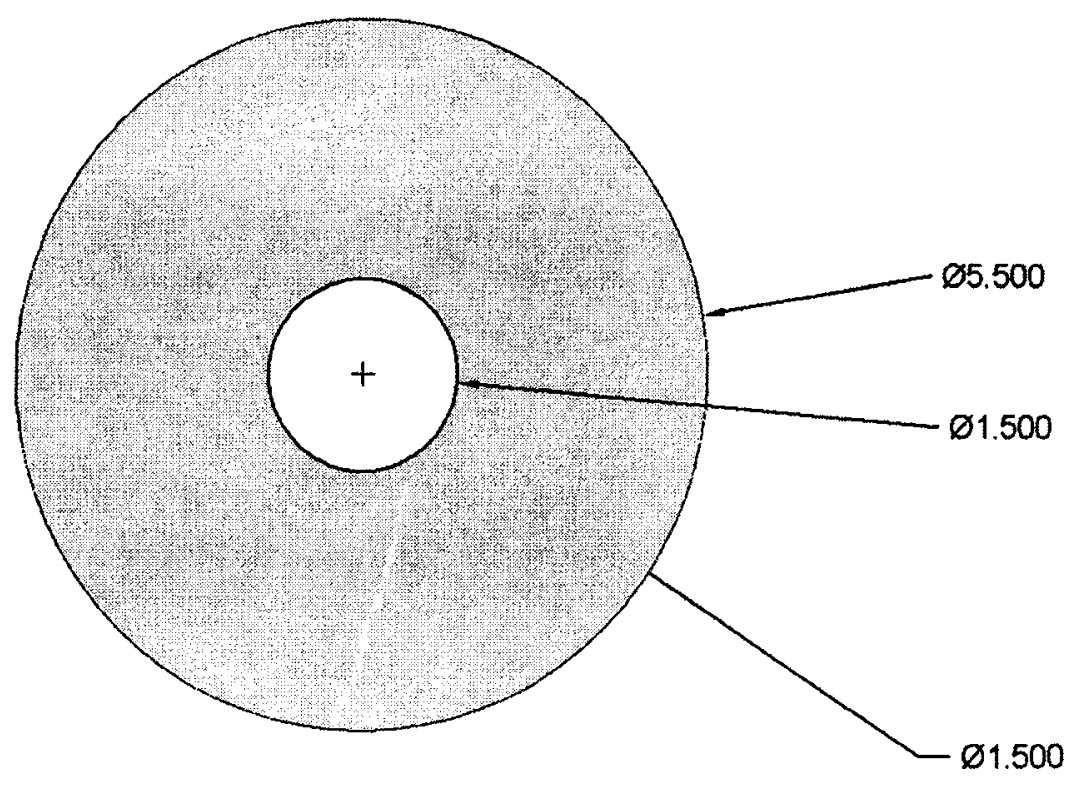

SIDE VIEW

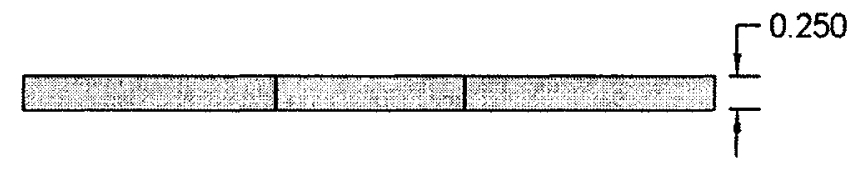

Student: Ramona Turcu

Drawing: Chamber Top Plate

Quantity: 1

Date: 22 Aug 2005

Not to scale. All dimensions in inches.

Drawing: Emmanuel Resch 

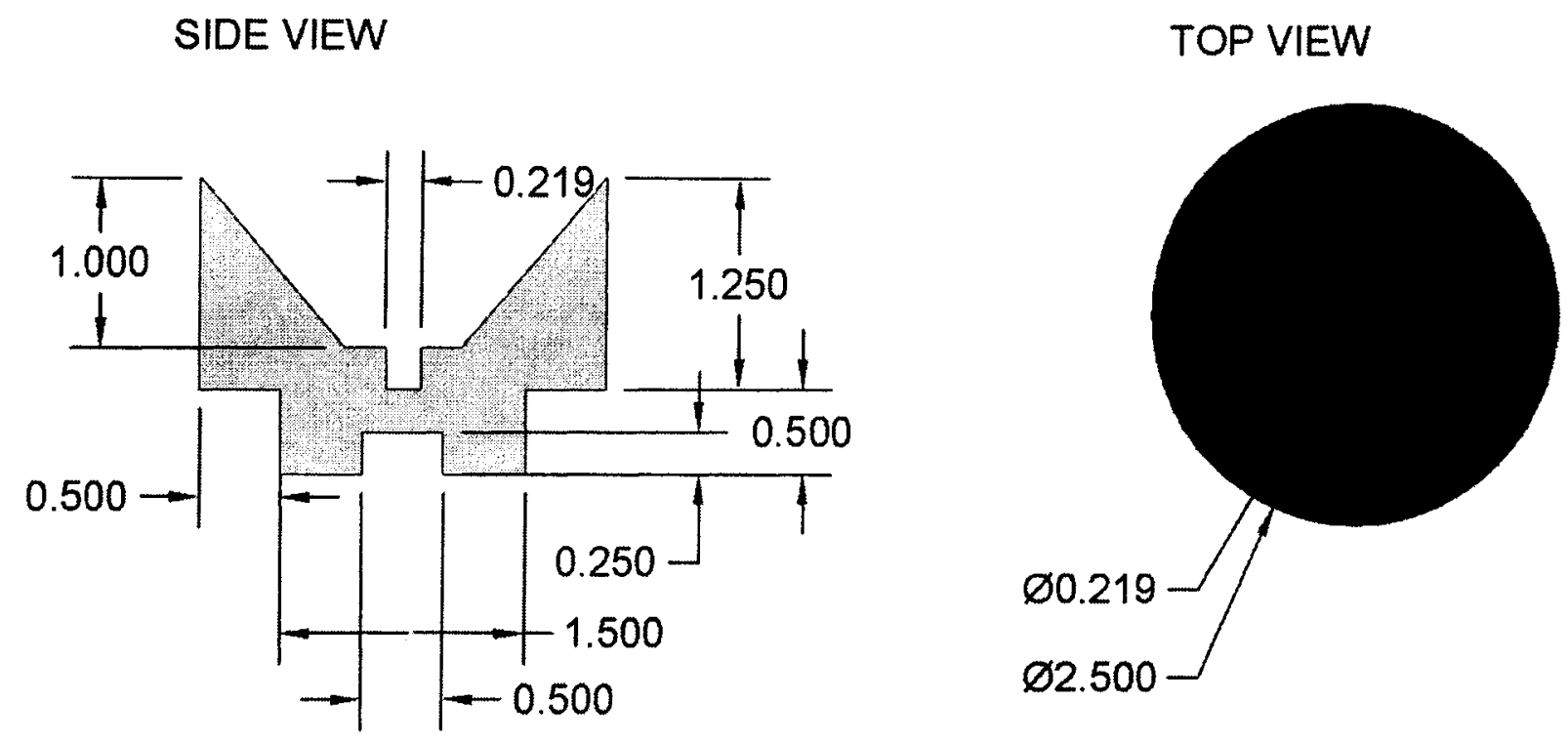

\begin{tabular}{l|l} 
& Student: Ramona Turcu \\
\cline { 2 - 2 } & Drawing: Crucible \\
\cline { 2 - 2 } & Quantity: 2 \\
\cline { 2 - 2 } & Date: 22 Aug 2005 \\
\hline Not to scale. All dimensions in inches. & Drawing: Emmanuel Resch \\
\hline
\end{tabular}


SIDE VIEW

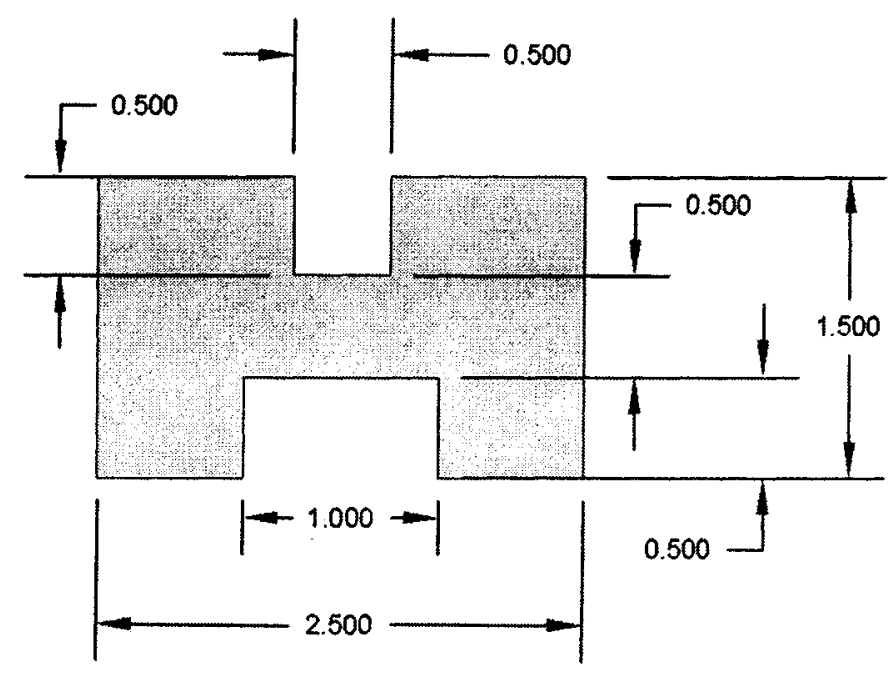

TOP VIEW

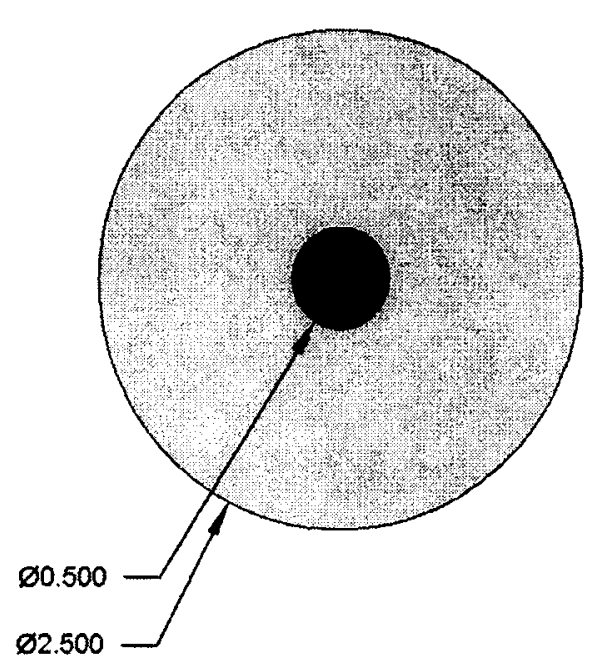

\begin{tabular}{l|l} 
& Student: Ramona Turcu \\
\cline { 2 - 2 } & Drawing: Anode Base \\
\cline { 2 - 2 } & Quantity: 1 \\
\cline { 2 - 2 } & Date: 22 Aug 2005 \\
\hline Not to scale. All dimensions in inches. & Drawing: Emmanuel Resch \\
\hline
\end{tabular}



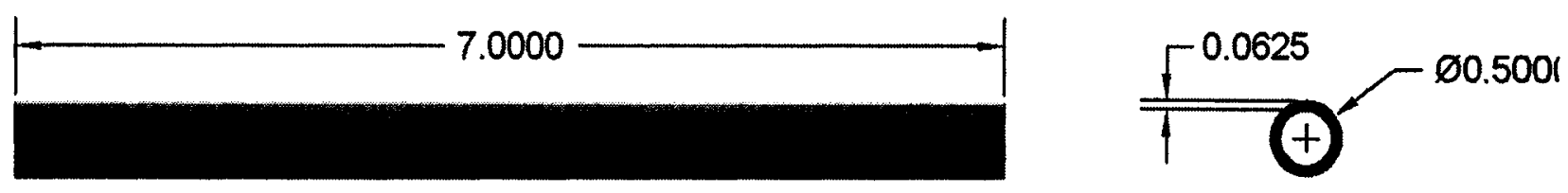

\begin{tabular}{l|l}
\cline { 2 - 2 } & Student: Ramona Turcu \\
\hline & Drawing: Anode Stem \\
\cline { 2 - 2 } & Quantity: 2 \\
\cline { 2 - 2 } & Date: 22 Aug 2005 \\
\hline Not to scale. All dimensions in inches. & Drawing: Emmanuel Resch \\
\hline
\end{tabular}




\section{E. APPARENT VISCOSITY DATA ANALYSIS}

\section{One-Sample Confidence Interval Testing}

\begin{tabular}{|r|r|r|r|c|c|c|c|}
\hline \multicolumn{10}{|l|}{ AEROSIL 200 } \\
\hline & & \multicolumn{2}{|c|}{$\begin{array}{c}\text { Apparent Viscosity before } \\
\text { agglomeration (cP) }\end{array}$} & \multicolumn{2}{|c|}{$\begin{array}{c}\text { Apparent Viscosity after } \\
\text { agglomeration (cP) }\end{array}$} \\
\hline $\begin{array}{r}\text { Time } \\
\text { (s) }\end{array}$ & RPM & B1 & B2 & B3 & A1 & A2 & A3 \\
\hline 6 & 5 & 7380 & 7210 & 7060 & 7920 & 7700 & 7870 \\
\hline 9 & 10 & 5290 & 5140 & 4980 & 5760 & 5620 & 5710 \\
\hline 10.3 & 20 & 3860 & 3790 & 3630 & 4190 & 4050 & 4140 \\
\hline 11.06 & 50 & 2700 & 2700 & 2550 & 3000 & 2930 & 2940 \\
\hline 11.24 & 100 & 2220 & 2140 & 2080 & 2400 & 2330 & 2350 \\
\hline 12 & 50 & 2700 & 2690 & 2530 & 2980 & 2890 & 2910 \\
\hline 13.3 & 20 & 3890 & 3740 & 3600 & 4170 & 3990 & 4120 \\
\hline 16.3 & 10 & 5340 & 5080 & 4920 & 5690 & 5570 & 5630 \\
\hline 22.3 & 5 & 7330 & 6880 & 6850 & 7600 & 7440 & 7520 \\
\hline
\end{tabular}

\begin{tabular}{|c|c|c|c|}
\hline \multicolumn{4}{|c|}{$\alpha=0.05$} \\
\hline $\mathrm{n} 1=$ & 3 & $\mathrm{n} 2=$ & 3 \\
\hline$\times 1=$ & 7216.667 & $\times 2=$ & 7830 \\
\hline $\mathrm{s} 1=$ & 160 & $s 2=$ & 110 \\
\hline
\end{tabular}

Formula: $\quad \mathrm{x}-\left(\mathrm{t}_{\alpha / 2, \mathrm{n}-1}\right) *(\mathrm{~s} / \sqrt{ } \mathrm{n}) \leq \mu \leq \mathrm{x}+\left(\mathrm{t}_{\alpha / 2, \mathrm{n}-1}\right) *(\mathrm{~s} / \sqrt{ } \mathrm{n})$

$\mathrm{x}_{1}-\left(\mathrm{t}_{\alpha / 2, \mathrm{n} 1-1}\right)^{*}\left(\mathrm{~s}_{1} / V_{\mathrm{n}_{1}}\right) \leq \mu_{1} \leq \mathrm{x} 1+\left(\mathrm{t}_{\alpha / 2, \mathrm{nl}-1}\right)^{*}\left(\mathrm{~s}_{1} / V_{\mathrm{n}_{1}}\right)$

$7217-(4.303) *(160 / \sqrt{ } 3) \leq \mu_{1} \leq 7217+(4.303)^{*}(160 / \sqrt{ } 3)$

$6820 \leq \mu_{1} \leq 7610$

$\mathrm{x} 2-\left(\mathrm{t}_{\alpha / 2, \mathrm{n} 2-1}\right)^{*}(\mathrm{~s} 2 / \sqrt{\mathrm{n} 2} 2) \leq \mu 2 \leq \mathrm{x} 1+\left(\mathrm{t}_{\alpha / 2, \mathrm{n} 2-1}\right)^{*}(\mathrm{~s} 2 / \sqrt{\mathrm{n} 2})$

$7830-(4.303) *(110 / \sqrt{3}) \leq \mu 2 \leq 7830+(4.303) *(110 / \sqrt{ } 3)$

$7557 \leq \mu 2 \leq 8103$ 


\begin{tabular}{|r|r|r|r|r|r|r|r|}
\hline \multicolumn{2}{|c|}{ EXPERIMENTAL POWDERS } \\
\hline & & \multicolumn{2}{|c|}{$\begin{array}{c}\text { Apparent Viscosity before } \\
\text { agglomeration (cP) }\end{array}$} & \multicolumn{2}{|c|}{$\begin{array}{c}\text { Apparent Viscosity after } \\
\text { agglomeration (cP) }\end{array}$} \\
\hline $\begin{array}{c}\text { Time } \\
\text { (s) }\end{array}$ & RPM & E11 & E16 & E13 & E11 & E16 & \\
\hline 6 & 5 & 2290 & 1870 & 1890 & 2400 & 2100 & \\
\hline 9 & 10 & 2110 & 1750 & 1730 & 2110 & 1890 & \\
\hline 10.3 & 20 & 2000 & 1650 & 1680 & 1940 & 1730 & \\
\hline 11.06 & 50 & 1860 & 1570 & 1600 & 1760 & 1630 & \\
\hline 11.24 & 100 & 1790 & 1530 & 1560 & 1670 & 1570 & \\
\hline 12 & 50 & 1830 & 1570 & 1610 & 1730 & 1600 & \\
\hline 13.3 & 20 & 1930 & 1650 & 1680 & 1900 & 1700 & \\
\hline 16.3 & 10 & 2050 & 1730 & 1750 & 2090 & 1830 & \\
\hline 22.3 & 5 & 2240 & 1850 & 1890 & 2290 & 2050 & \\
\hline
\end{tabular}

$\begin{array}{lrlr}n 1= & 3 & n=0.05 & 2= \\ x 1= & 2016.667 & x 2= & 2250 \\ s 1= & 210 & s 2= & 300 \\ 2017-(4.303)^{*}(210 / \sqrt{ } 3) \leq \mu 1 \leq 2017+(4.303)^{\star}(210 / \sqrt{ } 3) \\ 1495 \leq \mu 1 \leq 2539 \\ \\ 2250-(12.706)^{\star}(300 / \sqrt{ } 2) \leq \mu 2 \leq 2250+(12.706)^{\star}(300 / \sqrt{ } 2) \\ 445 \leq \mu 1 \leq 4945\end{array}$

Two-Sample Hypothesis-Testing

Aerosil 200

$H_{0}: \sigma_{1}^{2}=\sigma_{2}^{2}$

$\mathrm{H}_{1}: \sigma_{1}^{2} \neq \sigma_{2}^{2}$

$\alpha=0.05$

$f_{0}=s_{1}^{2} / s_{2}^{2}=25600 / 12100=2.115$

$\mathrm{f}_{\alpha / 2, \mathrm{nl}-1, \mathrm{n} 2-1}=39.00$

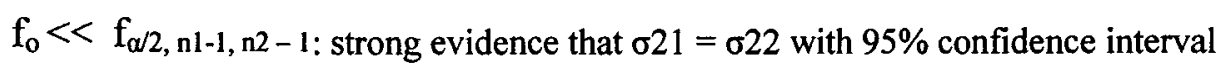




\section{Experimental Powders}

$H_{0}: \sigma_{1}^{2}=\sigma_{2}^{2}$

$\mathrm{H}_{1}: \sigma_{1}^{2} \neq \sigma_{2}^{2}$

$\alpha=0.05$

$\mathrm{f}_{0}=\mathrm{s}_{1}{ }_{1} / \mathrm{s}_{2}^{2}=44100 / 90000=0.49$

$\mathrm{f}_{\alpha / 2, \mathrm{n} 1-1, \mathrm{n} 2-1}=799.5$

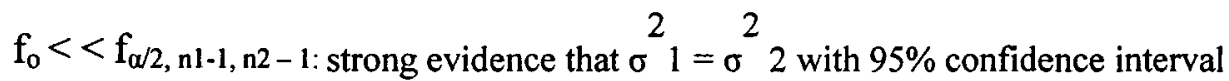

Note: $95 \%$ confidence interval $\rightarrow a=0.05$

$1=$ before agglomeration

$2=$ after agglomeration

$\mathrm{n}=$ number of replicates

$\mathrm{x}=$ the mean apparent viscosity value of the replicates

$\mathbf{s}=$ the standard deviation of the apparent viscosity value for the replicates

$t_{a / 2, n-1}=$ the percentage point of the $t$ distribution [1]

$\mu=$ the mean of a normal distribution of the apparent viscosity data

$\sigma^{2}=$ the population variance

$\mathrm{f}_{\alpha / 2, \mathrm{n} 1-1, \mathrm{n} 2-1}=$ the percentage points of the F-distribution 